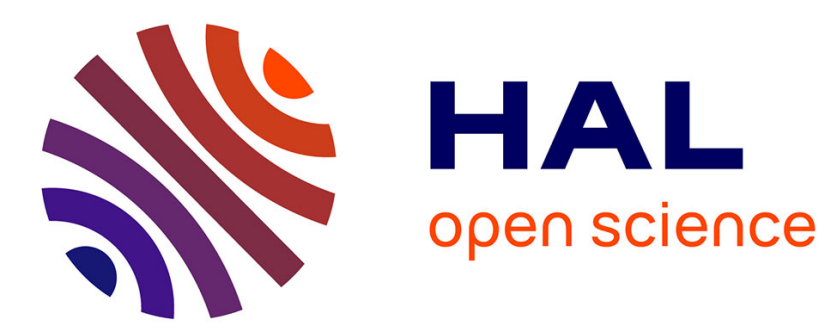

\title{
La rue du Commerce (voie II)
}

\author{
Laurence Brissaud
}

\section{To cite this version:}

Laurence Brissaud. La rue du Commerce (voie II). Gallia - Fouilles et monuments archéologiques en France métropolitaine, 1994, Évolution urbaine à Saint-Romain-en-Gal: la rue du Commerce et la maison aux Cinq Mosaïques, 51, pp.6-40. 10.3406/galia.1994.3090 . hal-02468403

\section{HAL Id: hal-02468403 \\ https://hal.science/hal-02468403}

Submitted on 5 Feb 2020

HAL is a multi-disciplinary open access archive for the deposit and dissemination of scientific research documents, whether they are published or not. The documents may come from teaching and research institutions in France or abroad, or from public or private research centers.
L'archive ouverte pluridisciplinaire HAL, est destinée au dépôt et à la diffusion de documents scientifiques de niveau recherche, publiés ou non, émanant des établissements d'enseignement et de recherche français ou étrangers, des laboratoires publics ou privés.

\section{(이) $\$$}

Distributed under a Creative Commons Attribution - NonCommercial - NoDerivatives| 4.0 
maison au Bassin Excentré 7 . Cette demeure cède ensuite la place à la maison aux Cinq Mosaïques qui constitue le quatrième et dernier état.

7 Afin de faciliter les comparaisons entre les différents édifices du site, nous donnons dorénavant un nom spécifique aux états dont la destination est suffisamment claire.
Nous présentons les résultats du sondage de la rue, puis ceux de la fouille de la maison. Les états les plus intéressants feront l'objet de développements particuliers. La datation des différentes structures sera ensuite discutée. Des aspects plus généraux, touchant les évolutions du parcellaire et de la voirie seront abordés en conclusion.

\title{
LA RUE DU COMMERCE (VOIE II)
}

\author{
par Laurence BRISSAUD
}

Le sondage Voie II 2 englobant toute la largeur de la chaussée, ainsi que la façade ouest de l'îlot voisin (îlot C), a été conduit, lors de la campagne de fouilles 1988. à la hauteur de l'ambitus IX 30 séparant la maison aux Cinq Mosaïques des Petits Entrepôts ${ }^{8}$. Son implantation s'est trouvée liée à l'existence d'un point d'inflexion marqué de la rue, coïncidant avec le passage d'un axe d'urbanisme générateur est-ouest (fig. 2).

L'objectif de l'opération était double :

- mettre en évidence la genèse et le devenir de l'une des rues principales du site, en connexion avec les différentes phases d'occupation humaine d'une parcelle révélatrice de l'évolution complexe du quartier :

- étudier la nature du rapport existant entre la voie et l'axe d'urbanisme, décelé lors de la fouille de la maison des Dieux Océans".

\section{ETAT 1: \\ UNE CONSTRUCTION AUGUSTÉENNE}

L'apport déterminant du sondage réside dans la mise au jour d'un mur est-ouest antérieur à la création de la rue nord-sud, attestant ainsi avec certitude l'existence d'un parcellaire et d'une division spatiale du quartier originel différents de ceux qui avaient été révélés jusqu'alors par les fouilles (fig. 4).

8 Ce sondage couvrait une superficie de $18 \mathrm{~m}^{2}$ el a été mené jusqu'à la couche naturelle de graviers fluviatiles qui se trouve à la cote 148,05 m (toutes les cotes sont indiquées en altitude absolue $\mathrm{NGF}$ ).

9 Dans la parcelle de la maison des Dieux Océans. cet axe se trouve matérialisé par plusieurs murs : M333 (sondages I 51 et I 66) et M336 (sondage I 55) (Desbat et alii, 1994 : chap. I Partie centrale nord).

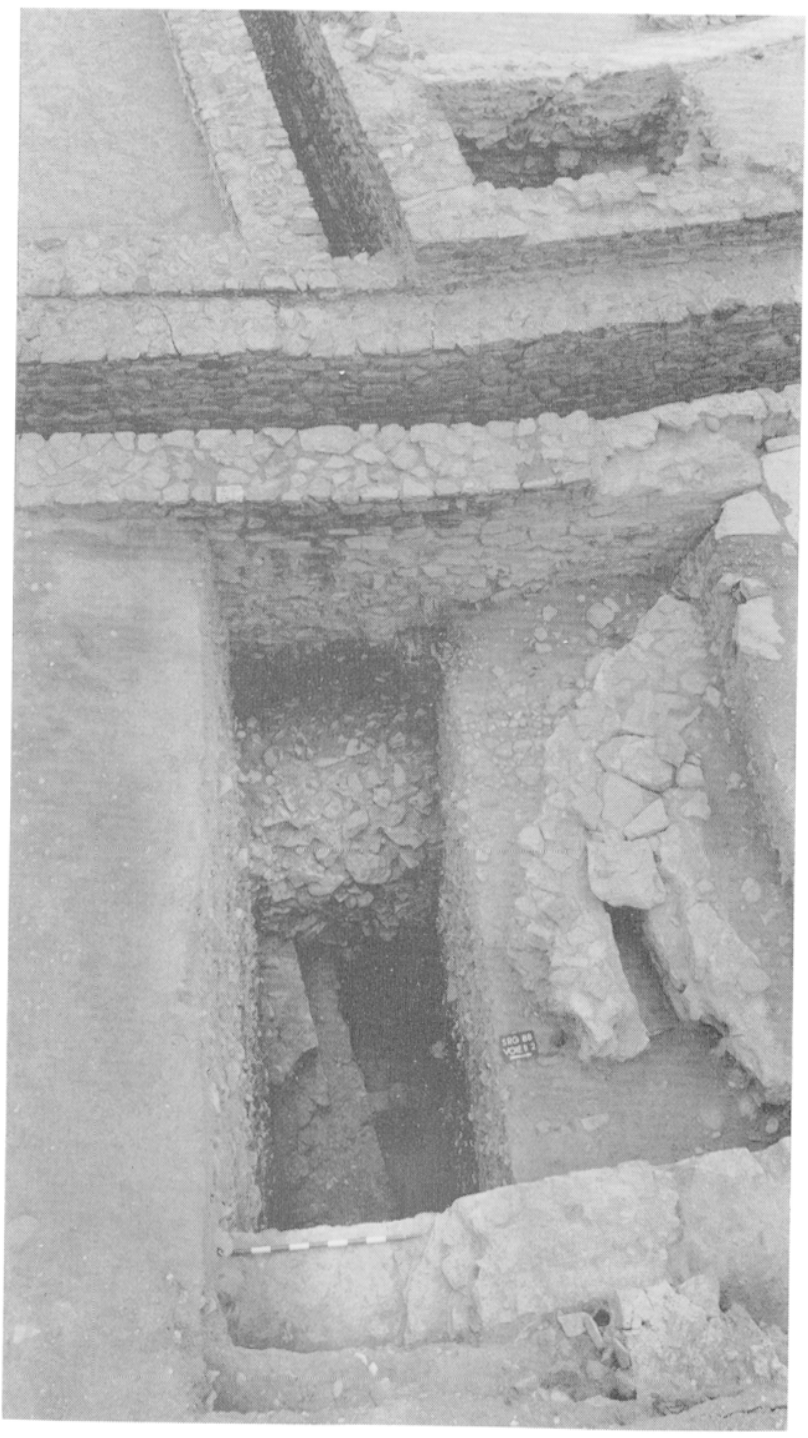




\section{ÉVOLUTION URBAINE À SAINT-ROMAIN-EN-GAL}

Fig. 4 -

A gauche. vue générale du sondage Voic II 2. avec le trottoir sur drain et l'ambitus. qui sépare la maison aux Cinq Mosaïques des Petits Entrepôts. A droite, relevé au pierre-àpierre des structures découvertes dans les sondages Voic II 2. IX 9 et $\mathrm{V} 13$

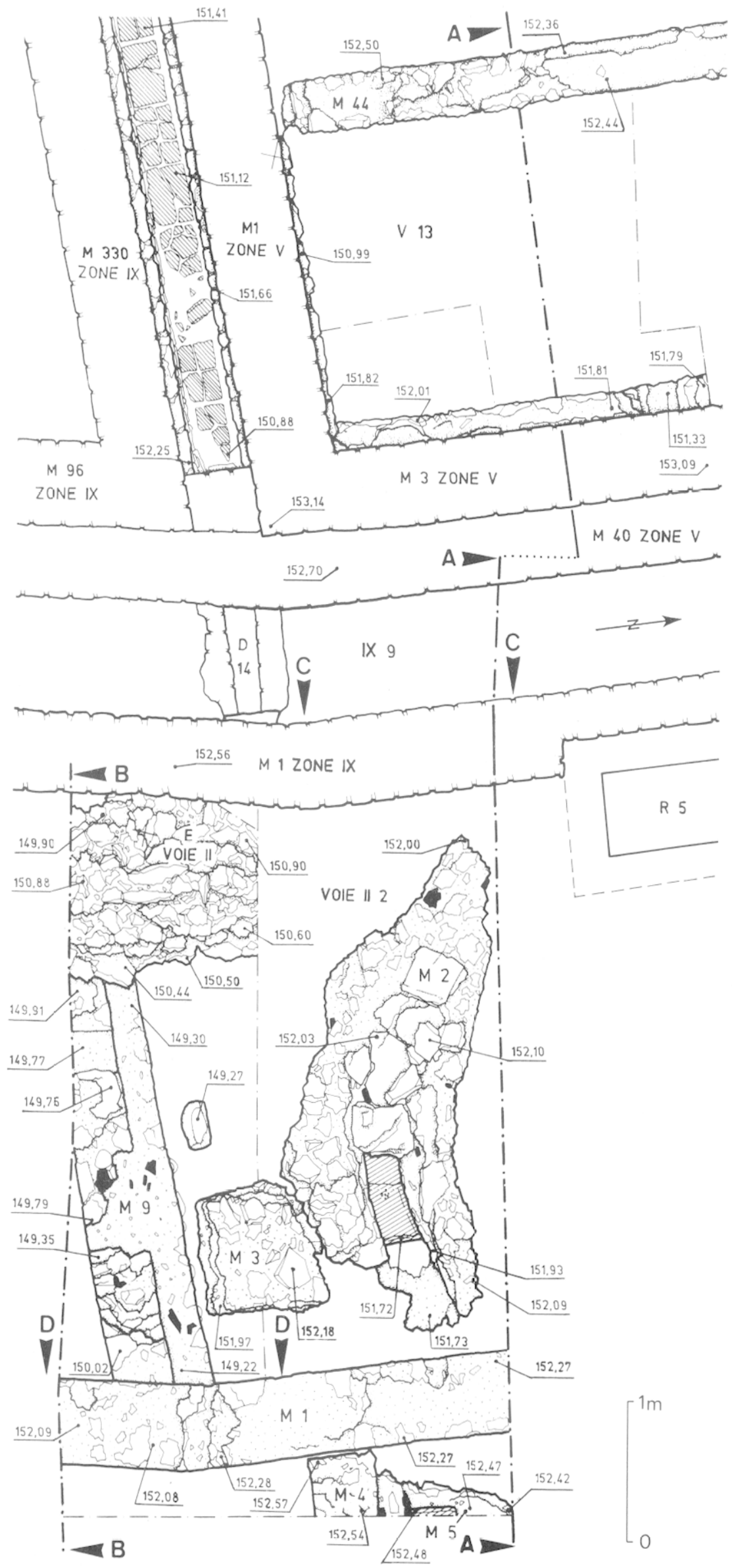




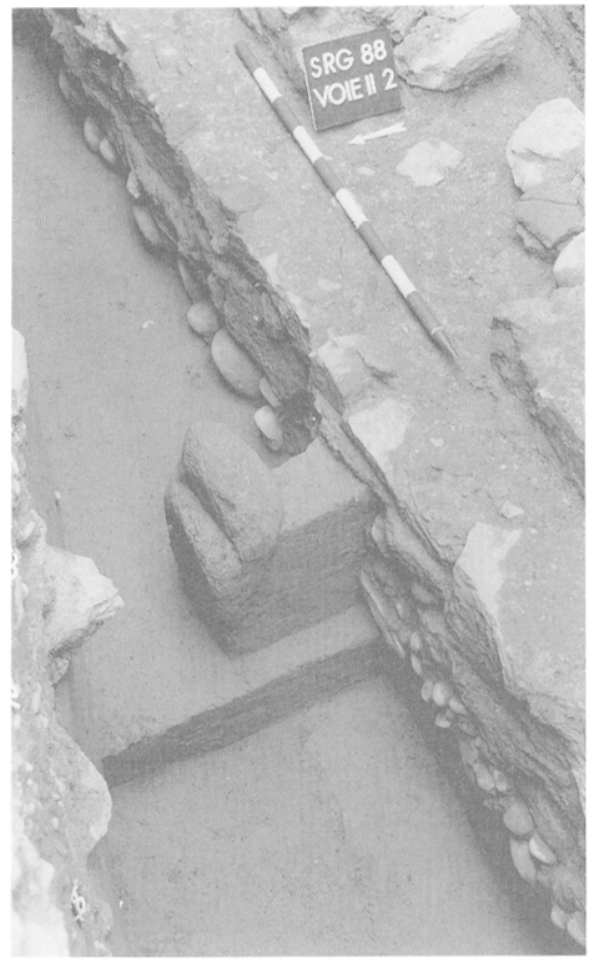

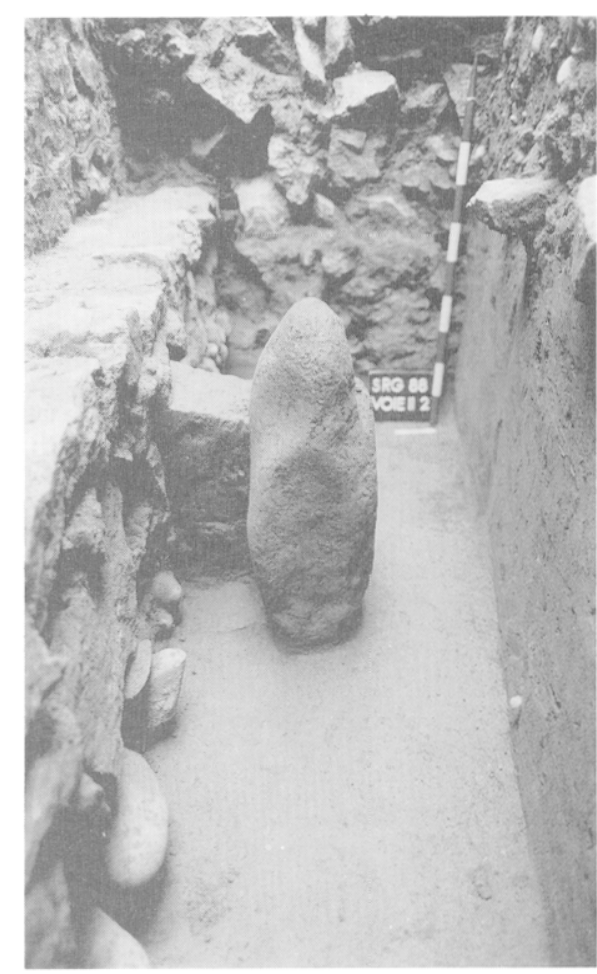

Fï. 5

Voie II 2 : borne cadastrale et fondations lissées du mur M9 (élat IA).

A droite. détail de la lace orientale de la borne.

\section{ETAT 1A}

\section{Une borne cadastrale?}

La présence d'une pierre dresséc de 0.50 in de haut. dont la face sud. plane. est parallèle au côté nord de M9. constitue un fait marquant de ce secteur d'occupation. II s'agit d'un grand galet oblong. de roche cristalline, situé à $0.30 \mathrm{~m}$ de la fondation du mur (soit environ un pied) (fig. 5). De section grossièrement rectangulaire, ce bloc de $0.38 \mathrm{~m}$ sur $0.22 \mathrm{~m}$ de largeur est fiché avec une verticalité parfaite dans la couche 126, de laquelle il émerge à peine (cote supérieure : $149.27 \mathrm{~m}$ ).

Son installation dans une couche limoneuse ne recelant par ailleurs que quelques graviers épars, de même que sa position très particulière indiquent qu'il s'agit bien là d'un repere placé intentionnellement. Avons-nous affaire à une borne de limite cadastrale d'axe est-ouest, ou bien alors à la trace d'un jalonnage lié à la création de M9 ? Dans tous les cas, cette borne s'avère antérieure au mur et matérialise une limite sans aucun doute en rapport avec sal construction.

Le bloc affleurait a peine lors des travaux de construction de M9 de sorte que nous pouvons nous demander si les ouvriers l'ont réellement utilisé, ou s'ils se sont servi. en guise de guide. d'autres repères plus visibles répondant au même tracé? Il est aussi possible que l'on ait tout simplement choisi de s'aligner sur des murs préexistants. Quoi qu'il en soit. M9 est situé ì un pied de la pierre, suivant une orientation similaire. Ces indices suggèrent ainsi l'existence d'une corrélation étroite entre ces deux éléments.
D'autre part. le comblement du sommet de la tranchée étroite de M9, légèrement évasée et large de $0.25 \mathrm{~m}$ à $0.30 \mathrm{~m}$ environ. est visible sur toute la longueur du sondage. Il n'a subi aucune perturbation à la hauteur de la borne (tranchée, recoupement), mais vient au contraire mourir contre elle.

Sommes-nous en présence d'un élément du maillage de base d'un cadastre, ou d'un point secondaire plus simplement destiné à délimiter l'étendue d'une parcelle $^{1()}$ ? Une exploration systématique le long de cet axe reconnu permettrait peut-être de mettre au jour d'autres marquages au sol du même type susceptibles de fournir des indications complémentaires sur le sujet.

Il est important de noter qu'une fois la construction de $\mathrm{M} 9$ achevée, la borne n'est plus visible puisqu'elle se trouve recouverte par le premier sol d'occupation 107 (fig. 6 et 7) et de ce fait elle devient donc définitivement inutilisable. Néanmoins, même occultée. elle marquera encore, après le tracé originel fort qu'elle a matérialisé, le faciès des bâtiments postérieurs du secteur.

10 II ne s'agil pas d'une borne ou d'un cippe gromatique indiquant une limite majeure (Chouquer e't alii. 1987. p. 310 312: (houquer, lavory. 1992, p. 15-25). (cette pierre se rapproche plutot des blocs utilisés pour borner les champs (Guy, 1983). Toutefois, notre borne, fortement enterrée et manifestement d'orientation ouest-est. pourrait constituer un simple jalon posé en cours d'arpentage, lors de la réalisation de cet axe caddastral. 


\section{Le mur est-ouest}

L'édification d'un mur. M9. s'effectue à partir de la surface du terrain naturel. composé de sables limoneux: couche 125 au sud (cote 149.22 m) et couche 126 au nord (cote $149.30 \mathrm{~m}$ ). perturbée en cet endroit par un remaniement antérieur de nature indéterminée (couche 116 : fosse ou tranchée ?) (fig. 7 et 8 ).

Cette maçonnerie, coupant le sondage selon un axe est-ouest. offre certaines particularités de construction.

Sa fondation en tranchée étroite est peu profonde (78 $\mathrm{cm}$ de largeur maximale pour $50 \mathrm{~cm}$ de hauteur), la base étant située à la cote $148.65 \mathrm{~m}$. Elle se compose de deux assises de moellons taillés dans des roches cristallophylliennes, liés par un mortier blanc-jaune. et reposant sur un lit de galets d'une quinzaine de centimètres d'épaisseur enfoncé dans le limon (fig. 9). A Saint-Romain-en-Gal, ce type de fondation n'a par ailleurs été reconnu que dans deux murs précoces d'époque augustéenne délimitant l'angle nord-ouest d'une parcelle (M25 et M24, issus des sondages Voie XI 1 et Voie XI 2 : campagne de fouille 1992, fig. 9). Dans ce cas précis. nous nous sommes trouvés face à une véritable construction de $25 \mathrm{~cm}$ de haut, constituée de galets de gros module $(10$ à $20 \mathrm{~cm})$, non liés, mais parfaitement imbriqués.

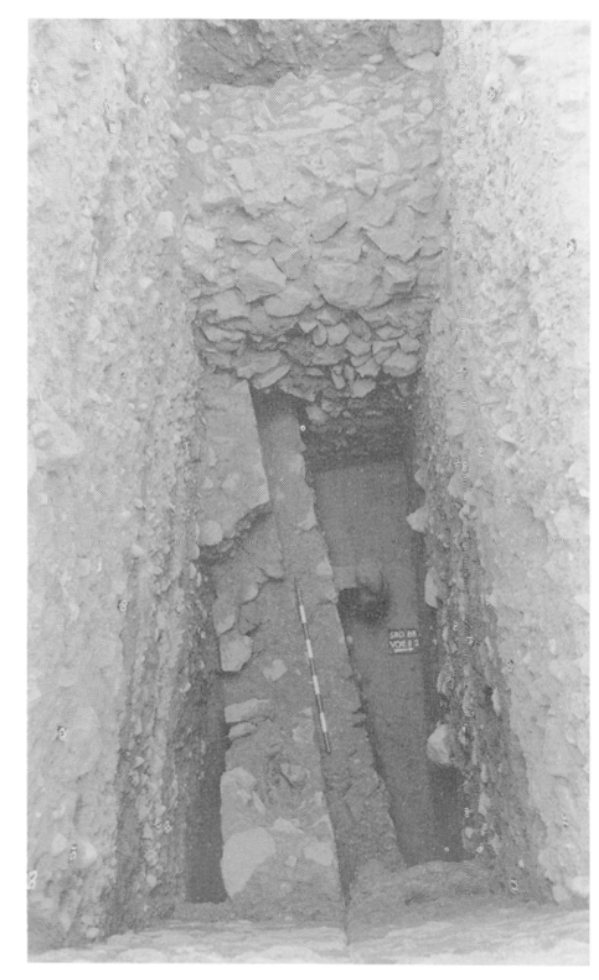

Fig. 6-Voie II 2 : borne et mur augustéen M9 (état IA) coupé par le collecteur de la rue (état 2B).
L'élévation, large de $0.46 \mathrm{~m}$. est construite à partir de moellons similaires liés au moyen d'un mortier jaune mêlé, dans le remplissage du mur. de nombreux éclats de terre cuite. Des joints beurrés. soulignés de marques au fer peu appuyées et très irrégulières, ont été réalisés à l'aide d'un enduit blanc épais, dissimulant en partic les pierres qui constituent le parement nord de la construction (fig. 10).

Ce traitement de façade particulier ne se retrouve pas sur le parement sud qui comprend. seulement dans sa moitié orientale, une demi-assise de briques ou de tuiles "1l à la cote supérieure $149,42 \mathrm{~m}$.

Dans la partie ouest du tronçon de mur dégagé. à $0.47 \mathrm{~m}$ du ressaut de fondation, il faut noter l'existence d'une empreinte de forme quadrangulaire traversant la maçonnerie de part en part (fig. 4). Trop proche, en altitude, du niveau initial de construction de l'élévation de M9. et d'une largeur appréciable $(30 \mathrm{~cm})$. ce négatif pourrait difficilement constituer la trace de l'installation d'un échafaudage encastré à boulin traversant. En effet. la largeur des trous de boulins recensés sur le site oscille entre 8 et $15 \mathrm{~cm}$ maximum. En revanche. les dimensions dont nous disposons (un pied $\mathrm{x}$ un pied et demi de côtés), nous incitent plutôt à penser que nous avons ici la trace d'une brique ou d'une tuile isolée. employée dans l'épaisseur de la maçonnerie. et récupérée après destruction de cette dernière.

Une couche de limon très fine (110), visible à la surface de 116, et reposant directement sur le ressaut de fondation du mur. correspond à un niveau d'occupation occasionné par les travaux de construction. C'est à partir de celui-ci que s'observe le creusement d'un trou de poteau. M10, de $0.30 \mathrm{~m}$ de profondeur et de $0.20 \mathrm{~m}$ de diamètre (fig. 7). Recouvert à la cote $149,35 \mathrm{~m}$ par le premier sol d'occupation lié, au nord, à la vie de M9 (couche 107), il s'agit là, sans aucun doute, d'une structure de nature éphémère. Ce trou, peu éloigné de l'élévation $(0,86 \mathrm{~m})$, pourrait être assimilable à l'encastrement d'une perche d'échafaudage.

Les niveaux de circulation s'avèrent peu marqués. Au nord. la couche de limon 107. d'une épaisseur d'environ $10 \mathrm{~cm}$. coïncide avec la surface du terrain naturel au niveau de la maison aux Cinq Mosaíques.

11 Peu habituelle en règle générale. l'utilisation de tegulue' dans la confection d'un mur ou d'arases horizontales est altestée en deux points du site:

- zone 11 : mur de limite nord (M248) de la maison au Portique Peint, datée de la seconde moitié du Ier s. apres J.-C. (SavayGuerra\% e't alii, 1992, p. 44)

- Voic II : regard R6 (cf. infra. p. 23. tabl. II et fig. 40).

En ce qui concerne $\mathrm{M} \%$. d'époque plus ancienne. l'état très dégradé de l'élévation n'a pas permis de savoir si les éléments de terre cuite observés provenaient ou non de briques ou de tuiles. 

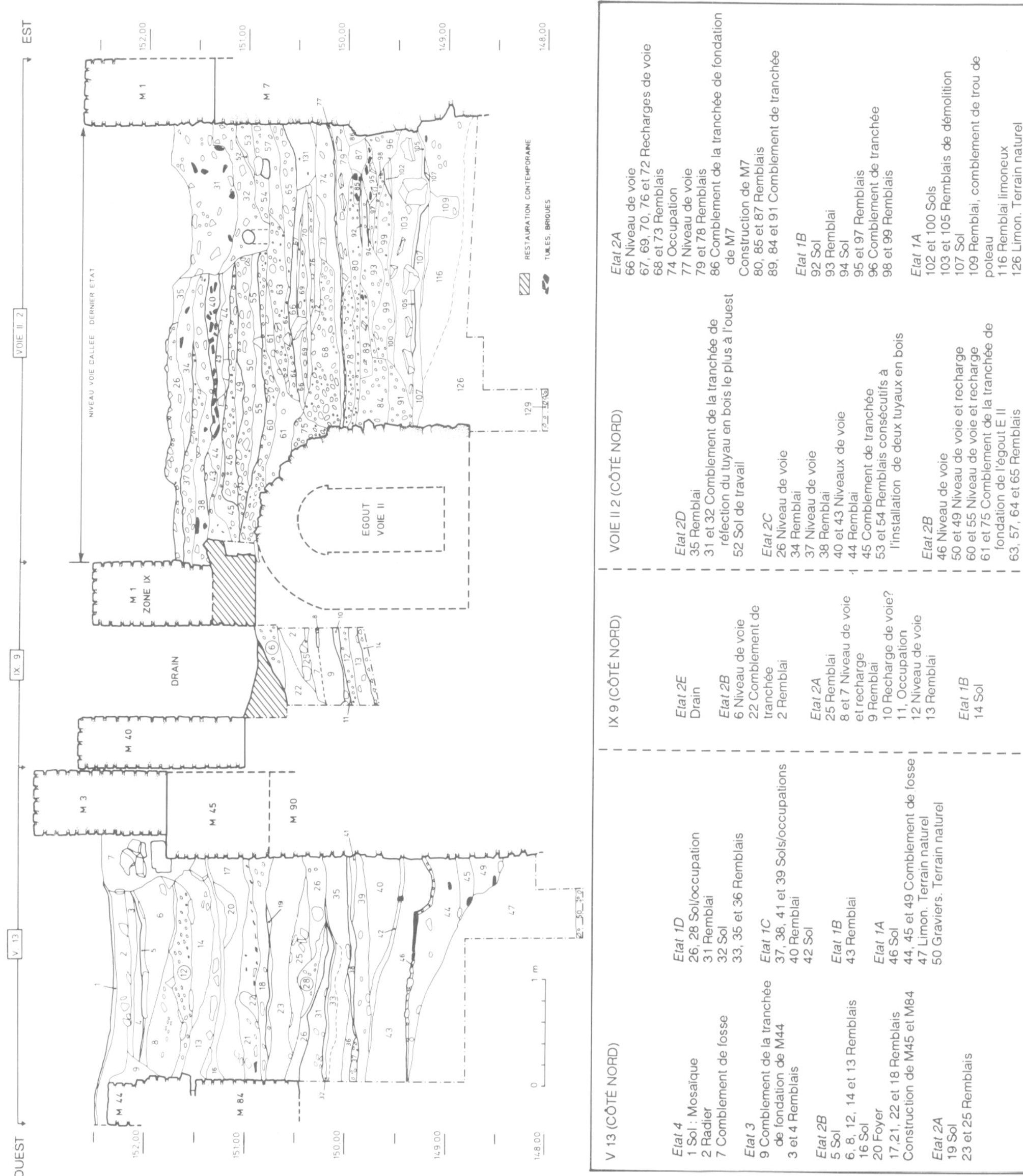

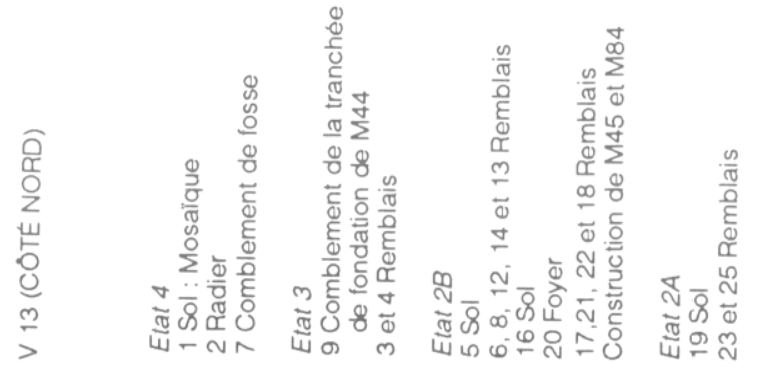




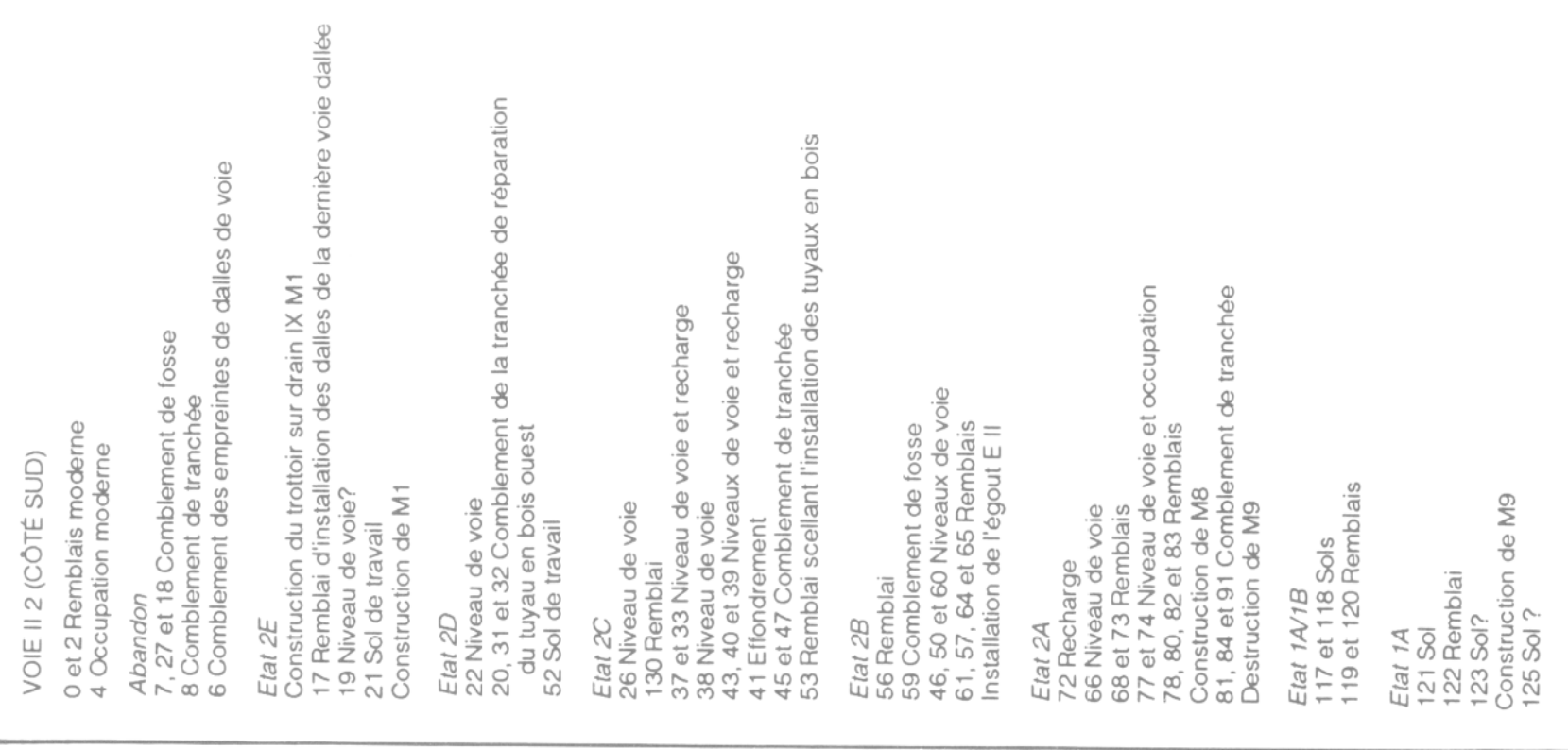

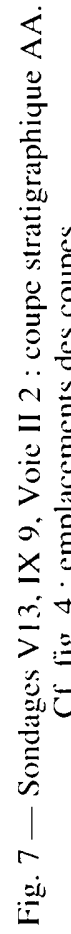

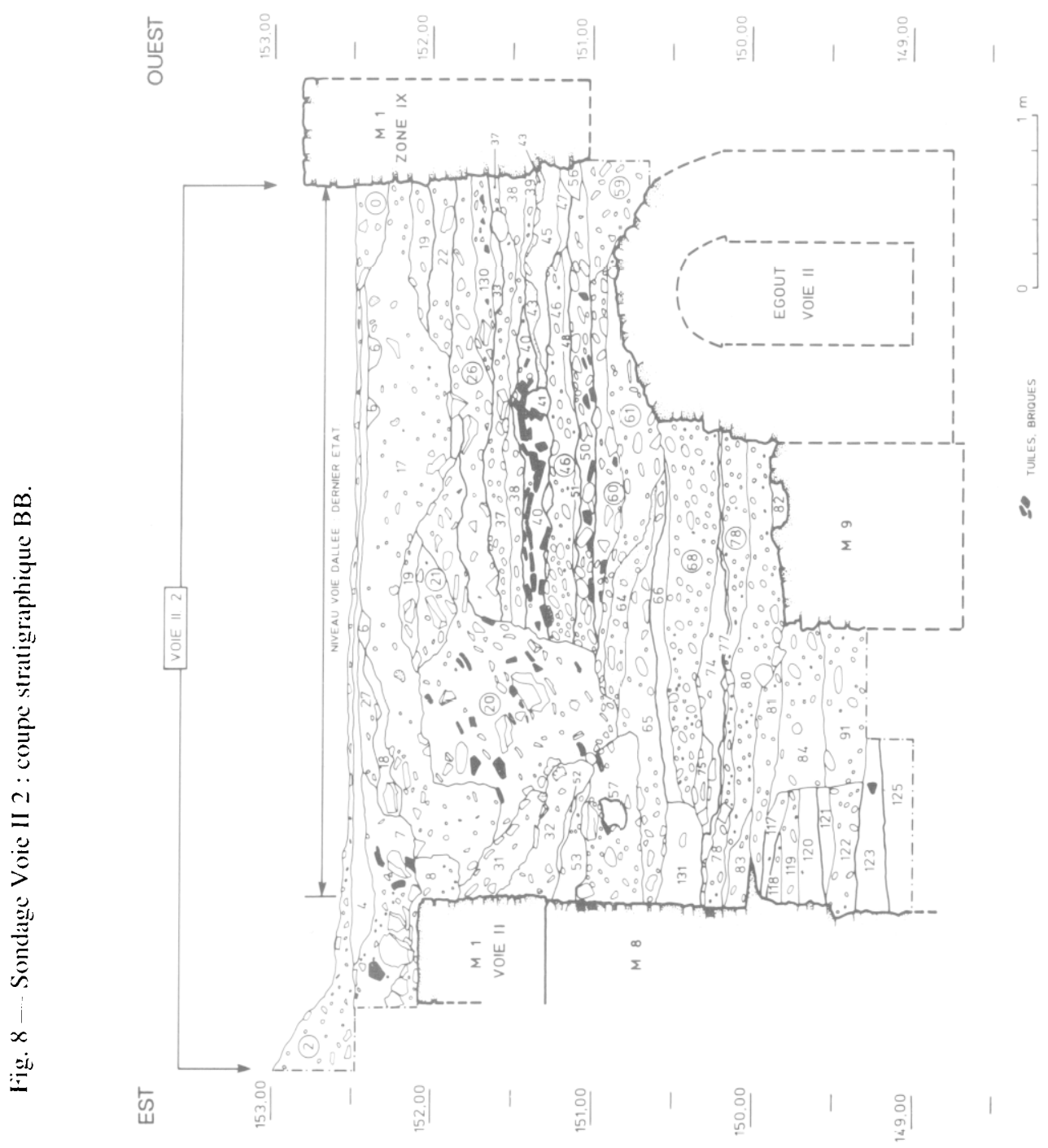



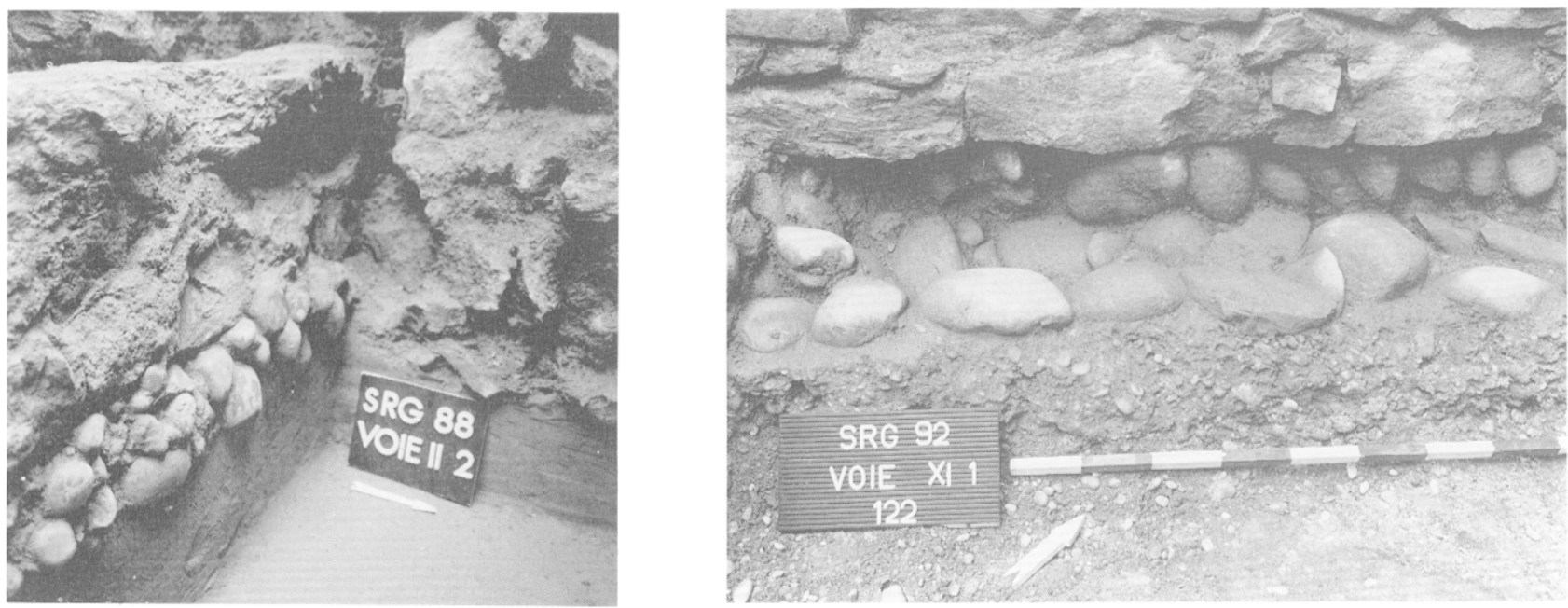

Fig. 9 - A gauche. Voic II 2 : détail des fondations du mur M9 (état 1A). A droite. Voic XI (place Triangulaire) : fondations sur lits de galcts.

Au sud du mur, le premier sol se situerait, selon toute présomption, à la cote $149,32 \mathrm{~m}$. Il s'agit en l'occurrence d'un niveau hétérogène (couche 123). constitué de limon, cailloutis et fragments de terre cuite. Toutefois, l'exiguïté du sondage à cet endroit ne permet pas d'être totalement affirmatif.

\section{Vie et rôle de M9}

L'élévation de M9 s'est révéléc complètement déportée vers le sud, à l'aplomb de sa fondation de plus grande ampleur, faisant ainsi apparaître, du côté nord, un important ressaut (0,34 $\mathrm{m}$ de largeur). Ce décalage. exceptionnel sur le site, allié à une légère différence de teinte observée dans les mortiers utilisés en sous-ceuvre et dans l'élévation, laissait supposer que la partie supérieure du mur pouvait être assimilée à une reprise postérieure de la maçonnerie.

Un autre indice venait renforcer cette idée: nous avons pu observer sur le ressaut la présence d'une couche épaisse de mortier, visible sur toute la longueur du tronçon de mur dégagé. Ayant fait l'objet d'un lissage particulièrement soigné (fïg. 5 et 6). ce niveau très net évoquait l'existence d'un lit d'attente destiné à recevoir la sablière basse d'un éventuel mur à colombage issu d'une première phase de construction.

Cette hypothèse s'est trouvée néanmoins réfutée par l'analyse stratigraphique. Le premier sol 107 lié à M9 repose en effet directement sur le ressaut de fondation et le recouvre dans son intégralité. attestant de ce fait la contemporanéité des deux éléments de la maçonnerie.

Nous avons donc bien affaire ici à un mur unique. La présence du lissage constitue plutôt l'indice d'un soin tout particulier apporté à la réalisation ainsi qu'à la finition des fondations. Dans l'hypothèse probable d'une mise à niveau générale de la base du mur. il jouerait le rôle d'une véritable assise de réglage permettant d'asseoir

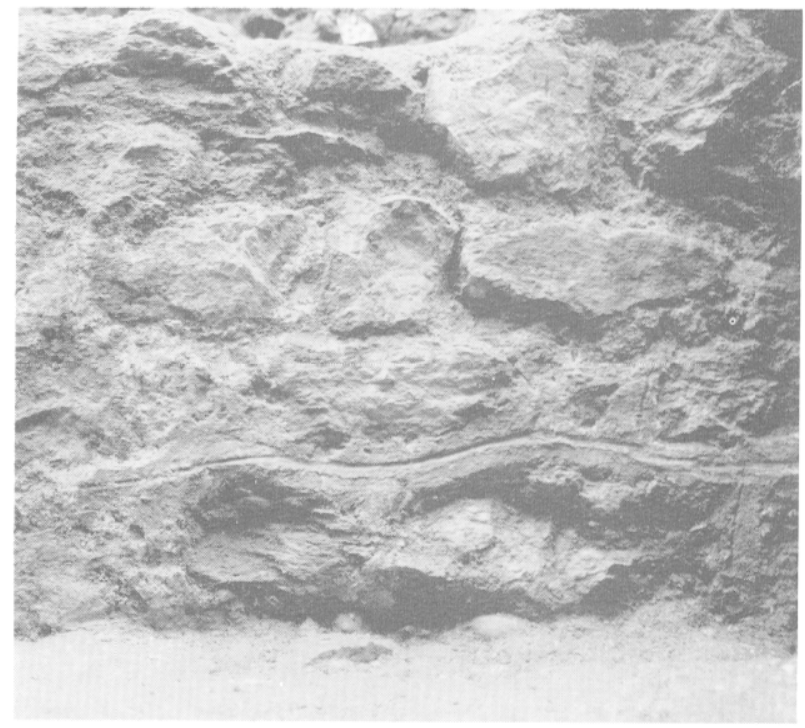

Fig. 10 - Voie II 2 : détail des joints beurrés de l'ćlévation du mur augustén M9) (élat IA).

correctement l'élévation ${ }^{12}$. Ce phénomène a déjà pu être mis en évidence lors de la fouille de la maison des Dieux Océans, notamment pour le mur M 20113 (fig. 11).

12 Les sommets de murs en sous-ocuvre. à Saint-Romainen-Gal, sont. dans l'ensemble, d'aspect beaucoup plus grossier (assises irrégulieres composées de grosses pierres émergeant du morticr).

1.3 Le mur M 201 constilue le côté sud du porticue nord domnant sur le jardin de la maison de létat $2 \mathrm{~A}$ (sondages 1/32/1/36). Un autre exemple est offert parr M112, mur nord de la branche nord du péristyle de cette même maison (sondage I.30) (Desbal o't alii. 1994: chap. III - L "chat 2A. Les fondal(ions). 


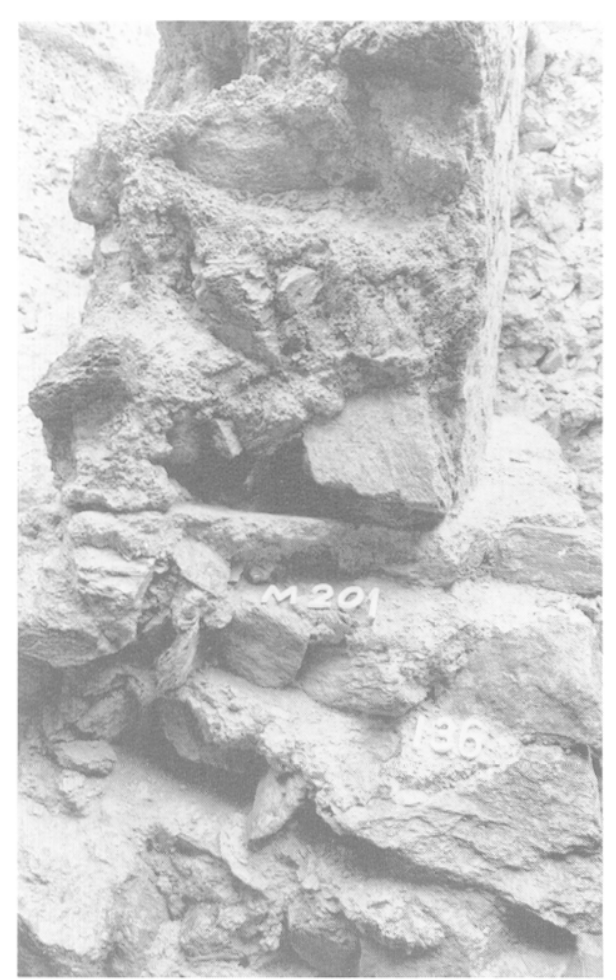

Fig. 11 - Maison des Dicux Océans (état 2A): ressaut de fondation lissé du mur M201.

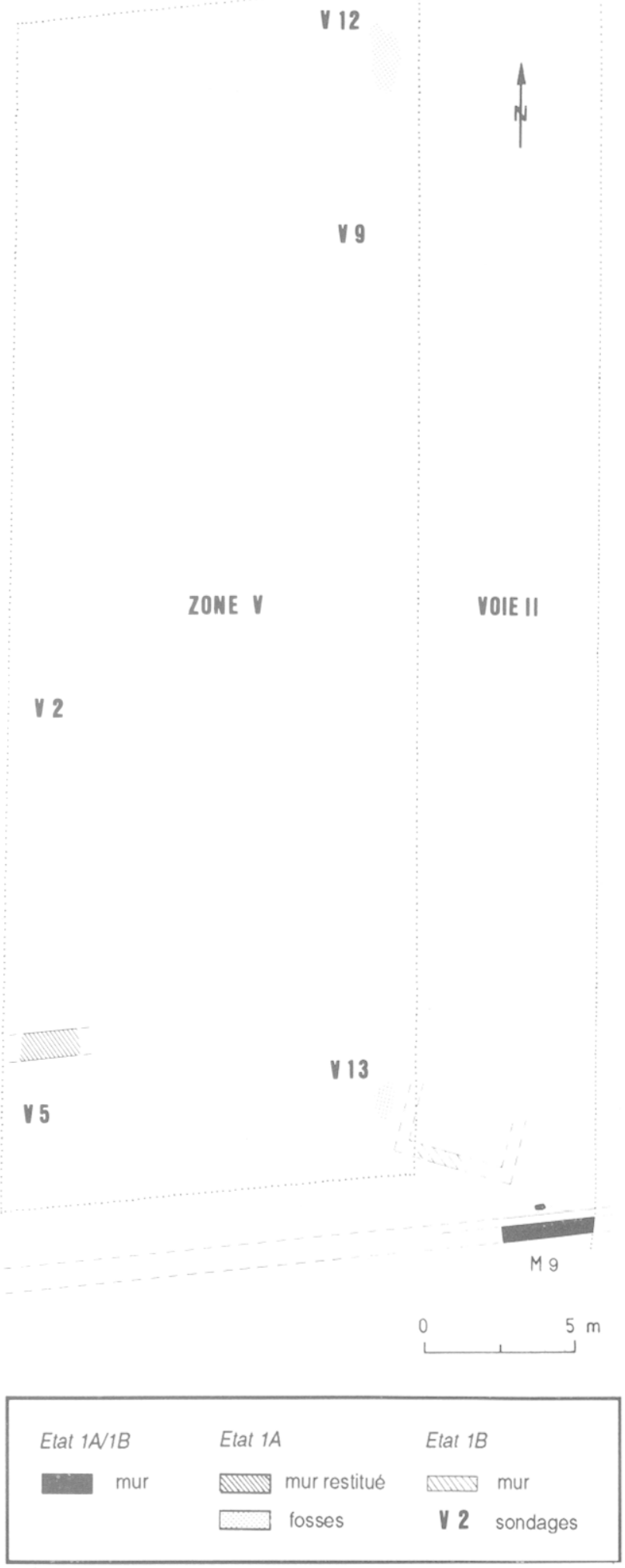

Fig. 12 - Plan des états IA et IB de la Voie II et de la zone $\mathrm{V}$.
La position et l'orientation de M9 nous incitent à penser que nous avons affaire ici à une limite de parcelle (fig. 12). Ce mur est en effet construit sur un axe fort contre lequel vient s'appuyer le côté nord de la parcelle des premiers états de la maison des Dieux Océans, dont M333 constitue la limite à l'état 1. elle-même prolongée par un autre mur situé plus à l'ouest: M336.

Ces maçonneries, repérées ponctuellement sur une distance de $41 \mathrm{~m}$. présentent néanmoins, par endroits, certaines différences (fïg. 13) :

- la profondeur de la fondation s'accroît au fur et à mesure que l'on se dirige vers l'ouest et on ne retrouve pas à la base la trace du lit de galets repéré en Voie II 2 :

- M3.33 ne possède pas de ressaut et M336, en I 55, ne présente qu'un léger débordement.

Enfin. il est important de noter qu'un mur. du même gabarit que M9 et d'axe similaire, a vraisemblablement été récupéré au nord des Petits Entrepôts durant la construction du bâtiment. ainsi qu'une tranchée le suggère (fig. 41. IX 28. position suggérée par un tireté reproduisant la forme de M9). La différence de stratigraphie observée de part et d'autre de M330. mur de limite nord du dernier état des Petits Entrepôts, vient renforcer cette hypothèse.

La matérialisation de cette limite s'effectue, soit à partir du terrain naturel (sondages Voie II 2 et 155 ). 
soit à partir d'un niveau de sol limoneux ou gravillonneux (sondages I 66 et IX 28) voisin du niveau moyen du terrain naturel.

Ces différences de construction indiquent qu'il existe sans aucun doute plusieurs murs correspondant chacun it une parcelle distincte, mais dont les longueurs exactes restent à déterminer. Tous matérialisent une même limite qui marquera durablement le quartier malgré les multiples transformations postérieures. On peut supposer que ce découpage parcellaire sous-jacent est issu d'une volonté d'aménagement général du secteur.

Dans la mesure où son élévation est calée sur le côté sud de sa fondation, dégageant ainsi un ressaut important, M9 pourrait constituer un mur périphérique sud, rattachable à une parcelle située au nord. Le soin apporté à l'aspect de son parement nord (joints au fer réguliers et profonds) suggère aussi que ce mur était destiné à être regardé préférentiellement de ce côté.

Ce type d'aménagement se retrouve en d'autres endroits du site : la façade est de la maison au Bassin Excentré et la limite parcellaire sud de l'état 2B de la maison des Dieux Océans. Dans le premier cas, nous avons affaire à la transformation d'un bâtiment. Le nouveau mur de façade se révèle plus étroit que le précédent. Il se trouve aligné sur le côté extérieur de la fondation antérieure, laissant ainsi un ressaut de $24 \mathrm{~cm}$ de largeur (fig. 7). En ce qui concerne le second exemple, nous nous trouvons face à un double mur (M5)8/M509) délimitant deux parcelles distinctes (cf. Desbat et alii, 1994 : chap. I - Aile ouest). Lors de sa construction. l'ćlévation de M508 $(60) \mathrm{cm}$ de large). limite sud de l'état 2B de la maison des Dieux Océans. laisse un ressaut de $42 \mathrm{~cm}$ de large du côté intérieur.
Ces décalages, observés sur de grandes longueurs, engendrent des gains de surface non négligeables.

Un autre indice vient renforcer cette assertion. La tranchée de construction de M9 ne s'évase que du côté nord, tandis qu'au sud elle demeure verticale. Cette différence de traitement indique que le mur a été construit depuis le nord et qu'il a été parfaitement calé au sud, contre le bord de l'excavation.

Les quelques tessons retrouvés dans le terrain naturel remanié ainsi que dans les premiers niveaux de sols repérés permettent de faire remonter la construction de M9 à l'époque augustéenne. Sa liaison relative avec les autres murs repérés, plus à l'ouest, sur le même axe au niveau de la maison des Dieux Océans et des Petits Entrepôts n`a pu être établie. En effet, il a été coupé par le passage de l'égout de l'état 2B, d’axe nord-sud (fig. 6) et nous ne pouvons pas déterminer, du côté ouest, sa limite ou son retour. Il se poursuit néanmoins vers l'est, peut-être sous des formes différentes, mais gardant la même orientation et ce jusqu'à la voie III où l'on observe un changement d'axe similaire à celui de la Voie II (fig. 2).

Après le premier sol d'occupation associé à $\mathrm{M} 9$, on note une remontée de niveau d'une vingtaine de centimètres puis l'apparition de nouveaux sols qui. malheureusement, ne nous ont pas permis de déterminer la nature des parcelles nord et sud.

Au nord du mur, ce remblaiement, d'une trentaine de centimètres d'épaisseur (fïg. 7, couche 103) a été réalisé avec des matériaux issus de la démolition d'une maçonnerie liée au mortier blanc. Du côté sud. l'exiguïté du sondage a rendu, une fois de plus, l'interprétation des couches délicate. Il semble néanmoins qu'une évolution similaire, mais plus lente. ait eu licu.

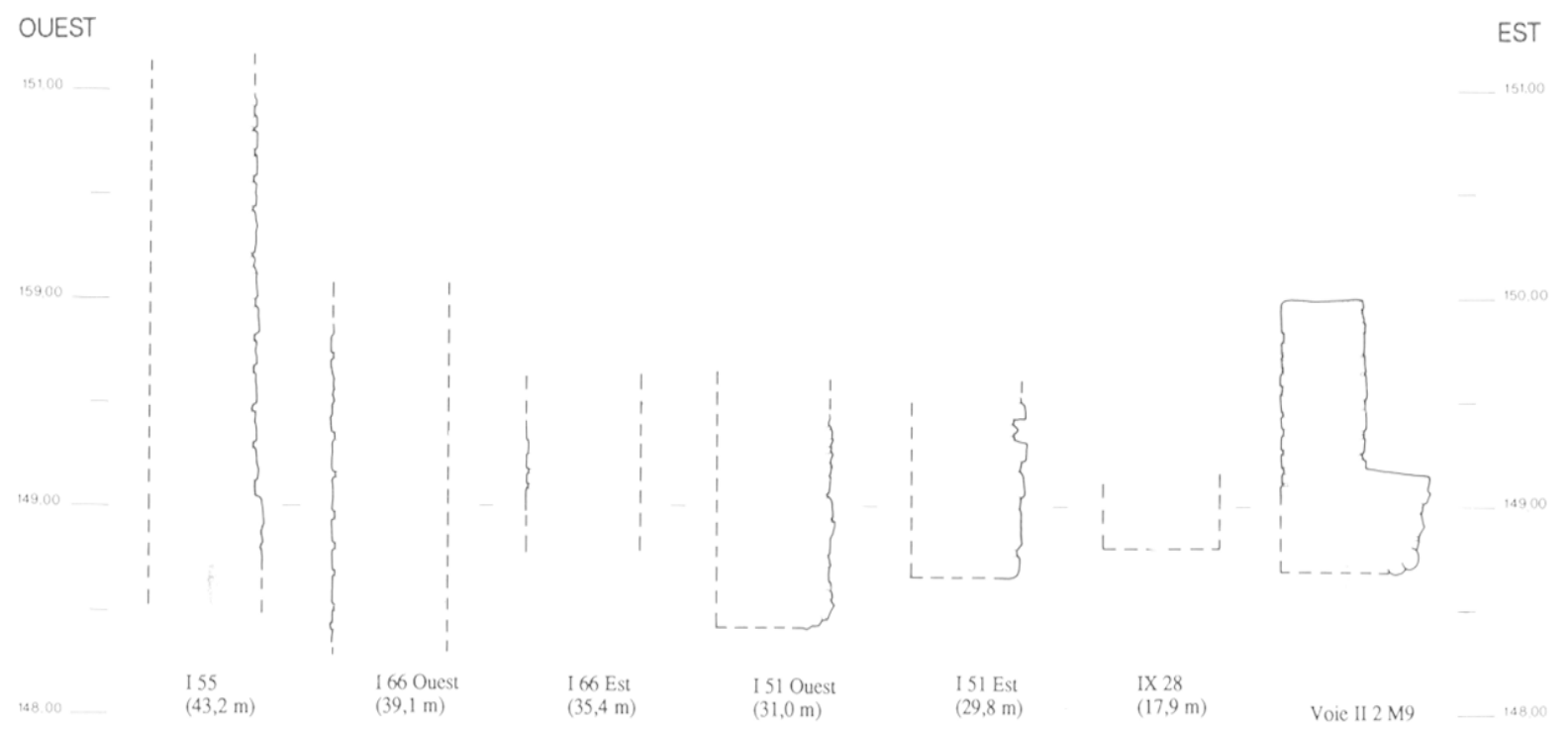

Fig. 13 - Schéma comparatif des sections des murs les plus anciens situés le long de l'axe de cadalstration (distances prisess à partir de l'extrémité ouest de M9 en Voie II 2). 


\section{ETAT 1B}

\section{L'édicule}

Cette phase voit l'établissement d'un remblai (couche 99) qui s'accompagne. en IX 9. de la construction d'un petit mur d'axe légèrement nord-ouestsud-est délimitant un sol compact (couche 14), à la cote $149.90 \mathrm{~m}$. Seule la tranchée de récupération a permis d'attester son existence (fig. 14, remblai de comblement de la tranchée, couche 16). Le fond de cette tranchée a permis d'estimer la largeur des fondations du mur. Elle n'excède pas une quarantaine de centimètres. Dans la mesure où cette structure n'apparaît ni dans la coupe nord de la Voie II, ni dans le sondage V 13, il faut envisager la présence de deux retours vers le nord aux extrémités du muret, permettant de restituer, sur trois côtés, les limites d'un édicule d'une largeur maximale de $4.50) \mathrm{m}$ (fig. 12).

A l'extérieur de cette construction. différents niveaux de sols ainsi que des recreusements ont pu être observés. montrant ainsi que ce secteur fut le lieu d'une activité certaine. La couche 98 constitue, à l'est, le premier sol de circulation repéré autour de l'édicule: cote $149,80 \mathrm{~m}$. On remarque au même endroit la présence d'une série de recharges extérieures dont la dernière (couche 92) se situe à la cote $149.90 \mathrm{~m}$ (fïg. 7. Voie II 2).

La fonction de ce petit bâtiment demeure inconnue. De dimensions modestes et placé à l'intérieur de la parcelle nord, à proximité immédiate du mur de limite sud (un mètre au plus près). nous pourrions l'assimiler à une petite cabane de jardin implantée au fond d'un hortus, mais il ne s'agit là que d'une hypothèse. Un bâtiment de largeur et de nature assez similaires a été mis au jour dans un espace ouvert. contre le mur de limite sud (M309) de la parcelle située au nord de la maison des Dieux Océans de l'état 2A (Desbat et alii. 1994 : chap. III - L'état 2A, Au nord).

A Pompéi, une cabane du même type se trouve conservée, en élévation. dans l'hortus d'une maison bâtie à l'angle de la Via de Nola et du Vicolo del Fauno Ebbro (IX 9, 6-10: De Vos, 1982, p. 214-215). Comme dans l'exemple précédent, cette petite construction se trouve accolée au mur de fond de la parcelle.

\section{La tranchée oblique}

La fin de l'état IB est marquée par la destruction de l'édicule et l'arasement de M9, en vue, probablement. de la création de la rue. Les couches 92 au nord et 117 au sud constituent les derniers niveaux de sols antérieurs à la destruction de M9.

Pour des raisons que nous ne pouvons déterminer. une tranchée d'axe nord-ouest-sud-est d'environ $0.60 \mathrm{~m}$ de large est exécutée à postériori, parachevant sur son passage et ce jusquau ressaut de fondation, la destruction de l'élévation remblayée de M9. La base de la tranchée correspond donc au sommet de la semelle de M9 ainsi qu'au fond de la couche 16 dans le sondage IX 9. Notons que cette excavation se poursuit. dans la même direction, au sud de M9. Elle ne peut être assimilée à une récupération de mur dans la mesure où son axe ne correspond à aucune orientation des maçonneries environnantes. D'autre part, elle n'est pas en relation avec la création ou le fonctionnement des bâtiments de l'état 2A car son comblement (fig. 7 et 8) a été achevé avant que ne débute la construction des murs de façade sur la rue.

A la hauteur du mur augustéen cette tranchée revêt, en plan, la forme d'un cône (figg. 4 et 6), évoquant ainsi

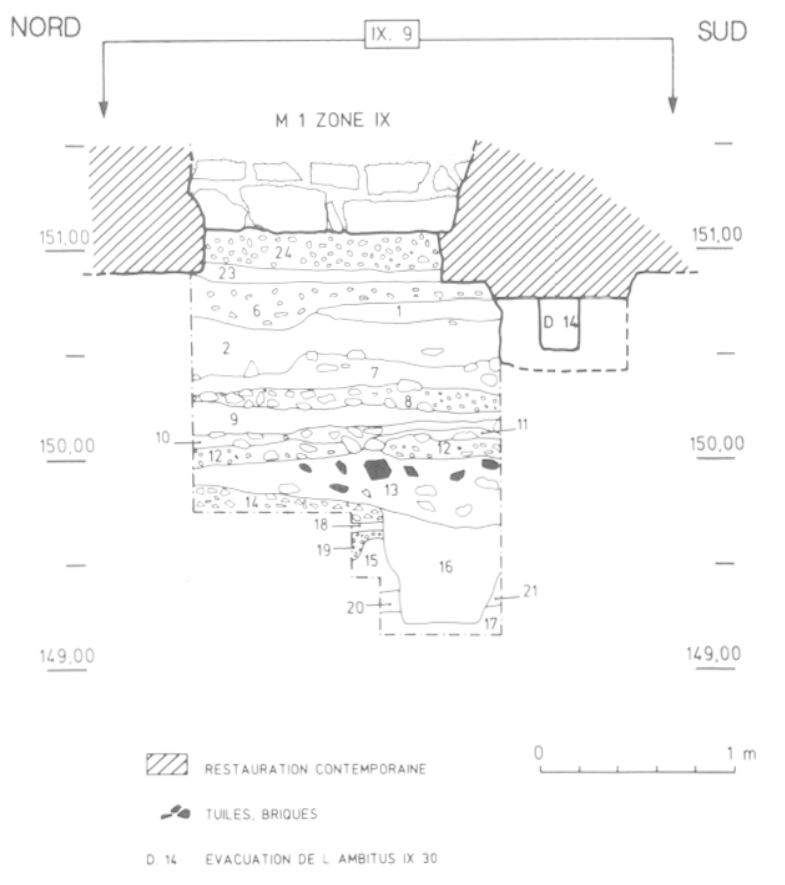

Fig. 14 - Sondage IX 9 : coupe stratigraphique CC. 
la récupération d'un égout ou d'un tuyau. en plomb ou en céramique ${ }^{14}$. Mais dans ces conditions deux problèmes se posent.

Le premier est relatif à la nature de l'espace situé au sud de M9. De part la présence d'une amenée ou d'une évacuation d'eau, nous serions tentés de l'assimiler, logiquement, à une zone de circulation publique. La nature des couches archéologiques exclue la présence d'une voie empierrée. Néanmoins, l'existence d'un chemin de terre demeure possible.

Si toutefois nous réfutons l'hypothèse du chemin, nous nous trouvons alors, au sud, dans une parcelle privée, traversée par une canalisation ou un égout issu, ou s'acheminant dans la parcelle voisine, au nord. Ce cas de figure est envisageable, mais rare ${ }^{15}$.

La seconde possibilité reviendrait à considérer que la tranchée oblique ait été réalisée, pour des raisons inconnues (fossé, drainage ?), après la destruction de M9 et de l'édicule. Si tel était le cas, il nous faudrait introduire une phase transitoire entre la récupération de M9 et la création de la rue. Cette supposition est à prendre en considération dans la mesure où nous observons un décalage chronologique entre le matériel issu des couches correspondant à la destruction de l'édicule et celui présent dans les niveaux d'installation de la première chaussée (cf. infra, p. 85).

Les données recueillies nous empêchent malheureusement de pousser plus avant nos investigations.

\section{ETAT 2 :}

\section{HISTOIRE DE LA RUE}

\section{ETAT 2A : CRÉATION DE LA RUE (10-15 après J.-C.) \\ Façade est}

La création de la rue débute par l'édification, sur le côté est, de deux murs limitrophes M8 puis M7, façades ou clôtures (fig. 15). Leurs constitutions différentes montrent bien qu'ils appartiennent à des parcelles distinctes (fig. 16).

14 Il s'agirait dans ce cas du premier tuyau en plomb d'époque augustéenne reconnu sur le site. La plus ancienne canalisation de ce type recensée jusqu'à ce jour à SaintRomain-en-Gal est en effet le tuyau d'amenéc d'eau de l'état 2A (15-20) après J.-C.) de la maison des Dieux Océans. (Cochet. Hansen, 1986, p. 74-76).

15 Un exemple de ce lype se rencontre à Saint-Romain-enGal avec l'évacuation du bassin du grand péristyle de la maison des Dieux Océans qui traverse la zone $V$ d'oucst en est, depuis l'époque de fonctionnement du Bâtiment Commercial jusqu'à celle de la maison aux Ciny Mosaïques (cf. infira. p. 45, le Bâtiment Commercial).
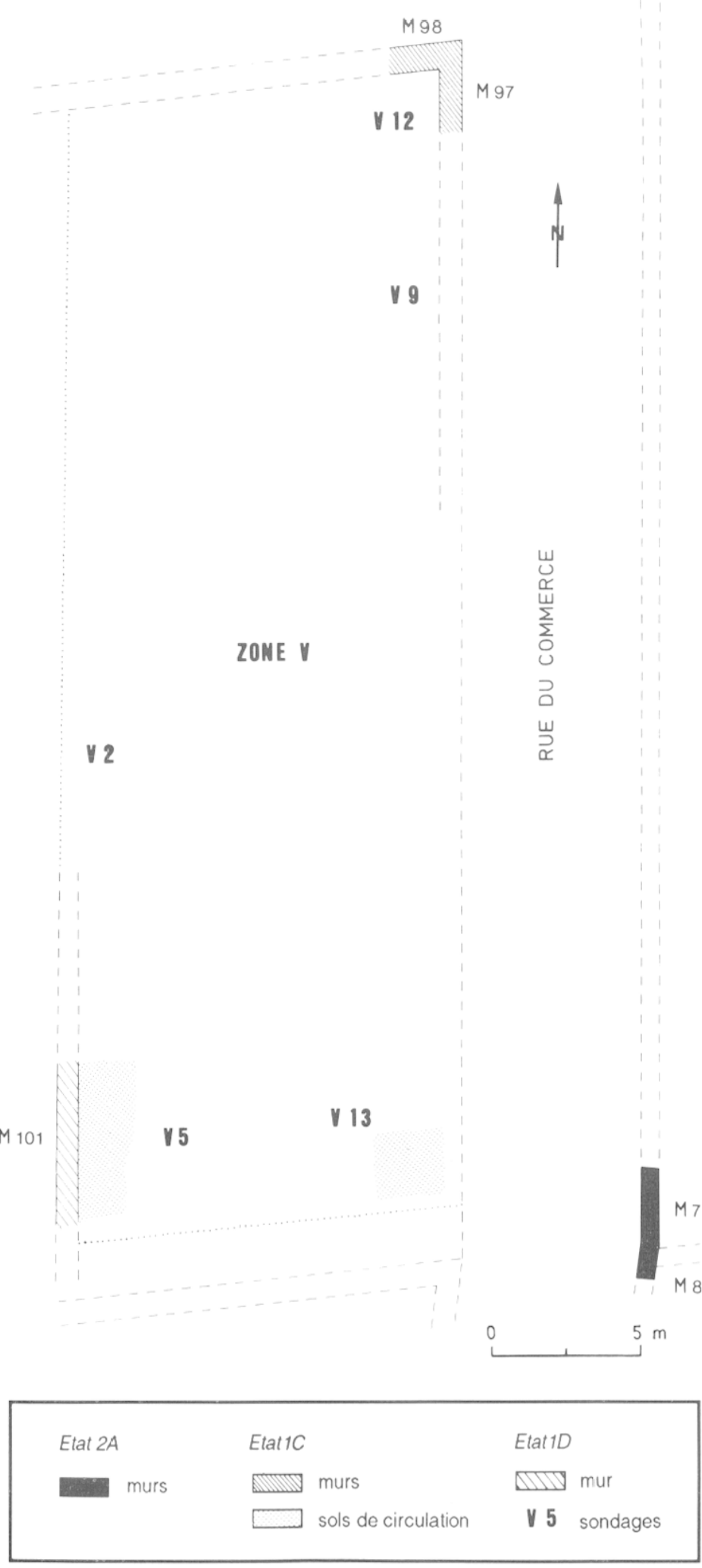

Fig. 15 - - Plan de létat $2 \mathrm{~A}$ de la Voie II (rue du Commerce) et des états IC et ID de la zone V. 


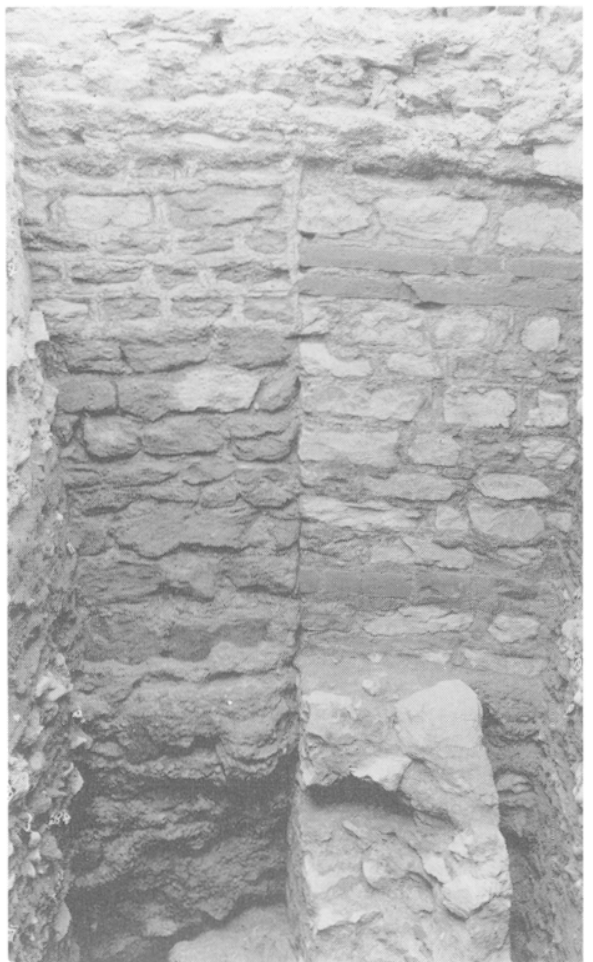

- Construction de M8. Le mur de façade sud-est M8. en opus mixtum ${ }^{16}$, est construit en tranchée étroite, à partir du remblai 81 (fig. 17). Les mocllons, taillés dans des roches cristallophylliennes et liés par un mortier jaune sont associés. en élévation, à des assises de brique disposées de manière irrégulière. Une première arase horizontale, basse, se trouve à la même altitude que la première chaussée (couche 77 . altitude de la rue au contact du mur: $150.30 \mathrm{~m}): 70 \mathrm{~cm}$ plus haut. une double assise s'observe à nouveau.

A partir de la cote $150,64 \mathrm{~m}$ (soit $60 \mathrm{~cm}$ au-dessus du sommet de fondation), ce mur est pourvu de joints au fer esquissés qui rendent compte du soin certain apporté à l'élaboration de l'élévation.

La base des fondations n'a pas été atteinte. Leur largeur. de même que celle de l'élévation, dont le départ se situe à la cote 150,04 m, sont également inconnues. L'extrémité nord de M8 ainsi que le mur faisant retour vers l'est dont on peut supposer l'existence s'appuient sur l'arasement de M9, gardant ainsi son axe, de même que son souvenir (fig. 18).

Avec M8, nous nous trouvons en présence de la plus ancienne maçonnerie connue à Saint-Romain-enGal au sein de laquelle une utilisation intentionnelle et organisée de briques est attestée. Compte-tenu de la faible portion dégagée. nous pouvons nous interroger sur l'ampleur de cet aménagement. Cet opus mixtum est-

16 Adam. 1989. p. 151-156: Synthèse sur ce mode de construction dans le monde romain. il limité à une chaîne d'angle, ou bien s'étend-il sur toute la longueur du mur ${ }^{17}$ ?

En l'absence d'autres sondages le long de cette façade. l'exemple sur le site de la maison au Vivier. datée du milieu du I I ${ }^{\mathrm{er}}$ s. après J.-C., peut nous éclairer (Savay-Guerraz of alii, 1992, p. 76). Dans cette demeure. les briques se trouvent employées dans la construction d'un escalier dont le massif de support. allégé au moyen d'une voûte, est aménagé en cave. Elles sont cantonnées aux angles visibles de la structure (piédroits de l'entrée de la cave, angle extérieur du massif), où elles alternent avec des moellons calcaires. Dans ce cas précis, elles constituent des arases plus ou moins longues qui pénètrent dans le parement de la maçonnerie composé de roches métamorphiques. Les parois n'étant pas enduites, la fonction ornementale de ces arases est ici indéniable.

En ce qui concerne M8, il n'existe aucune différence de taille ou de matériau entre les moellons de l'angle et ceux du reste de la façade. De ce fait, nous pouvons raisonnablement envisager l'existence d'arases horizontales continues sur la totalité de ce mur limite.

- Construction de M7. Le mur de façade nord-est M7 vient se plaquer contre l'angle nord de M8. Il est lui

17 Le réexamen récent des monuments lyonnais dotés d'arases de brique montre que cette technique est en usage dès le règne de Tibère. Une utilisation dans des encadrements est attestée dès l'époque augustéenne (Desbat, 1992). 


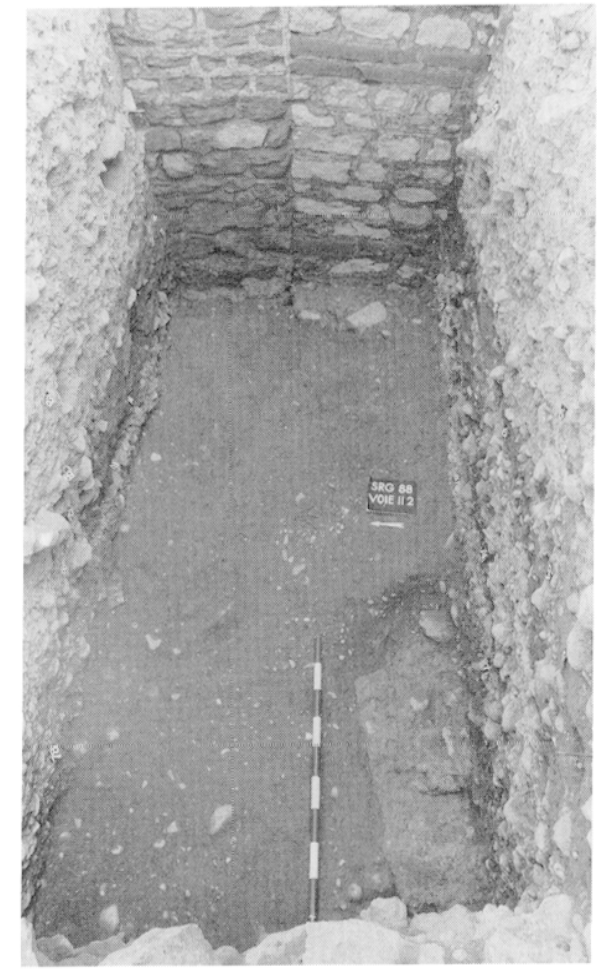

Fig. 17 - Voic II 2 : sol de construction de M7 et M8 (état 2A), ćtabli après l'arasement du mur M9 et la réalisation de la tranchéc oblique.

aussi construit en tranchée étroite, à partir du remblai 80 (fig. 7). Les moellons qui le composent sont issus de roches cristallophylliennes et ont été liés au moyen d'un mortier jaune foncé.

Comme pour M8, nous ne pouvons déterminer les largeurs des fondations et de l'élévation dont la base a été reconnue à une altitude moyenne de $149,95 \mathrm{~m}$.

La réalisation de deux clôtures maçonnées et élaborées, intervenant avant l'établissement du niveau de circulation proprement dit, montre bien que nous nous trouvons, au moins pour le secteur situé à l'est de la voie, dans un milieu en pleine phase d'urbanisation.

\section{Côté ouest de la rue}

La fouille, dans le sondage V 13, n'a pas permis de savoir si un mur avait été édifié dans le même temps. Il semble que nous nous trouvions plutôt en présence d'un petit fossé dont la couche 42 épouse le profil (fig. 7). Large de $2 \mathrm{~m}$ environ, il atteint $30 \mathrm{~cm}$ de profondeur en bordure de la rue et s'amenuise progressivement vers l'ouest. Son extension nord nous est inconnue dans la mesure où nous ne l'avons pas retrouvé dans le sondage $\mathrm{V} 12$.

Les différences de stratification existant entre ces deux secteurs indiquent qu'à la hauteur de la zone V. ce côté de la rue n'est pas de nature homogène. Peut-être nous trouvons-nous en présence de deux parcelles

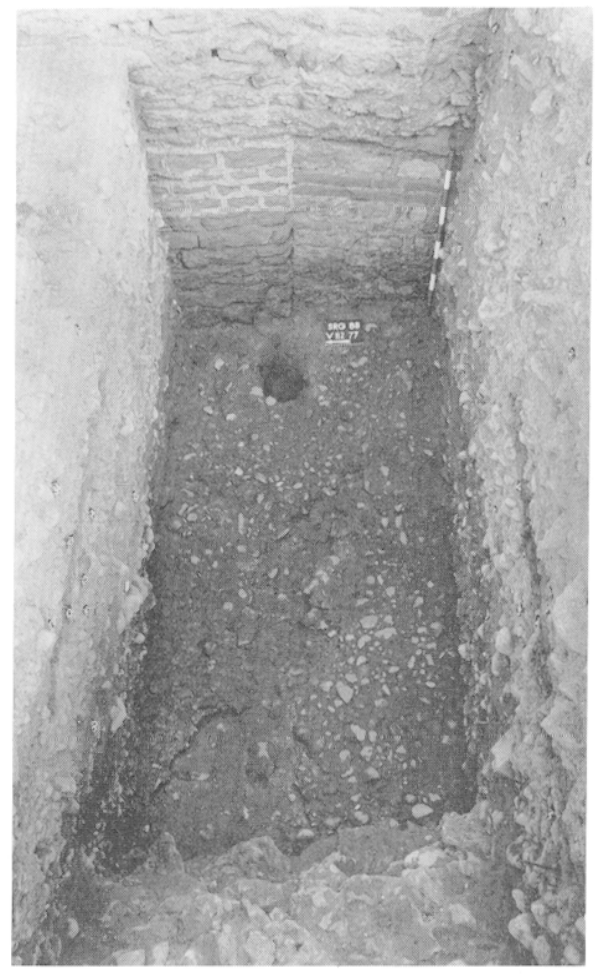

Fig. 18 - Voie II 2 : premier niveau de voie, couche 77 avec trace de ravinement (état 2A). En arrière-plan. élévations de M7/M8 (état 2A) sous la fondation de Ml(ćtat 2E).

distinctes dont les limites matérielles n'ont pas été reconnues (fig. 15). Si, dans cette hypothèse, un simple fossé marque au sud le bord de la parcelle, un mur de façade (M 97), au nord, pourrait avoir été réalisé dès cette époque (cf. infra, p. 41, État $1 \mathrm{C}$ de la maison aux Cinq Mosaïques).

\section{La chaussée}

Le premier niveau de voie (couche 77 en Voie II 2 et couche 11 en IX 9) atteint une largeur d'environ $6 \mathrm{~m}$. du bord est présumé du fossé repéré en $\mathrm{V} 13$ au contact de la façade orientale. Très compact et constitué de galets de rivière damés d'assez gros calibre (de 10 à $20 \mathrm{~cm}$ en moyenne), il est établi sur un remblai d'une vingtaine de centimètres.

Ce sol de circulation est entamé par un ravinement est-ouest qui s'est formé à la jonction des façades M7 et M8, vraisemblablement au point de chute des eaux de toiture (fig. 18). L'orientation du sillon et le profil convexe de la couche 77 suggèrent que les eaux de ruissellement étaient canalisées dans l'axe médian de la chaussée. Toutefois, il ne semble pas qu'une rigole centrale ait été spécifiquement aménagée. Cette chaussée très homogène est peu détériorée et s'avère exempte de recharges. Son bon état de conservation laisse présumer une durée de fonctionnement relativement brève 
expliquant ainsi l'absence de toute tentative de comblement du ravinement.

Notons quau cours de cette période. le fossé localisé sur le bas-côté ouest est condamné.

Sur la figure 18 , nous observons également la présence d'un trou de section circulaire de $20 \mathrm{~cm}$ de diamètre et d'environ $15 \mathrm{~cm}$ de profondeur. Situé sur la voie, à une quarantaine de centimètres de l'extrémité de M7. il pourrait désigner l'emplacement d'un poteau (support d'échafaudage ?), ou d'un bloc (chasse-roue?) récupéré lors de l'abandon de ce niveau. Nous ne disposons pas d'indices suffisants nous permettant de préjuger de la fonction d'un tel aménagement.

Nous observons ensuite un apport important de remblais (couches $68,73,74$ ) à la surface desquels une nouvelle chaussée est aménagée. Ce rehaussement de niveau d'une quarantaine de centimètres peut être mis en relation, dans la zone $\mathrm{V}$, avec le passage de l'état $\mathrm{IC}$ à l'état ID et la construction d'un mur de façade. M97. Dès lors et jusqu'à son abandon, la rue gardera devant la parcelle de la maison aux Cinq Mosaĭques une largeur constante de $5,96 \mathrm{~m}$ (20) pieds ${ }^{18}$ ), les façades successives respectant toujours les mêmes alignements.

Un bombement, coïncidant avec la partie centrale de la voie, est visible dans la zone ouest du sondage Voie II 2 (fig. 7). Du fait de l'absence de collecteur, celui-ci était sans doute destiné à faciliter l'écoulement des eaux pluviales sur les côtés.

Après l'installation de ce second niveau de rue, des recharges régulières (couches 72 à 66) permettent de le maintenir aux alentours de $150.60 \mathrm{~m}$ d'altitude. D'épaisseurs variables (de 2 à $10 \mathrm{~cm}$ au maximum). elles sont composées de cailloutis ou galets damés. mêlés à du sable ou à du limon.

Durant cette période, la rue conserve son aspect bombé et une cuvette se constitue progressivement au pied des murs de façade est. Celle-ci atteindra, dans sa forme finale, une profondeur de $15 \mathrm{~cm}$ pour une largeur de $60 \mathrm{~cm}$

Nous pouvons penser qu'une rigole similaire existait du côté ouest de la rue. Si nous retenons cette hypothèse, il faut alors considérer que la bande de roulement se trouvait réduite à une largeur de $4.75 \mathrm{~m}$ ( 16 pieds). Dans le cas contraire, cette dernière devrait être portée à $5.35 \mathrm{~m}$ ( 18 pieds).

Dans le même laps de temps, le parement ouest de M7 s’enrichit d'un décor de joints au fer (fig. 16 et 18). Cinq assises conservées en portent la trace (altitude inférieure : $150,86 \mathrm{~m}$ ). Ces joints correspondent bien à un aménagement de façade postérieur à la construction de M7 puisque la couleur de l'enduit. jaune clair, est nettement différente de celle du mortier du mur.

18 Pour toute valeur donnée en pieds, dans le texte ou dans les tableaux. nous utiliserons le pes monetalis de $0.296 \mathrm{~m}$ comme unité de référence.
La rigole orientale est finalement comblée (couche 131) à la hauteur du remblai 66 dont la surface en galets damés constitue la dernière chaussée de l'état 2A.

\section{ETAT 2B (40-50 après J.-C.)}

\section{Construction de l'égout}

L'état 2B marque une étape essentielle dans l'histoire de la voie II. Il correspond en effet à l'installation d'un grand collecteur public destiné à assurer l'évacuation des
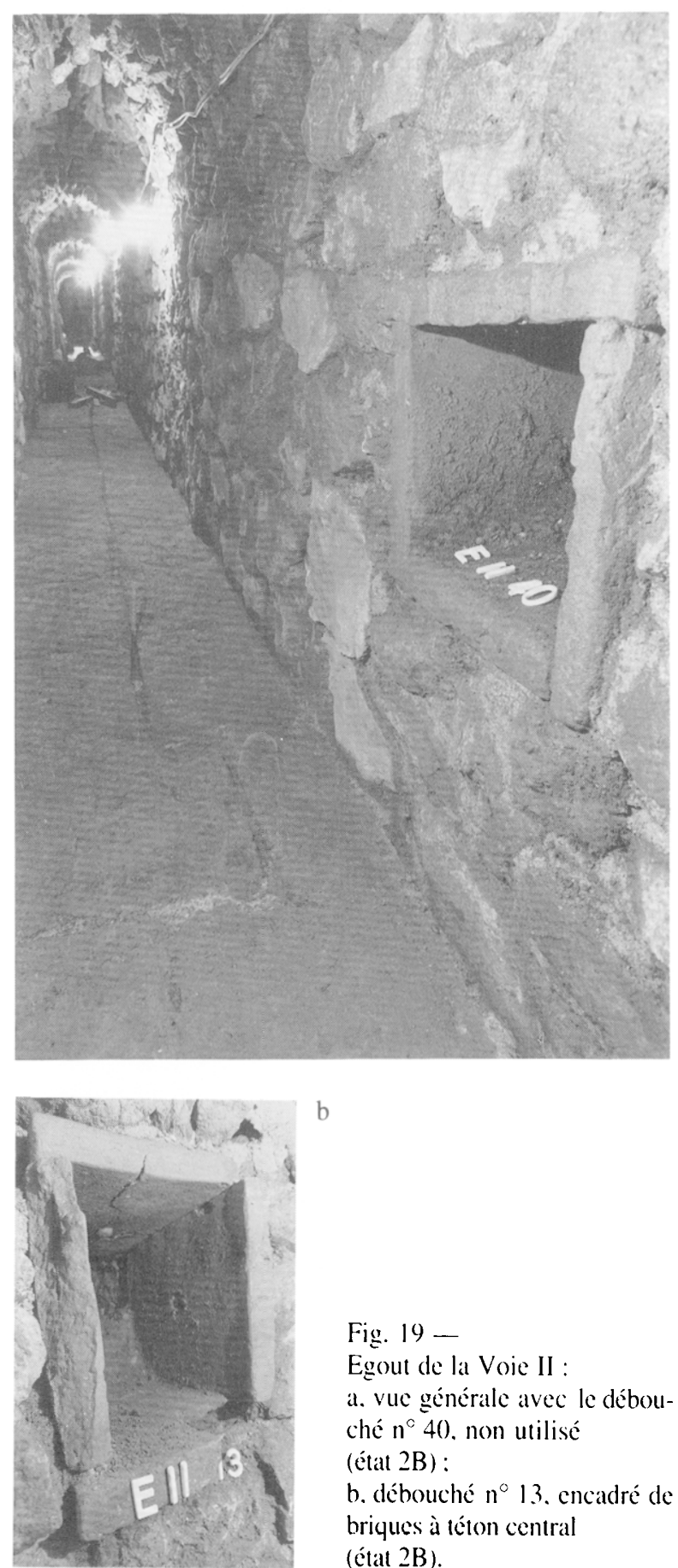

Fig. $19-$

Egout de la Voie II :

a. vue générale avec le débouché $n^{\circ} 40$, non utilisé (état 2B) :

b. débouché n 13 , encadré de briques à téton central (élat 2B). 


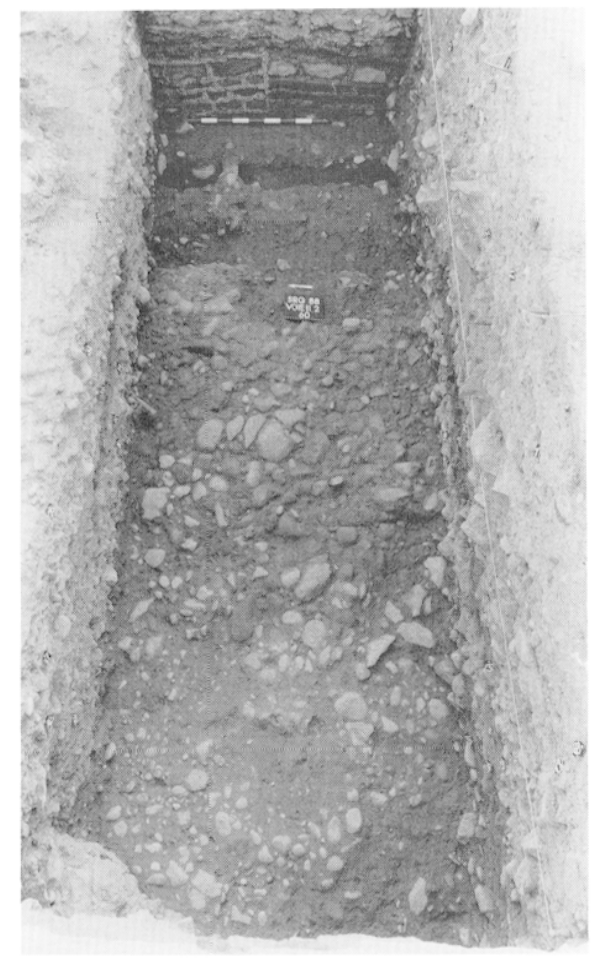

Fig. 20 - Voie II 2 : niveau de voic 60, établi après la construction du collecteur public (élat 2B).

eaux usées (fig. 44). Situé sous la chaussée de circulation, du côté ouest à la hauteur du sondage (fig. 6), il se révèle construit en tranchée étroite, à partir du niveau de voie 66 (fig. 7 et 8 ). Cette tranchèe atteint plus de $1.70 \mathrm{~m}$ de profondeur et s'évase au niveau du départ extérieur de la voûte de l'égout. à partir de la cote $150,20 \mathrm{~m}$.

Ses dimensions extérieures sont de $2.10 \mathrm{~m}$ de hauteur pour une largeur de $1.75 \mathrm{~m}$. La maçonnerie est constituée de roches métamorphiques liées avec du mortier jaune. La largeur du conduit intérieur est de $0.60 \mathrm{~m}$. Posées sur un radier maçonné d'une épaisseur moyenne de $0,25 \mathrm{~m}$, des briques, placées deux par deux dans le sens de la longueur et encastrées sur $5 \mathrm{~cm}$ environ dans la base des piédroits, en tapissaient le fond (fig. 19a).

Les parois de l'égout atteignent $1.15 \mathrm{~m}$ de haut et $0.60 \mathrm{~m}$ de large. Elles sont pourvues, dans leur partie supérieure, d'un léger ressaut intérieur $(6 \mathrm{~cm}$ de largeur) qui était destiné, au moment des travaux de construction, à soutenir le coffrage de bois indispensable à l'ćlaboration de la voûte surbaissée du collecteur $^{19}$.

La création du collecteur a entrainé un rehaussement général de la rue de 30 à $40 \mathrm{~cm}$ et par là même. la création d'une nouvelle chaussée. constituće de galets

19 Les empreintes laissćes dans le mortier par les planches du coffrage sont encore nettement visibles par endroits.

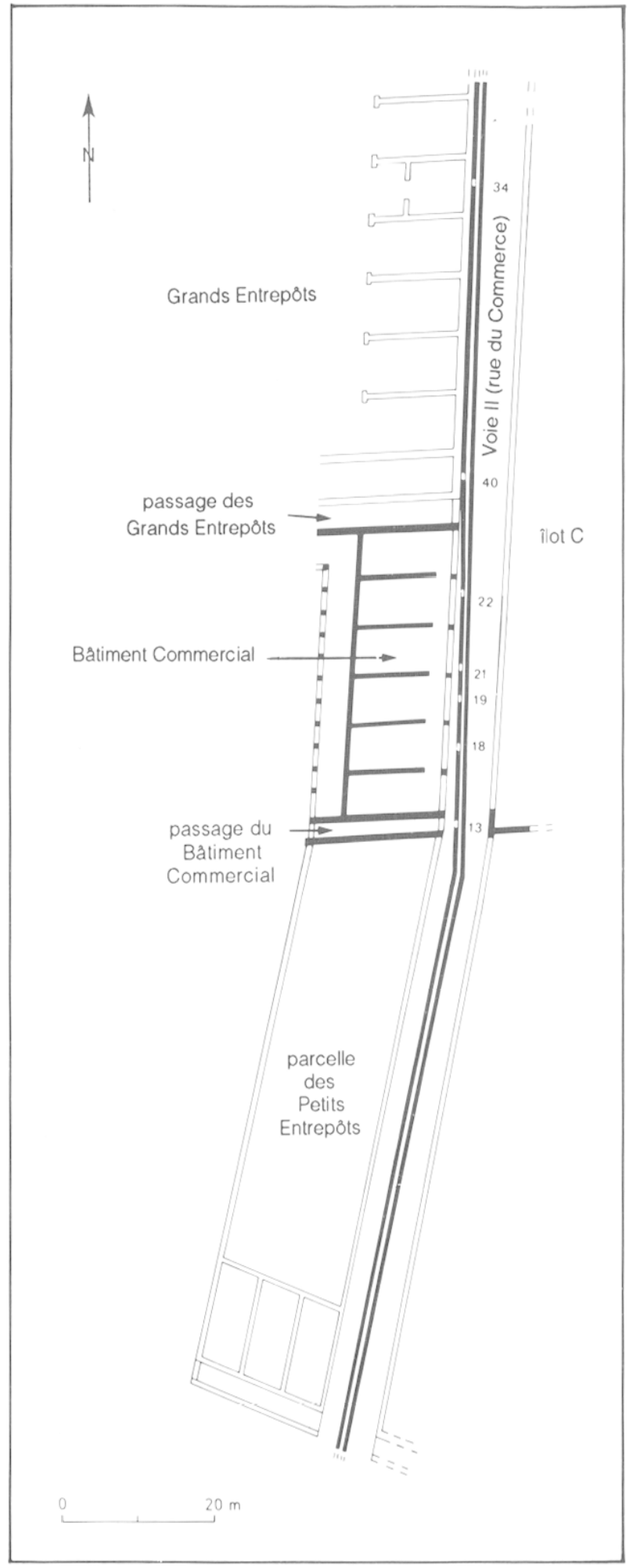

Fïg. 21 - - Voie II : emplacements des différents débouchés prévus lors de la construction du collecteur public.

damés (fig. 7.8 et 20, couche 60). Après cet aménagement majeur, la voie retrouve un rythme de recharges plus régulier, jusqu'au niveau de rue 46.

L'égout présente la particularité d'être équipé, dès sa 
Tabl. I - Les premiers débouchés du collecteur de la Voie II et leur évolution.

\begin{tabular}{|c|c|c|c|c|c|c|c|}
\hline Numéro du débouché & 34 & 40 & 22 & 21 & 19 & 18 & 13 \\
\hline $\begin{array}{l}\text { Position du débouché par } \\
\text { par rapport au } \\
\text { bâtiment de l'époque } \\
\text { lui faisant face }\end{array}$ & \begin{tabular}{|l|} 
Entrte des \\
Grands Entrepôts
\end{tabular} & $\begin{array}{l}\text { Boutiques sud des } \\
\text { Grands Entrepots }\end{array}$ & $\begin{array}{l}\text { Bâtiment } \\
\text { Commercial : } \\
\text { cellule } 6\end{array}$ & $\begin{array}{l}\text { Bâtiment } \\
\text { Commercial : } \\
\text { cellule } 5\end{array}$ & $\begin{array}{l}\text { Bâtiment } \\
\text { Commercial : } \\
\text { cellule } 4\end{array}$ & $\begin{array}{l}\text { Bâtiment } \\
\text { Commercial : } \\
\text { cellule } 3\end{array}$ & $\begin{array}{l}\text { Passage du } \\
\text { Bâtiment } \\
\text { Commercial }\end{array}$ \\
\hline Distance en mètre $\left(^{*}\right)$ & 0 & $35,95 \mathrm{~m}$ & $14,30 \mathrm{~m}$ & $9,10 \mathrm{~m}$ & $4,15 \mathrm{~m}$ & $5,82 \mathrm{~m}$ & $9,93 \mathrm{~m}$ \\
\hline Distance en pieds $(*)$ & - & 121 & 48 & 31 & 14 & 20 & 34 \\
\hline $\begin{array}{l}\text { Position de la base } \\
\text { du débouché par rapport } \\
\text { au fond de l'égout }\end{array}$ & $0,46 \mathrm{~m}$ & $0,41 \mathrm{~m}$ & $0,36 \mathrm{~m}$ & $0,33 \mathrm{~m}$ & $0,74 \mathrm{~m}$ & $0,67 \mathrm{~m}$ & $0,84 \mathrm{~m}$ \\
\hline $\begin{array}{l}\text { Dimensions de l'orifice } \\
\text { (hauteur } \mathbf{x} \text { largeur) }\end{array}$ & $0,44 \mathrm{~m} \times 0,24 \mathrm{~m}$ & $0,26 \mathrm{~m} \times 0,33 \mathrm{~m}$ & $0,26 \mathrm{~m} \times 0,315 \mathrm{~m}$ & $0,30 \mathrm{~m} \times 0,31 \mathrm{~m}$ & \begin{tabular}{|c|}
$0,98 \mathrm{~m} \times 0,33 \mathrm{~m}$ \\
totalement restauré
\end{tabular} & $0,275 \mathrm{~m} \times 0,33 \mathrm{~m}$ & $0,315 \mathrm{~m} \times 0,235 \mathrm{~m}$ \\
\hline $\begin{array}{l}\text { Type d'assemblage } \\
\text { du gainage de brique }\end{array}$ & $\begin{array}{c}\text { B } \\
\text { (fig. 49) } \\
\end{array}$ & $\begin{array}{c}\text { A } \\
\text { (fig. 19a) }\end{array}$ & $\bar{A}$ & $\mathrm{~A}$ & $?$ & $\begin{array}{c}\text { A } \\
\text { (fig. } 48 \text { ) } \\
\end{array}$ & $\begin{array}{c}\text { B } \\
\text { (fig. 19b) }\end{array}$ \\
\hline $\begin{array}{l}\text { Position par rapport } \\
\text { au plus proche regard }\end{array}$ & $\begin{array}{c}\text { aे } 6,30 \mathrm{~m} \\
\text { au sud de } \mathrm{R} 9\end{array}$ & $\begin{array}{c}\text { à } 6,70 \mathrm{~m} \\
\text { au sud de } \mathrm{R} 8\end{array}$ & $\begin{array}{c}\text { à } 2,20 \mathrm{~m} \\
\text { au nord de } \mathrm{R} 7\end{array}$ & $\begin{array}{c}\text { aे } 4,00 \mathrm{~m} \\
\text { au nord de } \mathrm{R} 6\end{array}$ & sous R6 & $\begin{array}{c}\text { à } 5,90 \mathrm{~m} \\
\text { au nord de R5 }\end{array}$ & $\begin{array}{c}\text { à } 4,10 \mathrm{~m} \\
\text { au sud de } \mathrm{R} 5\end{array}$ \\
\hline Particularités & $\begin{array}{l}\text { condamné par le } \\
\text { mur de façade des } \\
\text { Grands Entrepôts }\end{array}$ & \begin{tabular}{|l|} 
condamné par le \\
mur de façade des \\
Boutiques Sud des \\
Grands Entrepôts
\end{tabular} & $\begin{array}{l}\text { n'a jamais été } \\
\text { raccordé }\end{array}$ & $\begin{array}{l}\text { n'a jamais été } \\
\text { raccordé }\end{array}$ & \begin{tabular}{|l|} 
évacuation de la \\
maison au Grand \\
Peristyle (M48)
\end{tabular} & $\begin{array}{l}\text { bouché à sa } \\
\text { sortie de l'égout } \\
\text { par un gros bloc }\end{array}$ & semble avoir servi \\
\hline Débouché remplacé par le $\mathrm{n}^{\circ}$ & 35 & - & 23 & 20 & - & 17 & 14 \\
\hline $\begin{array}{l}\text { Décalage par rapport à } \\
\text { I'ancien débouché }\end{array}$ & 0 & - & $1,03 \mathrm{~m}$ plus au nord & $1,00 \mathrm{~m}$ plus au sud & - & $1,63 \mathrm{~m}$ plus au sud & $0,80 \mathrm{~m}$ plus au nord \\
\hline Fonction & \begin{tabular}{|l|} 
bassin des Grands \\
Entrepôts
\end{tabular} & - & \begin{tabular}{|l|} 
débouché de l'égout \\
M61
\end{tabular} & \begin{tabular}{|l|} 
débouché de l'égout \\
M58
\end{tabular} & - & \begin{tabular}{|l|} 
débouché de l'égout \\
M68
\end{tabular} & \begin{tabular}{|l} 
débouché de \\
l'ambitus (IX 30)
\end{tabular} \\
\hline Distance en mètres $\left({ }^{*}\right)$ & 0 & - & $49,22 \mathrm{~m}$ & $12,13 \mathrm{~m}$ & $2,15 \mathrm{~m}$ & $7,45 \mathrm{~m}$ & $7,50 \mathrm{~m}$ \\
\hline Distance en pieds $\left({ }^{*}\right)$ & - & - & 166 & 41 & 7 & 25 & 25 \\
\hline $\begin{array}{l}\text { Position de la base du } \\
\text { nouveau débouché par } \\
\text { rapport au fond de l'égout }\end{array}$ & $1,22 \mathrm{~m}$ & - & $1,14 \mathrm{~m}$ & $1,16 \mathrm{~m}$ & - & $1,19 \mathrm{~m}$ & $1,31 \mathrm{~m}$ \\
\hline $\begin{array}{l}\text { Position par rapport } \\
\text { au plus proche regard }\end{array}$ & $\begin{array}{c}\text { à } 6,30 \mathrm{~m} \\
\text { au sud de R9 }\end{array}$ & - & $\begin{array}{c}\text { a } 3,50 \mathrm{~m} \\
\text { au nord de R7 }\end{array}$ & $\begin{array}{c}\text { à } 2,00 \mathrm{~m} \\
\text { au nord de R6 }\end{array}$ & - & $\begin{array}{c}\text { a } 4,30 \mathrm{~m} \\
\text { au nord de R5 }\end{array}$ & $\begin{array}{c}\text { a } 3,25 \mathrm{~m} \\
\text { au sud de R5 }\end{array}$ \\
\hline $\begin{array}{l}\text { Dimensions de l'orifice } \\
\text { (hauteur } \mathbf{x} \text { largeur) }\end{array}$ & $0,29 \mathrm{~m} \times 0,29 \mathrm{~m}$ & - & $? \times 0,35 \mathrm{~m}$ & $0,49 \mathrm{~m} \times 0,31 \mathrm{~m}$ & - & $0,40 \mathrm{~m} \times 0,26 \mathrm{~m}$ & $0,61 \mathrm{~m} \times 0,36 \mathrm{~m}$ \\
\hline Altitude du fond de l'égout & $149,44 \mathrm{~m}$ & $149,16 \mathrm{~m}$ & $149,09 \mathrm{~m}$ & $149,09 \mathrm{~m}$ & $149,07 \mathrm{~m}$ & $149,02 \mathrm{~m}$ & $149,02 \mathrm{~m}$ \\
\hline $\begin{array}{l}\text { Hauteur du piédroit } \\
\text { de l'égout }\end{array}$ & $1,18 \mathrm{~m}$ & $1,15 \mathrm{~m}$ & $1,21 \mathrm{~m}$ & $1,16 \mathrm{~m}$ & $1,16 \mathrm{~m}$ & $1,19 \mathrm{~m}$ & $1,17 \mathrm{~m}$ \\
\hline Hauteur de l'égout sous vôte & $1,51 \mathrm{~m}$ & $1,46 \mathrm{~m}$ & $1,51 \mathrm{~m}$ & $1,49 \mathrm{~m}$ & $1,50 \mathrm{~m}$ & $1,49 \mathrm{~m}$ & $1,46 \mathrm{~m}$ \\
\hline
\end{tabular}

(*) De centre à centre, par rapport au débouché précédent de même époque.

construction. de débouchés de canalisations installés uniquement à travers son piédroit ouest (fïg. 21)20. Sept évacuations de ce type ont pu ainsi être observées sur le tronçon reconnu du collecteur (tabl. I). D'autres. situces plus au nord. ne sont pas à exclure :

- la plus septentrionale $\left(n^{\circ} 34\right)^{21}$ vient se placer en face de l'entrée des Grands Entrepôts (fïg. 49):

- la suivante $\left(n^{\circ} 40\right)$ se trouve au centre des Boutiques adossées au mur de limite sud des Grands Entrepôts (fig. 19a) :

20) Cétle constatation a été effectuće après que nous ayons sýstématiquement positionné et décrit l'ensemble des débouchés présents dans le collecteur.

21 Les numéros des évacuations correspondent à la numerotation continue adoptée pour identifier. tous états confondus, les débouchés de la Voie Il.
- quatre d'entre elles $\left(n^{\circ} 22.21,19.18\right)$ sont réparties en façade du Bâtiment Commercial (cf. infra. p. 45, État 2A de la parcelle de la maison aux Cing Mosaïques) :

- la plus méridionale enfïn ( $n^{0}$ i3) est logée au niveau du débouché du passage du Bâtiment Commercial sur la Voie Il (fig. 19b).

Un assemblage de quatre briques, limité à l'arrivée des évacuations dans l'égout, tient lieu de gaine à ces orifices rectangulaires, à l'exception du débouché 13, de section carrée. Ce dispositif très particulier est destiné à renforcer l'embouchure (en arrière des briques, les parois des conduits sont simplement maçonnées) et constitue l'indice du soin remarquable apporté à la construction. ainsi qu'à la finition intérieure du collecteur public.

Il est intéressant de noter que les carreaux de terre cuite utilisés pour le gainage des évacuations, munis pour la plupart d'un téton central peu saillant (fig. 19b 
et 48), ont le même module que ceux que l'on retrouve sur le fond de l'égout (dimensions moyennes des briques : $0,45 \mathrm{~m} \times(0,33 \mathrm{~m} \times 0,06 \mathrm{~m})$.

Deux systèmes de montage des briques ont pu être observés (tabl. I) :

- dans le premicr cas de figure (Type A, auquel se rattachent quatre débouchés), la brique supérieure est placée dans le sens de la largeur, la brique du bas venant alors se caler entre les piédroits (fig. 19a) :

- dans le second cas (Type B pour les débouchés n 34 et $\mathrm{n}^{\circ} 13$ ), la brique du haut se trouve placée dans le sens de la longueur et la brique du bas supporte alors les piédroits à ses extrémités (fïg. 19b).

L'utilisation continue du débouché 19 jusquau IIIe s. et sa restauration n'ont pas permis de connaître sa morphologie originelle.

\section{Caractéristiques du collecteur}

L'ćgout longe dans un premier temps la parcelle des Grands Entrepôts puis, avant de passer le regard R8, s'écarte du bord de la façade pour se diriger vers l'intérieur de la rue (fig. 22). A la hauteur du regard R7. une nouvelle inflexion le déporte encore pour l'amener, entre les regards $\mathrm{R} 4$ et $\mathrm{R} .5$, au centre de la chaussée. Un dernier changement de direction le conduit à demeurer dans l'axe de la rue jusqu'à son entrée dans la rue du Portique (Voie I). Aucun de ces infléchissements ne correspond à une reprise du collecteur qui possède donc dès l'origine ce tracé particulier.

Nous pouvons nous interroger sur les raisons qui ont conduit ses constructeurs à le faire passer ainsi du bord au centre de la rue. Il semble yue son implantation ait été conditionnée par la nature des parcelles qu'il longeait. En effet, il se trouve plaqué contre celle des Grands Entrepôts, mais dès qu'il s'apprête à la quitter, il s'éloigne de la façade pour arriver au milieu de la rue à peu près à la hauteur de son changement d'axe, qui coïncide également avec des limites parcellaires. Si nous nous référons aux autres égouts publics connus sur le site, nous remarquons qu'ils sont collés aux façades des édifices publics qu'ils longent (thermes, Portique Monumental Nord) tandis qu'ils passent au centre de la chaussée lorsque celle-ci est bordée de part et d'autre de bâtiments privés 22 . Ces constatations nous suggèrent l'existence d'un règlement selon lequel le collecteur public doit passer au centre de la rue, espace lui aussi public, lorsque les parcelles limitrophes sont privées. Un usage lui permettrait également d'être déplacé sur un côté lorsqu'un bâtiment public s'y trouve installé. Les Grands Entrepôts étant vraisemblablement

22 Scule exception, l'égout de la Voie VI est plaqué contre la maison de Sucellus Mais dans cet exemple, la ruelle est étroite et le collecteur particulièrement gros puisqu'il évacue la plus grande partie des caux recueillies dans l'égoul de la Voie III.

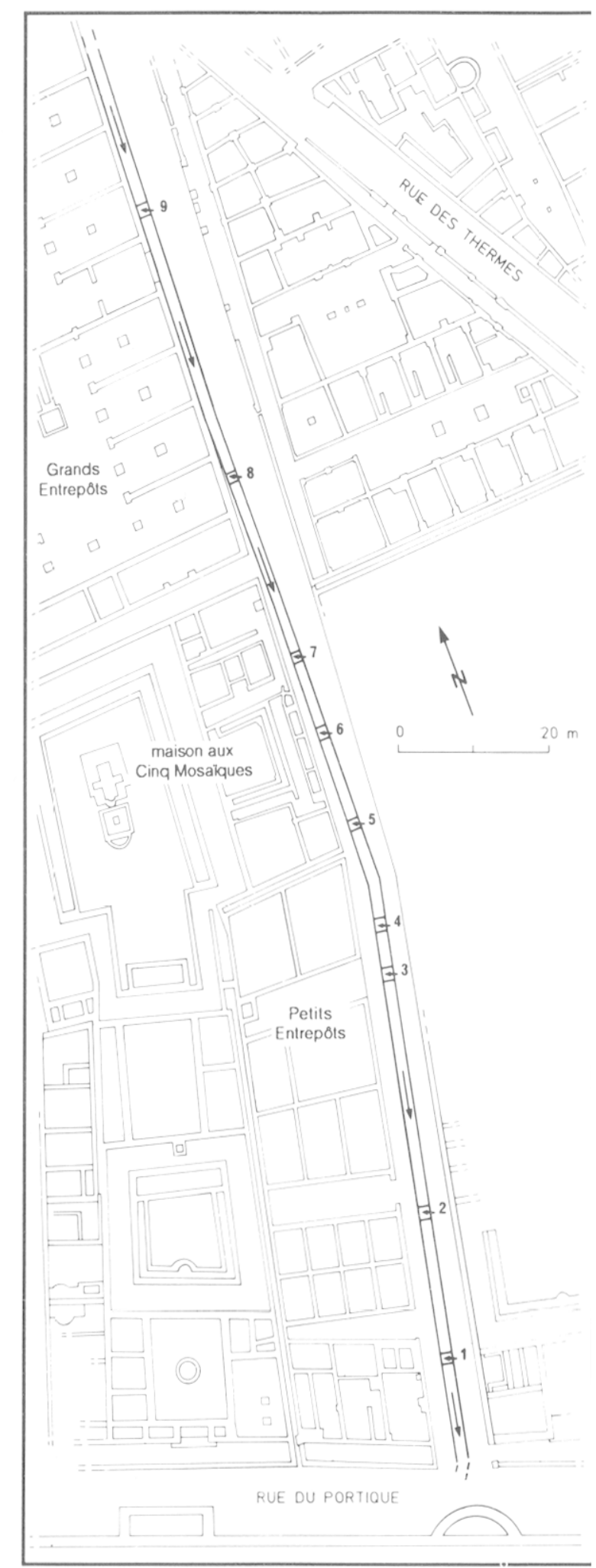

Fig. 22 - Voic II : tracé de l'égout et positionnement des regards. 


\begin{tabular}{|c|c|c|c|c|c|c|c|c|c|c|c|}
\hline$\tilde{x}$ & 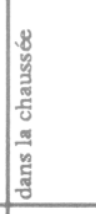 & 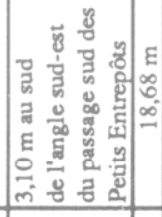 & & & 死 & 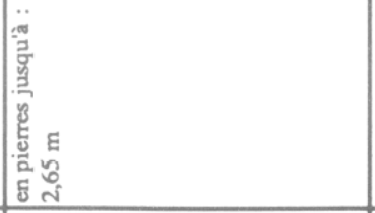 & 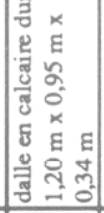 & 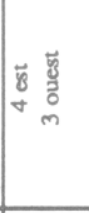 & 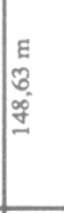 & $\underset{\Xi}{E}$ & 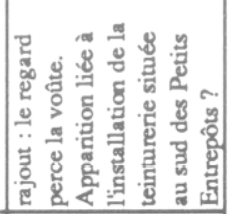 \\
\hline$\tilde{N}$ & 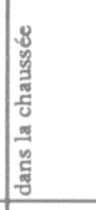 & 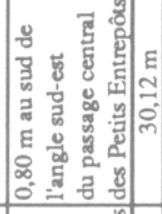 & & 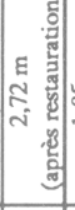 & 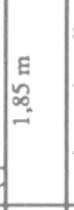 & 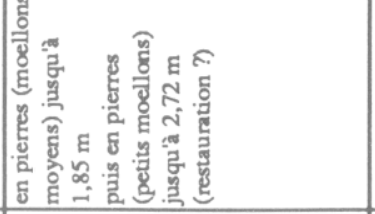 & & $\mid \begin{array}{l}5 \\
0\end{array}$ & 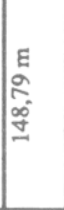 & E్ & 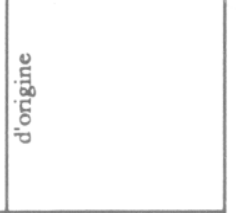 \\
\hline$\ddot{m}$ & 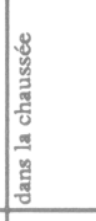 & 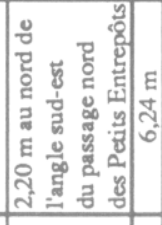 & & & 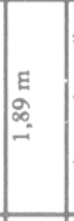 & 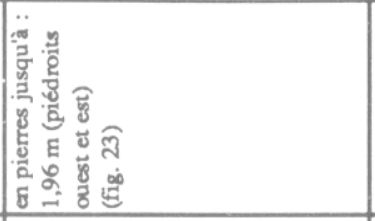 & 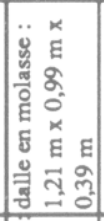 & & 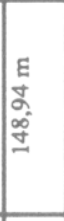 & $\begin{array}{l}E \\
\stackrel{\infty}{\infty} \\
=\end{array}$ & 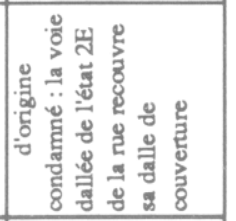 \\
\hline$\ddot{\alpha}$ & 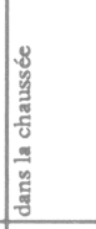 & 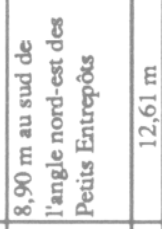 & E & $\begin{array}{l}E \\
5 \\
5 \\
m \\
m\end{array}$ & I & 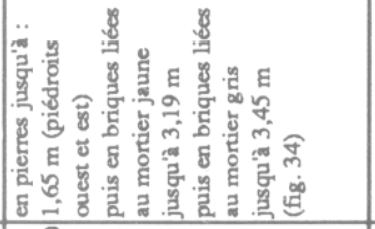 & 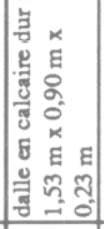 & 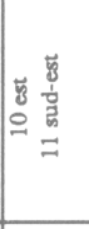 & 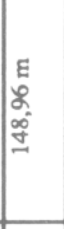 & $\stackrel{E}{\leftrightarrows}$ & 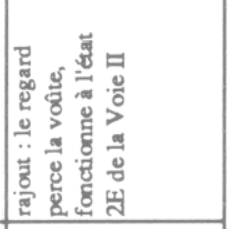 \\
\hline $\begin{array}{l}n \\
\alpha\end{array}$ & 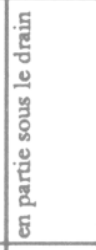 & 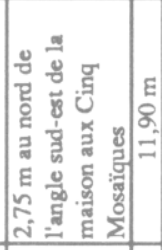 & & 希 & $\mid$\begin{tabular}{l}
$E$ \\
$\infty$ \\
$\infty$ \\
\hdashline \\
\hdashline
\end{tabular} & 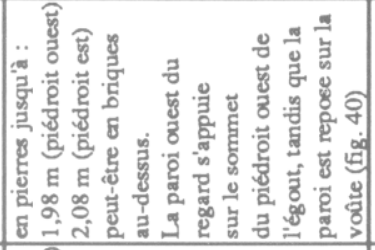 & & 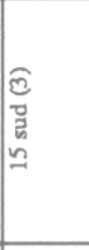 & $\mid \begin{array}{l}E \\
0 \\
0 \\
\sigma \\
\end{array}$ & E⿱ & 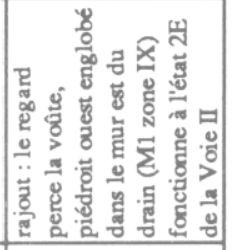 \\
\hline$\ddot{x}$ & 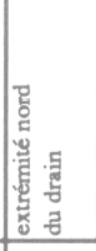 & 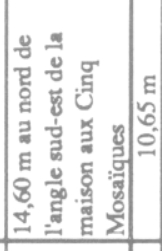 & & & 若 & 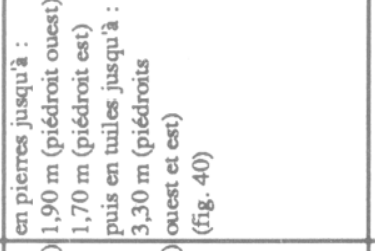 & & 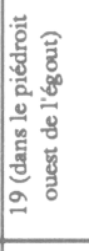 & $\mid \begin{array}{l}E \\
5 \\
0 \\
0 \\
0 \\
0\end{array}$ & \begin{tabular}{l}
$E$ \\
0 \\
\hdashline \\
\hdashline
\end{tabular} & 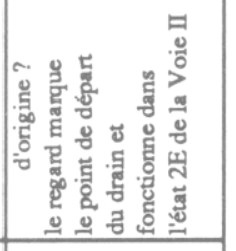 \\
\hline$\hat{\alpha}$ & 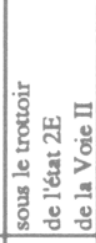 & 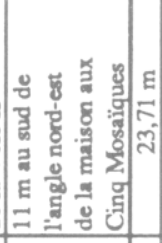 & & & $\mid \begin{array}{l}E \\
\infty \\
\infty \\
-\oplus\end{array}$ & 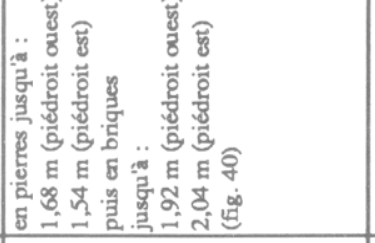 & & . & $\mid \begin{array}{l}E \\
8 \\
\sigma \\
\vdots \\
\vdots\end{array}$ & $\stackrel{E}{\infty}$ & 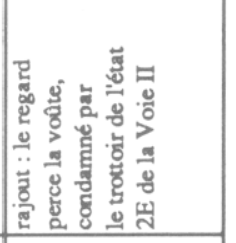 \\
\hline$\infty$ & 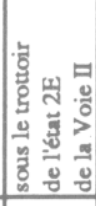 & 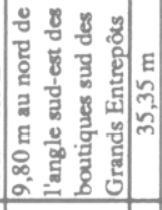 & & 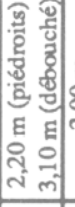 & 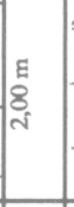 & 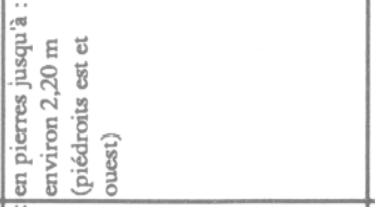 & & 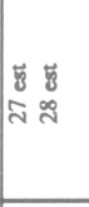 & 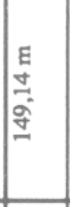 & $\mid \begin{array}{l}E \\
0 \\
0 \\
-2\end{array}$ & 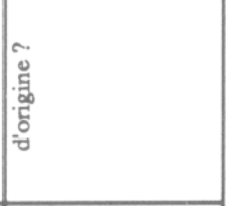 \\
\hline$\vec{x}$ & 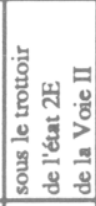 & 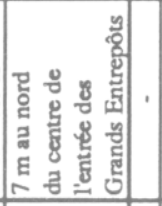 & E & 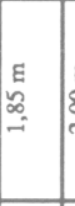 & \begin{tabular}{|l|} 
\\
8 \\
4 \\
4 \\
\end{tabular} & 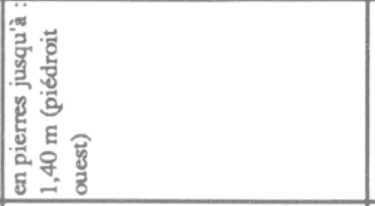 & ' & & $\mid \begin{array}{l}E \\
\frac{5}{n} \\
2 \\
\frac{2}{2}\end{array}$ & 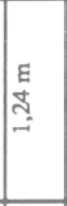 & 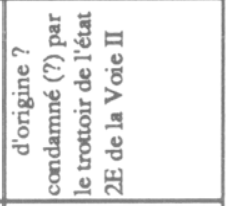 \\
\hline 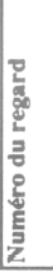 & 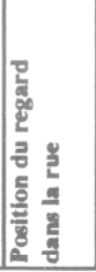 & 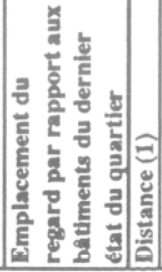 & 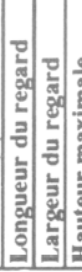 & : & $\begin{array}{ll}0 \\
0 \\
0\end{array}$ & 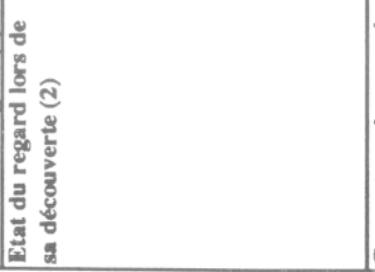 & 望 & 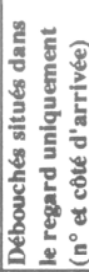 & 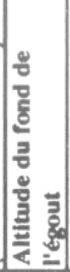 & 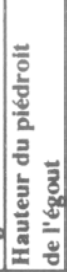 & 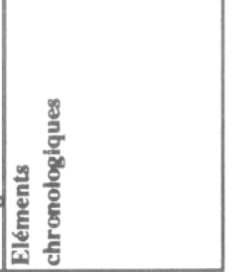 \\
\hline
\end{tabular}


une construction publique 23 , l'égout ne ferait que suivre cette règle qui apporterait, par ailleurs, la confirmation du caractère privé des Petits Entrepôts.

Du nord vers le sud et sur l'ensemble du tronçon reconnu. le collecteur présente une pente descendante moyenne de $0.5 \mathrm{~cm} / \mathrm{m}$, ce qui sur une longueur de $170 \mathrm{~m}$ correspond à une dénivellation de $1,03 \mathrm{~m}$. En réalité, l'inclinaison du fond de l'égout ne se révèle pas constante sur tout le trajet. Ainsi, le long de la parcelle des Grands Entrepôts, sur une longueur d'au moins $40 \mathrm{~m}$. la pente est de $0.9 \mathrm{~cm} / \mathrm{m}$. A la hauteur de R8. elle passe à $0.5 \mathrm{~cm} / \mathrm{m}$ sur $35 \mathrm{~m}$ de long, puis à $0,3 \mathrm{~cm} / \mathrm{m}$ à partir de R6. Nous observons alors l'existence d'un palier de $45 \mathrm{~m}$ qui s'interrompt très nettement à mi-longueur de la parcelle des Petits Entrepôts. La pente devient ensuite plus forte, $1 \mathrm{~cm} / \mathrm{m}$, jusqu'au raccord avec l'égout de la rue du Portique (Voie I), c'est-à-dire sur une longueur de $45 \mathrm{~m}$.

Ces variations, somme toute assez faibles, ne sont pas consécutives à des tassements différentiels du soussol. Il faut également noter qu'elles se produisent à peu près aux mêmes endroits que les changements d'axe du collecteur. Ainsi, elles semblent correspondre aux phases d'avancement des travaux. Dans ces conditions. l'irrégularité de la pente traduit plutôt la difficulté que représente la mise en place d'un égout. sur une longue distance, dans une plaine basse dont le seul exutoire est constitué par un fleuve peu encaissé24. Compte-tenu de la faible dénivellation qui existe entre le niveau de circulation et celui du Rhône, le collecteur doit nécessairement avoir une inclinaison modérée sur l'ensemble de son parcours.

Une alternance de pentes faibles et plus fortes. permettant de moduler le débit de l'eau afin de faciliter l'élimination des déchets, se rencontre sur d'autres sites (Wiblé, Tissières, 1978, p. 186-187). Mais ici, une telle régulation paraît délicate à réaliser du fait du manque de relief. En ce qui concerne le collecteur de la rue du Commerce. les inclinaisons rencontrées nous paraissent trop proches les unes des autres pour que l'effet recherché soit réellement efficace.

Si l'égout et ses débouchés initiaux ont fait l'objet. sur tout le tronçon connu, d'une grande homogénéité de construction, il n'en va pas de même pour les regards qui possèdent des dimensions variables et sont

23 Ce hâtiment est construit à la mêmé époque et sur le même plan que les gigantesques docks implantés sur la rive gauche, au sud de Vienne (Le Bot, 1989, p. 348-35.3).

24 Ainsi. le collecteur de la Voie Il, après son carrefour avec la Voie I, doit parcourir près de $230 \mathrm{~m}$ pour se déverser dans le Rhône. En gardant une pente de $0.5 \mathrm{~cm} / \mathrm{m}$, il lui faut encore perdre $1.40 \mathrm{~m}$ d'altitude, ce qui place l'altitude de son débouché dans le fleuve vers $147,30 \mathrm{~m}$. Cette valeur nous donne une indication sur l'altitude moyenne du fleuve. Par rapport au niveau de la chausséc 66 , le fleuve coule donc à peu près $3.30 \mathrm{~m}$ plus bas. implantés de manière irrégulière 25 (tabl. II). Chacun d'entre eux semble avoir eu une évolution propre. Leur diversité alliée à leurs restaurations plus ou moins radicales, rendent délicate l'identification de ceux qui existaient à l'origine. Toutefois, la présence du regard R3, yui a été condammé au cours de l'histoire de la rue, de même que les relevés de certains autres, réalisés au moment de leur dégagement, permettent de proposer un ordre d'apparition que nous découvrirons au fur et à mesure des phases.

Ainsi. il ressort que les premiers regards sont constitués d'une cheminée rectangulaire en pierre qui prend naissance au sommet des piédroits et émerge à peine du sommet de la voûte dans laquelle elle s'intègre parfaitement (fig. 23). Aucune standardisation des dimensions ne semble avoir été appliquée (tabl. II).

Leurs dalles de couverture, dont la nature nous est inconnue, ne devaient pas excéder $20 \mathrm{~cm}$ d'épaisseur. sous peine de dépasser fortement de la surface de la chaussée 60.

Cinq regards sont susceptibles de répondre à ces critères: R9, R8, R6, R3 et R2. Ils sont séparés les uns des autres par les distances suivantes :

- R9 - R8 : $35,35 \mathrm{~m}$, soit 119 pieds :

- R8 - R6 : $34,36 \mathrm{~m}$, soit 116 pieds ;

- R6 - R3 : $24.51 \mathrm{~m}$, soit 83 pieds :

- R8 - R3 : $58,87 \mathrm{~m}$, soit 199 pieds :

- R3 - R2 : 30,12 m, soit 102 pieds

Comme on peut le constater, il ne s'opère pas de répartition régulière. Néanmoins les mesures approchent de valeurs rondes, traduisant ainsi l'existence d'une certaine règle d'implantation qui demanderait à être préciséc. Seul le regard R6 déroge à cette tendance mais. dans son cas, sa position est liée sans conteste à la présence d'un débouché particulier. Il s'agit en l'occurrence de l'évacuation qui dessert les bassins successifs de la maison des Dieux Océans, puis celui de la maison aux Cinq Mosaïques. Destiné à répondre à un besoin bien spécifique, comme cela sera aussi le cas pour $R 1^{26}$, ce regard ne šintègre pas dans une répartition des orifices d'accès qui a pu être décidée à priori. Son implantation lui vaudra une évolution particulière. Il sera en effet le seul regard à se trouver rehaussé avec des tuiles. lors de sa dernière phase d'utilisation (état 2E).

25 Contrairement à ce qu'écrit A. Pelletier qui note, dans la Voie II. la présence de six regards en briques régulièrement espacés de $12 \mathrm{~m}$ (Pelletier. 1982. p. 166). Outre le fail que celte affirmation ne prend pas en compte l'ensemble des regards, il inclut dans les six un effondrement silué à l'extrémité de la Voie IV qui. en réalité, n'est pas assimilable à un regard du collecteur.

26 Ce regard étroit (tabl. II) est percé affin de recevoir l'évacuation des bassins de l'atelier de teinturerie installé tardivement dans le bâtiment sud des Petits Entrepôts. 


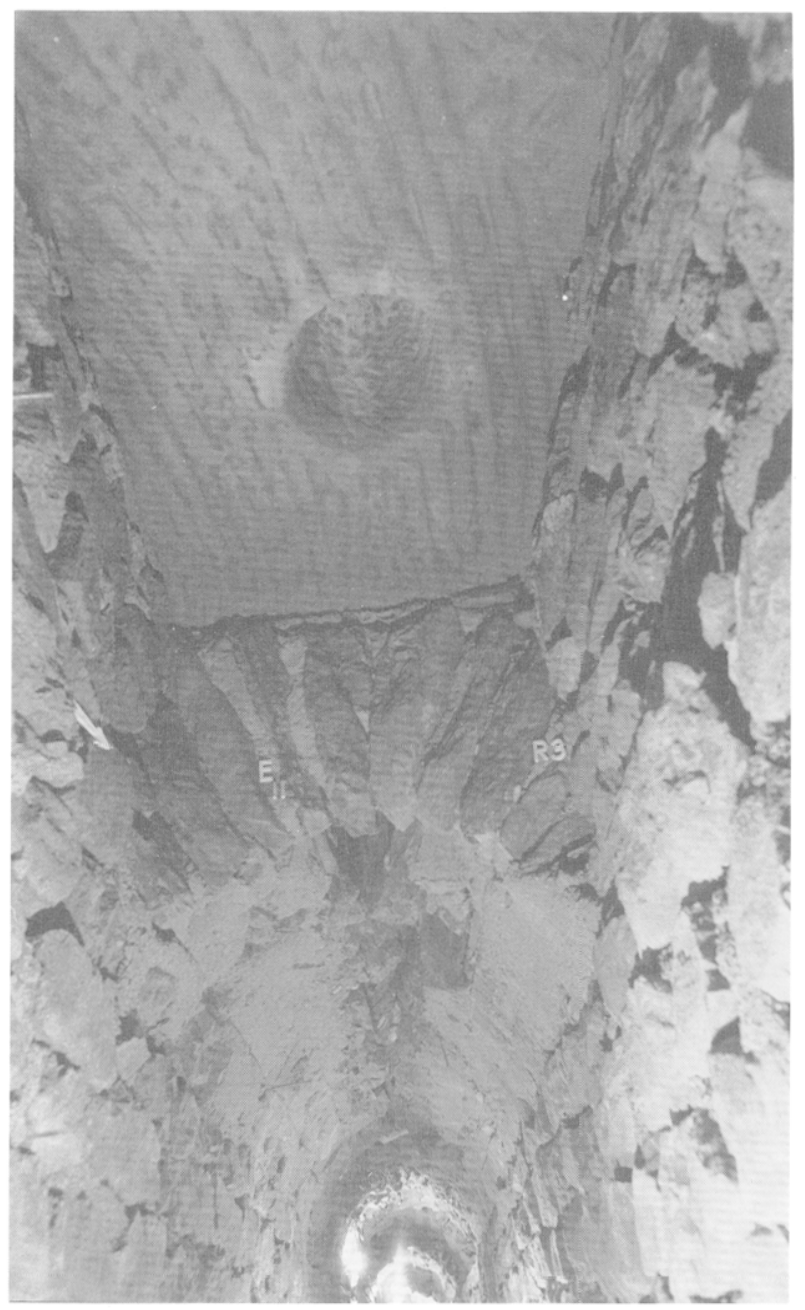

\section{Apparition d'un premier réseau d'adduction d'eau}

La construction d'un collecteur d'une telle capacité ne peut s'expliquer sans la réalisation. en parallèle. d'un réseau élaboré d'adduction d'eau.

Dans la zone V. sous le sol du portique du Bâtiment Commercial (état 2A), une canalisation en plomb est installée, après qu'ait été menée à bien la construction de l'égout M48 qui draine la maison au Grand Péristyle (fig. 24) ${ }^{27}$. Lors du franchissement de la façade, ce tuyau repose simplement dans une légère dépression pratiquée sur le faîte de M90 (fig. 45) à la cote $150,64 \mathrm{~m}$. le sol du portique étant situé à une altitude de $150.80 \mathrm{~m}$

Une fois parvenu dans la rue, se posait la question de son devenir. Compte-tenu de son parcours à travers le portique. sa poursuite vers le sud paraissait évidente. Etant mis en service après la création du grand collecteur $^{28}$. nous étions en droit d'espérer retrouver sa

27 Il s'agit désormais du nom de la demeure définie dans l'état 2B de la maison des Dieux Océans. En ce qui concerne la conduite et l'égout. cf. infia, p. 4.5.

28 La canalisation est posée sur la couverture de l'égout

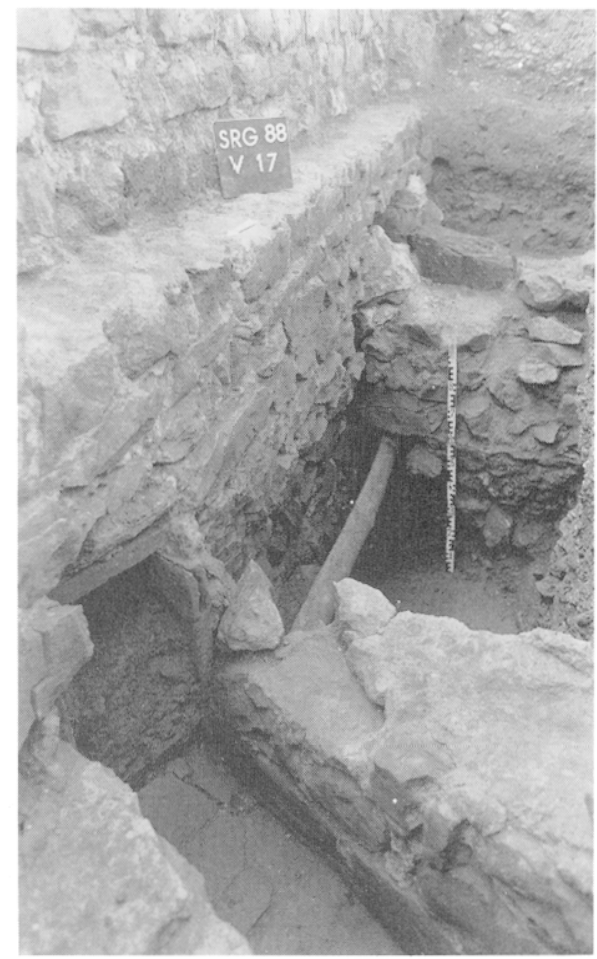

A galuche, Fig. 23 - Egout de la Voic II : regard R.3 avec sa dalle de couverture en molasse.

Ci-dessus, Fig. 24 - Zone V: tuyau en plomb (étal 2A). recouvert, au premier plan. par l'égout M58 (état 2B) et coupé, en arrière, par l'égout M27 (état 3) qui repose sur l'égout M48 (ćtat 2A).

trace dans la chaussée Voie II 2 60) qui se situe vers $151.20 \mathrm{~m}$. Or. qu'observe-t'on? A l'est de l'égout, aucun indice pouvant suggérer le passage d'une canalisation n'apparaît. les deux tuyaux de bois visibles (T1 et T2) appartenant aux états suivants. Du côté ouest de la rue, en IX 9 (fig. 7), l'établissement d'une semelle de béton moderne, destinée à soutenir le mur M40 du drain, a détruit toute relation stratigraphique sur une largeur de $0.85 \mathrm{~m}$.

Enfin, sur la paroi sud du sondage Voie II 2, nous observons l'existence d'une fosse, comblée au ras de la chaussée 60 par la couche 59, qui pourrait correspondre au passage de la conduite. Néanmoins, du fait de la position méridionale de cette coupe, il est possible que nous soyons ici en présence d'une tranchée de fondation liée à l'établissement des Petits Entrepôts ${ }^{29}$, qui sont

domestique M48 qui est alors la seule évacuation à se déverser dans le collecteur de la rue.

29 Si tel est le cas, l'extrémité orientale de cette tranchée se situe à plus de $2 \mathrm{~m}$ de leur façade. Celte largeur au sommet. qui peut paraître excessive. est. quoi qu'il en soit, conforme à ce que l'on observe pour d'autres murs porteurs issus de cet ensemble architectural (cf. la tranchée de fondation de M330). fig. 41). 
construits quelques temps après la période qui nous intéresse pour l'instant.

Les données relatives à cette adduction d'eau sont, on l'aura remarqué, plutôt insatisfaisantes. Aussi, afin de mieux cerner le problème, convient-il de prendre en considération ce qui se passe plus au sud, dans la Voie I.

A cette époque, deux canalisations, l'une en bois, l'autre en plomb (fig. 25), sont en place sous le sol du portique de façade de la maison aux Pierres Dorées (Desbat 't alii. 1994 : chap. I, Portique de façade). Elles sont installées à la même profondeur $(151,06 \mathrm{~m}$ et $151.12 \mathrm{~m}$ : cotes restituées du fait du tassement important des couches). sous le niveau de circulation considéré commc identique dans la rue et dans le portique (altitude moyenne: 151,28 m).

Présentes sur toute la façade de cette habitation. elles se poursuivent d'une part sous le portique de l'édifice qui

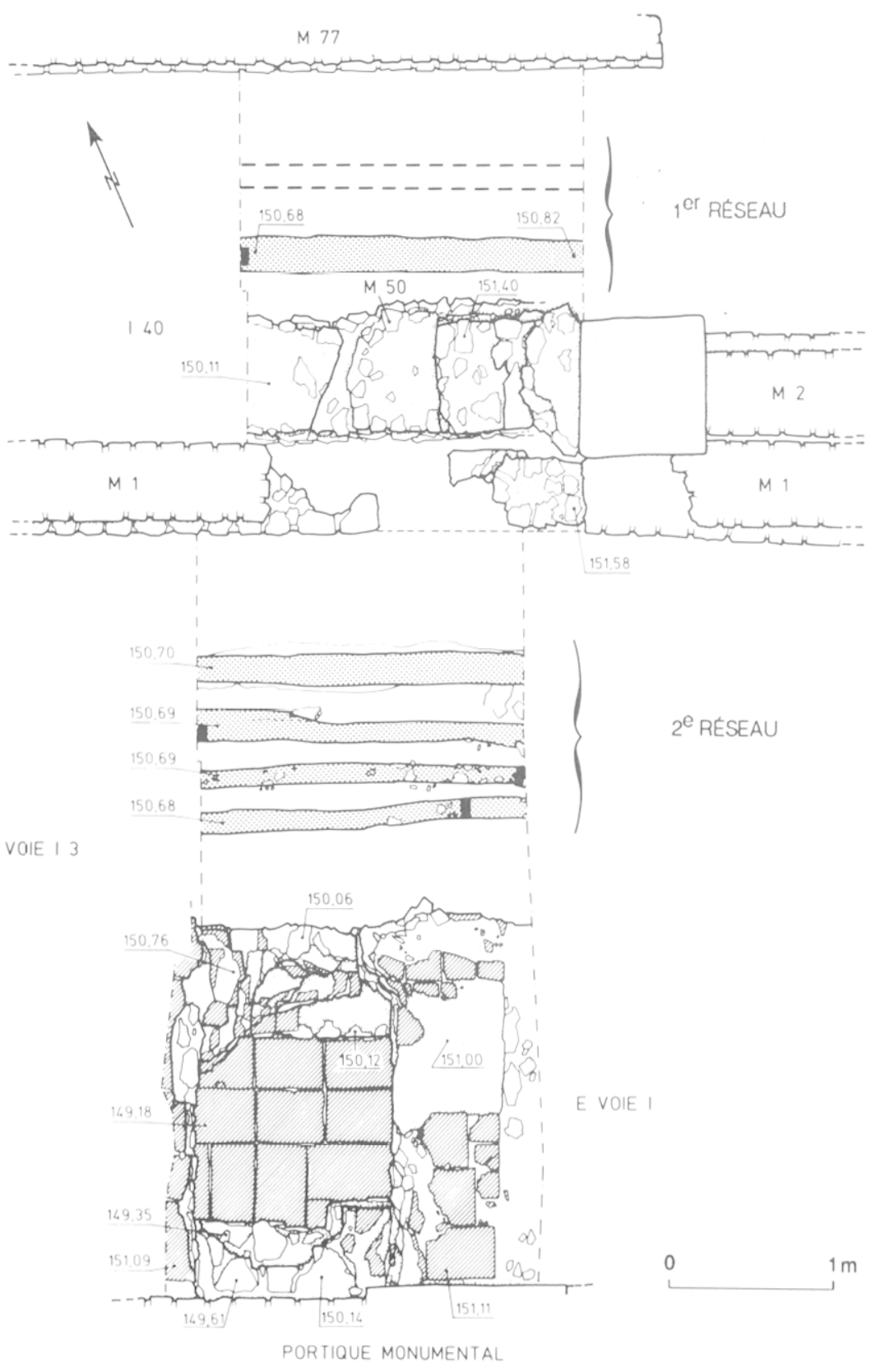

négatifs des tuyaux en bois $=ニ ニ$ passage pressume du tuyau en plomb

frolles briques

Fïg. 25 - Voic I (rue du Portique) :

les réseaux de canalisations à la hauteur de l'entrée de la maison des Dieux Océans (sondages I 40 el Voie I 3). 
flanque. à l'ouest, la maison de l'état $2 \mathrm{~A}$, et d'autre part sous celui qui borde le bâtiment sud de la parcelle des Petits Entrepôts ${ }^{30}$.

Dans ces portiques, le tuyau en bois, dont plusieurs frettes ont été retrouvées en place, est installé du côté des piliers tandis que la conduite en plomb, totalement récupérée à l'époque antique ${ }^{31}$, longe le mur intérieur. C'est sur celle-ci que s'effectue, en face de l'entrée, le raccordement du tuyau, lui aussi en plomb, destiné à alimenter la maison aux Pierres Dorées (Cochet. Hansen, 1986, p. 47-49 et 77).

Nous constatons plusieurs points de convergence intéressants. Les altitudes des deux rues, Voie I et Voie II, sont tout d'abord très similaires. Il apparaît aussi. pour cet état du moins, que l'implantation des canalisations s'effectue préférentiellement dans les portiques. Enfin, la conduite qui parât alimenter les différents édifices cités plus haut se trouve à proximité du mur de façade.

Tous ces indices nous amènent à proposer l'existence d'un réseau d'adduction commun au sein duquel le tuyau en plomb de la Voie I aurait deux tracés possibles lorsqu'il débouche dans la Voie II (fïg. 26) ${ }^{32}$. Soit il tourne en direction du nord, soit il se poursuit vers l'est, en présentant alors un raccordement avec la canalisation qui vient du nord. Dans les deux cas, il a toutes les chances d'avoir été placé près de la façade et devrait se situer, à la hauteur du sondage IX 9, dans le secteur perturbé par le socle de béton.

La conduite qui nous préoccupe ici était-elle en plomb sur tout son parcours? Si nous prenons en considération l'utilisation massive des canalisations en bois dans les rues aux époques suivantes, nous pouvons en effet nous poser la question pour le tronçon qui se trouve sous la chaussée de la Voie II. Cependant l'utilisation d'un tuyau en plomb dans les différents portiques du sud de l'îlot $A$, sur une grande section rectiligne, laisse augurer une canalisation de même nature dans la rue nord-sud.

En ce qui concerne la conduite en bois, sa position plus éloignée de la façade semble plutôt la destiner à l'alimentation d'un autre secteur du quartier. Présente-t-

30 Dans la zone IX. ce bâtiment est beaucoup plus ancien que les trois autres qui, comme nous venons de le dire. ne sont pas encore construits à cette époque (fig. 2). Il n'a d'ailleurs qu'un seul point commun avec eux : celui d'être installé sur la même parcelle.

31 Nous ne disposons pas de preuve absolue permettant d'affirmer que cette conduite était bien en plomb. Cependant. seule la présence d’un tuyau de ce métal parât pouvoir justifier l'existence d'une tranchée d'une telle ampleur. que nous retrouvons dans chacun des sondages.

32 Si le tuyau en plomb devait s'interrompre avant la Voie II. la canalisation en bois pourrait alors se substituer à lui dans le réseau tel que nous le présentons. elle aussi un embranchement à la hauteur de la Voie II? Il est impossible de l'affirmer avec certitude. Si l'espace nécessaire au passage de deux conduites le long de la façade existe matériellement. toujours à l'emplacement du socle en béton du sondage IX 9, nous devons toutefois considérer que rien n'obligeait les tuyaux à emprunter des parcours similaires, leurs destinations finales, selon toute logique, étant plutôt distinctes. C'est pourquoi nous pensons que la canalisation en bois de la Voie I devait se diriger directement vers l'îlot est.

Le réseau que nous restituons est bien évidemment sommaire et demanderait à être précisé. notamment au

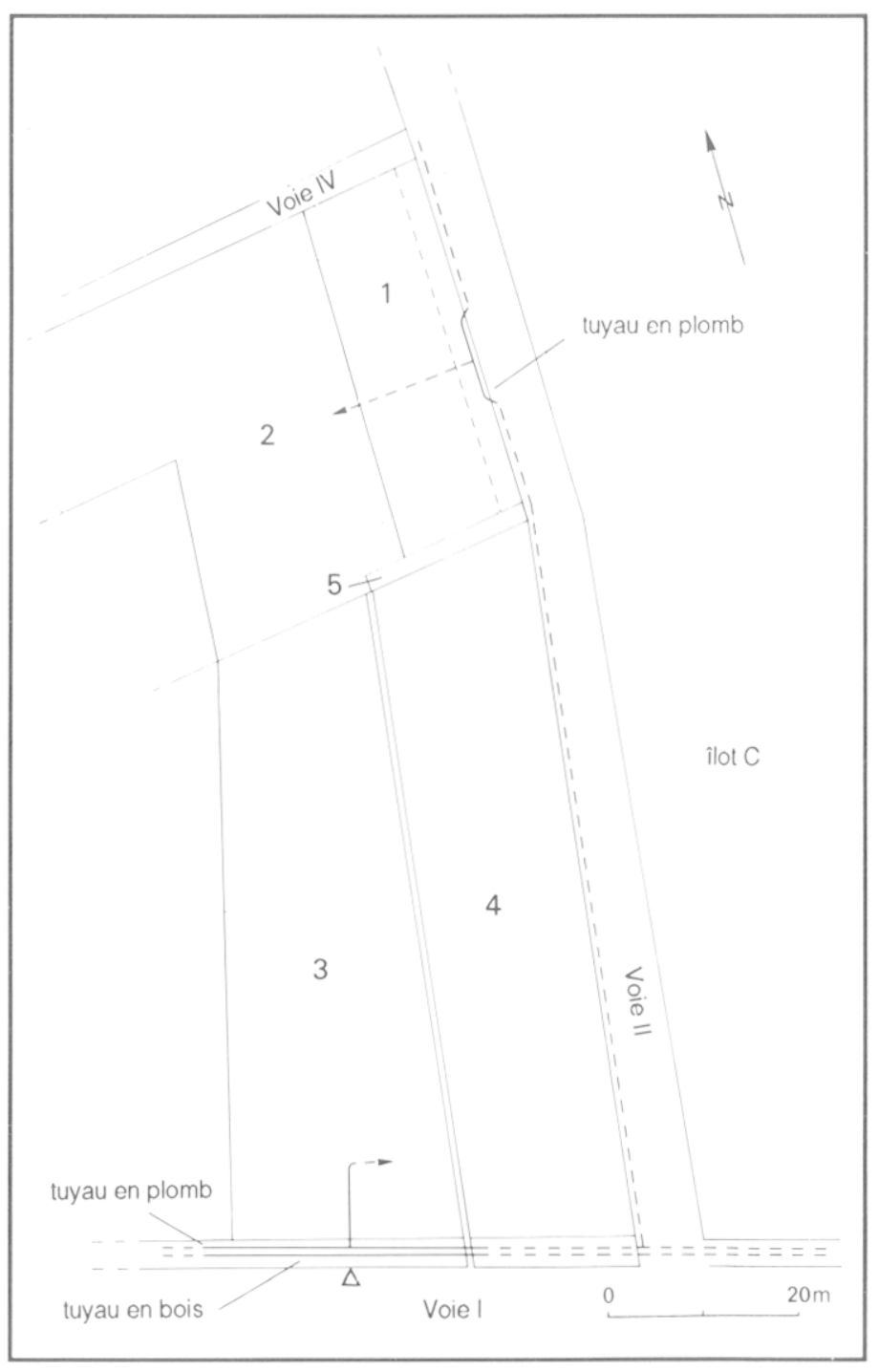

Fig. 26 - Plan du premier réseau d'adduction (état $2 \mathrm{~A}$ de la Voie II) : 1, zone V, état 2A : Bâtiment Commercial : 2. zone 1: maison au Grand Péristyle: 3, zone I : maison aux Pierres Dorées : 4, zone IX : parcelle des Petits Entrepôts: 5, passage du Bâtiment Commercial : $\Delta$ : emplacement du sondage I 40 (cf. fig. 25). 
niveau de l'îlot $C^{3.3}$. Il présente cependant l'avantage de mettre en connexion des découvertes ponctuelles de canalisations dont la raison d'être ne peut être perçue qu'à l'échelle du quartier.

\section{Evolution de la rue}

A la suite du tassement des remblais de comblement de la tranchée de fondation du grand collecteur, la couche 60) a fait l'objet d'un affaissement conséquent. Celui-ci semble intervenir assez rapidement dans la mesure où une première recharge, composée d'un remblai hétérogène issu de la démolition d'une construction, est étendue sur la chaussée alors que celle-ci apparaît peu détériorée.

L'installation de la couche 50 correspond à la remise à niveau de la voie 60 à $151.18 \mathrm{~m}$ et marque la fin de cette perturbation. Dès lors. le nouveau niveau de rue. homogène et compact, est stabilisé. Il se constitue d'un empierrement dans lequel se mêlent des fragments de tuiles et de briques. Si l'on en juge par les recharges éparses qui comblent ses fondrières (couches 48,49 et 51) et par la diversité du petit mobilier retrouvé en son sein (monnaie en argent d'Auguste, fragments de bronze, os, clous...). il présente une durée de vie correspondant à celle de l'état $2 \mathrm{~A}$ de la parcelle de la maison aux Cinq Mosaïques.

Une autre chaussée est par la suite établie (couche 46). Il s'agit en l'occurrence d'un épais galetage. fortement damé et parfaitement nivelé, qui rehausse le niveau de circulation d'une quinzaine de centimètres. Il constitue, de ce fait. la première étape d'un exhaussement régulier qui va peu à peu amener la chaussée à la cote $151.80 \mathrm{~m}$. Nous dissocions toutefois cette voie des niveaux suivants dans la mesure où elle est la dernière à pouvoir fonctionner avec l'état $2 \mathrm{~A}$ de la zone $\mathrm{V}$ et, également, la dernière à être mise en place avant la pose de nouvelles canalisations.

\section{ETAT 2C (60-70 après J.-C.)}

Cette nouvelle étape de la vie de la Voie II est caractérisée par deux événements : d'une part la mise en place d'une batterie de deux tuyaux en bois, d'autre part la surélévation continue de la rue.

\section{Installation d'un second réseau d'adduction d'eau}

Deux conduites en bois. parallèles, sont posées du côté est de la rue (infira, p. 51, fig. 50)). La première. $T 1$, se trouve à environ $46 \mathrm{~cm}$ des murs de façade $\mathrm{M} 7$ et M8 tandis que la seconde. T2, est située $60 \mathrm{~cm}$ plus

33 Un sondage implanté dans l'extrémité ouest du portique de la maison à la Colombe (situće à l'angle sud-ouest de l'îlot C) permettrait certainement de connaître le sort réservé à ces deux conduites.

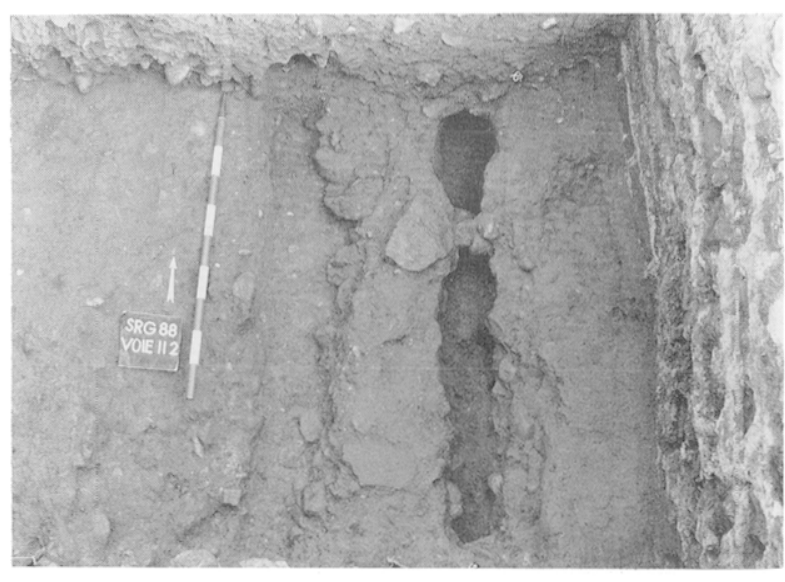

Fig. 27 - Voie II 2 : empreintes des deux tuyaux en bois T1 (état 2C) et T2 (état 2D, à gauche).

à l'ouest. Elles sont déposées, à des altitudes voisines $(150,80 \mathrm{~m}$ pour $\mathrm{T} 1,150,86 \mathrm{~m}$ pour $\mathrm{T} 2)$, dans deux sillons aménagés au fond d'une tranchée comblée par le remblai 53 (fig. 27$)^{34}$.

La réfection du tuyau $T 2$, à l'état $2 \mathrm{D}$, a entraîné une importante perturbation stratigraphique qui empêche de connaître avec exactitude le niveau de voie à partir duquel l'installation des deux canalisations en bois a eu lieu.

Compte-tenu des observations que nous avons pu effectuer en différents points du site, il s'avère qu'en règle générale la profondeur d'enfouissement des canalisations en bois atteint au moins une vingtaine de centimètres sous la surface de circulation initiale ${ }^{35}$. Dans ces conditions, la chaussée 46 constitue le point minimal d'installation des conduites (fig. 28), et la chaussée 26 le point maximal, puisqu'elle correspond également au point de départ de la réparation de T2 (fig. 33).

Afin de préciser le niveau d'apparition de T1 et T2. il convient, comme ce fut le cas pour le premier réseau d'adduction mis en évidence à l'état 2B, d'effectuer une comparaison avec la Voie I. Dans celle-ci, on observe l'installation d'un groupe de quatre tuyaux en bois. parallèles, espacés de manière régulière dans la chaussée.

$34 \mathrm{Au}$ fond des saignées d'installation respectives. plusicurs fragments de frettes ont été retrouvés. Ils ont permis de fixer à une dizaine de eentimètres le diamètre extérieur des pièces de bois utilisées.

35 Celle valeur moyenne est seulement valable pour les voies empierrées. Lorsque l'on a aflaire à des chaussées dallees. la profondeur d'enfouissement devient bien plus conséquente. Elle peut atteindre une cinquantaine de centimetres sous la base des dalles (c'est par exemple le cas pour la batterie de six tuyaux mise au jour sous le premier niveau de voie dallée de la place Triangulaire (Voie XI) durant la campagne de fouilles 1991). 


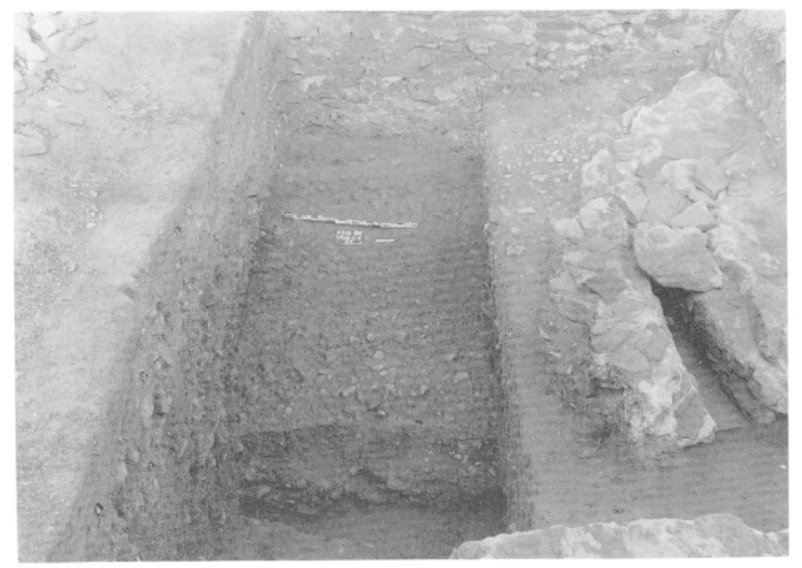

Fig. 28 - Voie II 2 : niveau de voie 46 (état 2B).

Dans le sondage Voie I 1, situé du côté ouest de la façade des Petits Entrepôts, la tranchée d'installation commune de ces canalisations débute à $150,96 \mathrm{~m}$. altitude qui correspond assez bien, compte-tenu de la pente de l'égout de la Voie II, au sommet de la chaussée 46, si nous supposons que celle-ci suit de manière régulière l'inclinaison du collecteur public jusqu'au carrefour sud.

Toujours dans le même sondage, la profondeur d'installation des tuyaux se situe à $150,48 \mathrm{~m}$. A la jonction des deux voies, la nécessité de franchir l'égout de la Voie II les oblige à remonter à la cote minimale de $150,70 \mathrm{~m}$. ce qui les rapproche du niveau de pose des canalisations nord-sud. Ces concordances nous incitent à restituer un seul réseau au sein duquel viennent s'intégrer ces deux batteries.

Au carrefour. le problème est de savoir comment s'effectue la rencontre des deux groupes de tuyaux. Trois solutions potentielles s'offrent à nous :

- les deux conduites de la Voie II se greffent sur deux des tuyaux de la Voie I:

- les deux canalisations est-ouest les plus septentrionales de la Voie I obliquent au nord, laissant les deux autres continuer seules vers l'est :

- les tuyaux de la Voie II tournent vers l'est et poursuivent leur chemin en concordance avec les quatre autres en direction de la Voie X.

De ces trois possibilités, nous ne retiendrons que la dernière qui découle des observations que nous avons effectuées sur la place Triangulaire, située à l'angle nord-ouest des thermes des Lutteurs (fig. 2). Cette place, créée lors de la construction de l'édifice thermal et désignée sous la référence Voie XI, est en effet le lieu de passage d'une batterie homogène de six canalisations en bois qui occupe une largeur de $2,10 \mathrm{~m}^{36}$. Cet ensemble n'a pas été retrouvé dans la partie sud de la Voie $X$ où un sondage restreint a été réalisé en 1991 le long des

36 L'étude chronologique en cours des sondages effectués sur la place ne nous permet pas, pour l'instant. d'affirmer qu'il thermes, laissant du côté de la façade ouest une bande de $2.30 \mathrm{~m}$ non explorée. La largeur de cette bande est suffisante pour permettre le passage des six tuyaux qui, après avoir traversé la place en diagonale, se révèlent ainsi collés contre l'îlot $C$. Nous sommes en droit de penser qu'il en va de même dans la Voie I, jusqu'à la jonction de la Voie II (fig. 29). Ce dispositif se trouve corroboré par la position des conduites dans le sondage Voie I 3 (fig. 25). Celles-ci s'avèrent décalées vers le sud, laissant ainsi une bande dont la largeur passe de $1,20 \mathrm{~m}$, à la hauteur des Petits Entrepôts, à $0,70 \mathrm{~m}$ devant la façade de la maison des Dieux Océans ${ }^{37}$. Nous sommes incités à voir dans cet espace inoccupé l'emplacement des deux conduites qui ont bifurqué dans la Voie II.

\section{Le rehaussement continu de la chaussée}

Des épandages successifs de remblais vont amener le niveau de la rue à une altitude proche de celle du sol du portique de l'état 2B de la parcelle de la maison aux Cinq Mosaïques, c'est-à-dire vers la cote $151,90 \mathrm{~m}^{38}$.

En dehors de la possible installation des tuyaux $\mathrm{T} 1$ et T2 à partir de sa surface, la couche 46 subit un recreusement dans la partie ouest du sondage (fig. 7 et 8). Est-il imputable aux aménagements de la deuxième phase du Bâtiment Commercial ou bien plus spécifiquement lié à un problème de voirie (ravinement. pose ou récupération d'une canalisation...) ? La présence du trottoir sur drain de l'état $2 \mathrm{E}$ nous empêchant de prendre la mesure réelle de cette perturbation, sa finalité nous échappe.

Quoi qu'il en soit, son comblement (couches 45 et 44) ainsi que le colmatage de plusieurs dépressions (couche 43) entraînent l'apparition d'un nouveau niveau de voie plus régulier, à $150,50 \mathrm{~m}$, dont la couche 40 constitue la partie est. Cette chaussée compacte, composée de galets et de nombreux fragments de tuiles, reste en service suffisamment longtemps pour présenter des ornières très marquées (fig. 30).

Au sein de la voie 40, une empreinte dont la largeur

s'agit bien du même réscau initial de tuyaux. Compte-tenu des bouleversements qu'a engendré la construction des thermes des Lutteurs, tels que l'interruption de la Voic I. nous pouvons très bien nous trouver en présence d'un détournement du réseau initial, exécuté à une date plus récente.

37 Les quatre tuyaux occupant une bande large de $1.00 \mathrm{~m}$. la conduite la plus méridionale se trouve donc à $2,20 \mathrm{~m}$, puis à $1.70 \mathrm{~m}$ des façades. Ces valeurs, et plus particulièrement la première, sont du même ordre de grandeur que la largeur occupée par les six canalisations reconnues au niveau de la place Triangulaire.

38 Sur la stratigraphie nord du sondage V 13 (fig. 7), le sol du portique (couche 16) a subi d'importants tassements. Son niveau originel se situe à $152.00 \mathrm{~m}$. Cette altitude correspond au sommet de M45, recevant un stylobate d'une vingtaine de centimètres de haut au moins. 


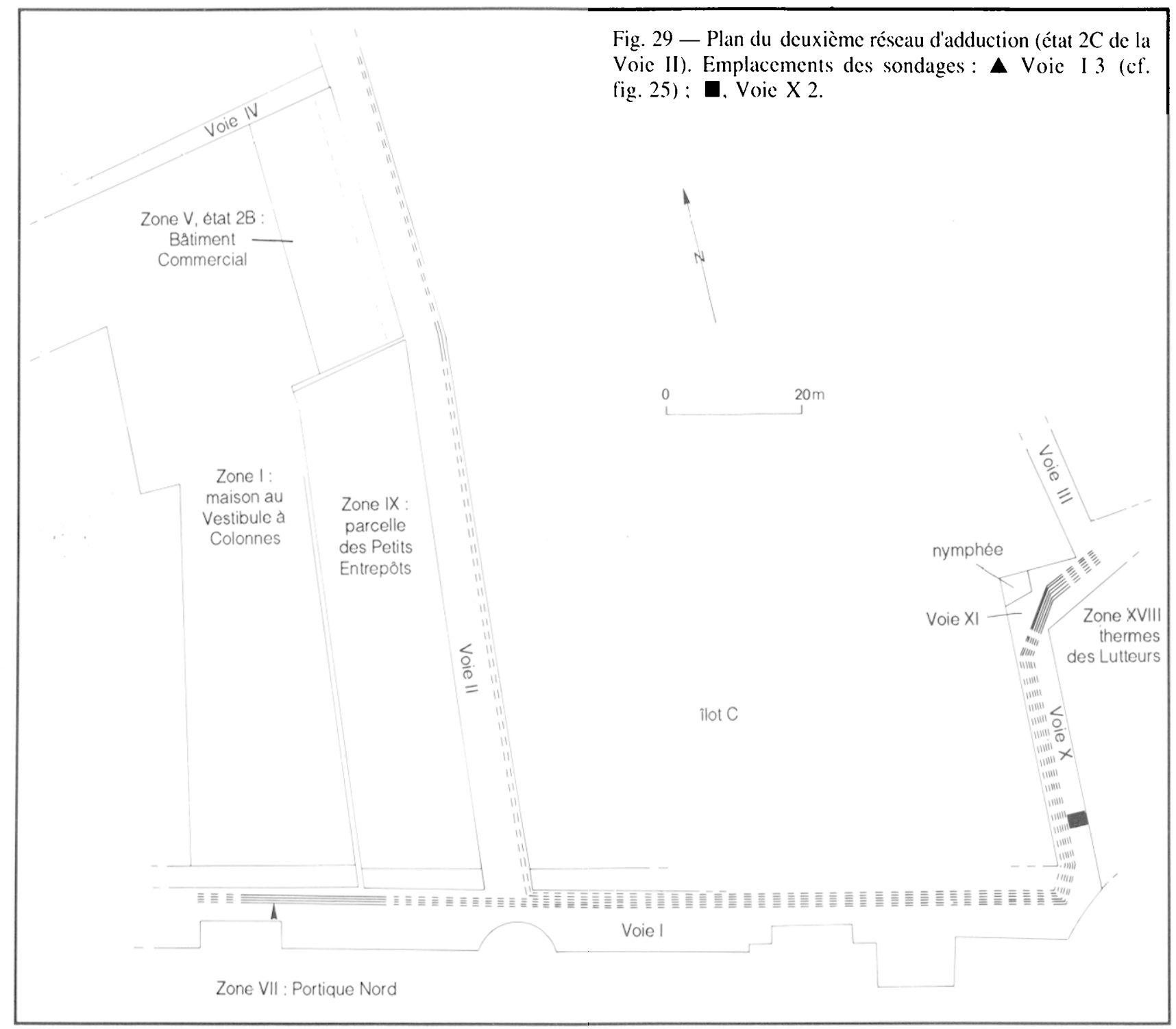

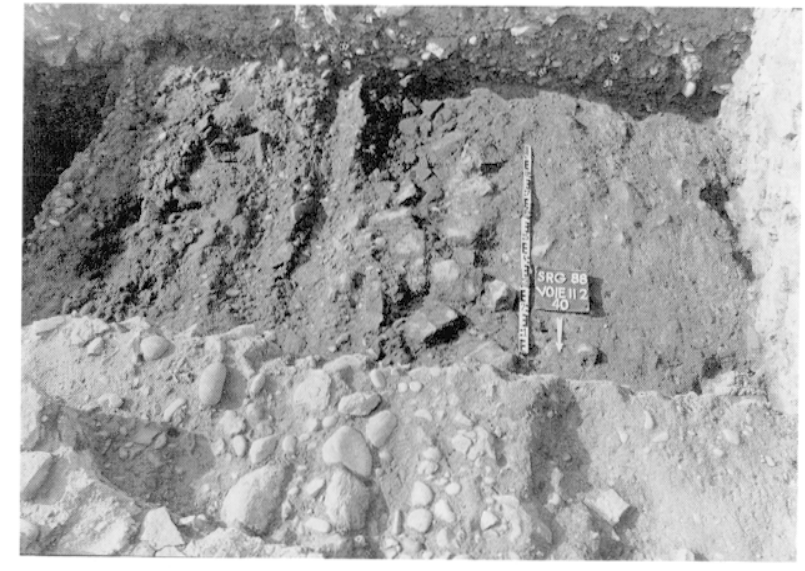

Fig. 30 - Voic II 2 : ornières des chaussées 40 et 26 (ćtat 2C). varie de 22 à $34 \mathrm{~cm}$ (fïg. 8 et 31 ) est comblée par la couche 41 , plutôt meuble, qui recèle de nombreux fragments de charbon de bois et de tuiles. La faible hauteur de ce sillon, $10 \mathrm{~cm}$ tout au plus, suggère le passage d'un tuyau en bois qui, si tel était le cas, affleurerait la surface de la rue. Cette position superficielle alliée à l'absence de frette et à la grande largeur du négatif nous incitent à rejeter l'hypothèse d'une canalisation et à considérer que nous avons plutôt affaire à une ornière particulièrement défoncée.

$\mathrm{Ce}$ niveau de voie reçoit une seule recharge, ponctuelle (couche 39), avant de faire à son tour l'objet d'un rehaussement d'une vingtaine de centimètres portant l'altitude de la rue à $150,70 \mathrm{~m}$ (fïg. 32, couche 37 ). Bien que plusieurs rebouchages soient visibles, cette chaussée de graviers et de sables grossiers, peu dégradée, semble avoir été utilisée durant une période relativement brève. 


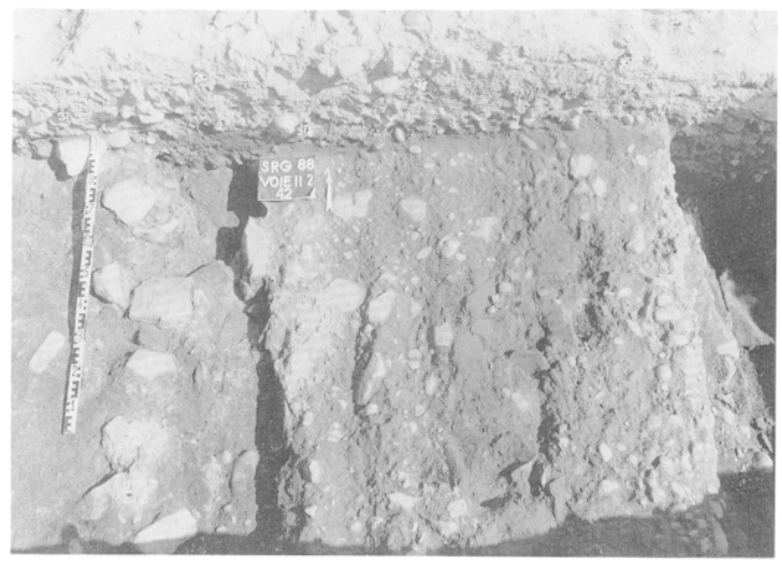

Fig. 31 - Voic II 2. (i-dessuss, niveau de voie 40 et omière 42 (état 2C). (ii-contre. détail de l'ornière 42.

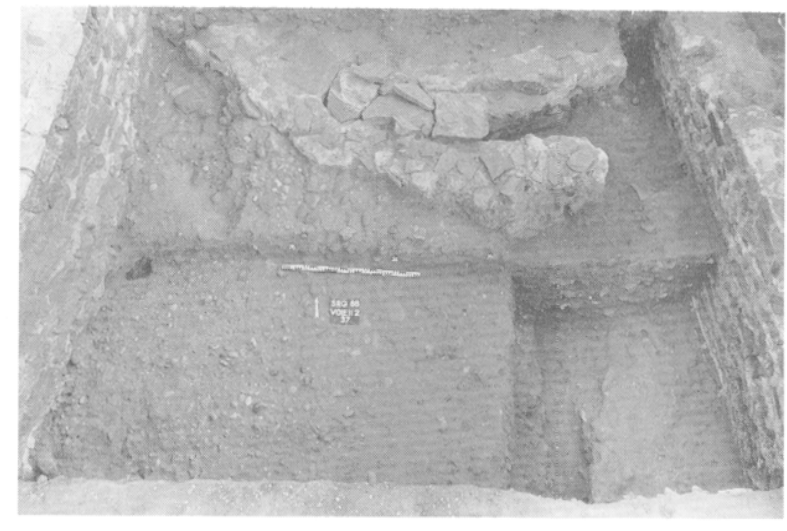

Fig. 32 - Voie II 2 : niveau de voie 37 (ćtat 2C).

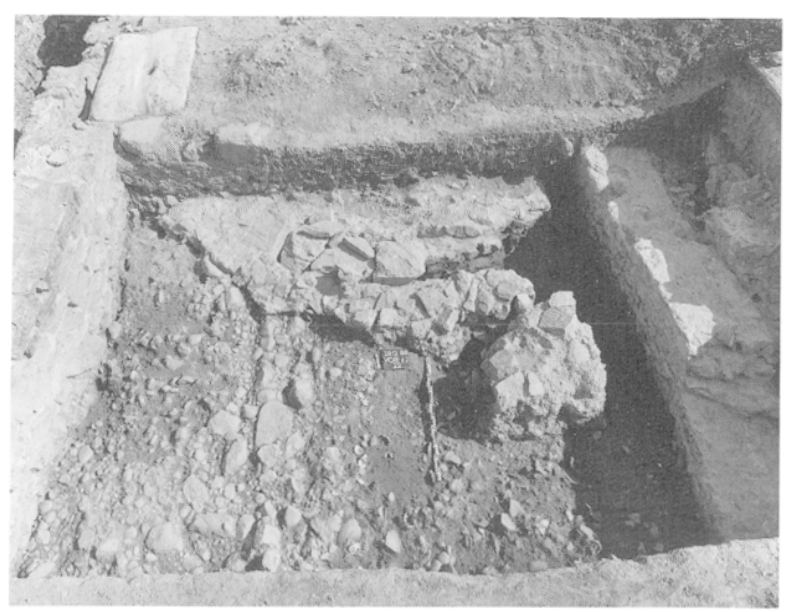

Fig. 33 - Voie II 2 : ornières du niveau de voie 26 (ćtat $2 \mathrm{C}$ ). Drain, regard R5, égout M2, massif M3, et mur de façade M1 (état 2E). A l'arrière plan. regard $\mathrm{R} 5$ recouvert par la dalle de couverture en calcaire découverte sur le regard R4.

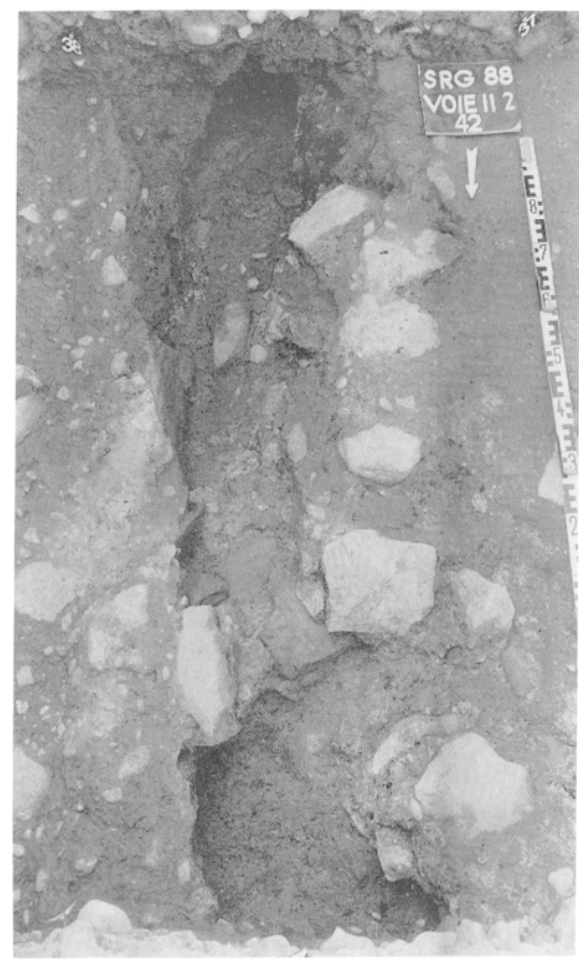

Un nouveau remblaiement porte ensuite la zone de circulation à la cote $150.90 \mathrm{~m}$. L'établissement d'un empierrement compact (fig. 33, couche 26), présentant plusieurs lits de galets dans lesquels se mêlent des fragments de tuiles en concentrations plus ou moins marquées, instaure une chaussée stable dont la surface de roulement, constituée de gros galets, conserve les traces du charroi.

La présence d'ornières sur les niveaux 26 et 40 , quasiment au même endroit, témoigne non seulement d'une forte fréquentation de ces voies par des véhicules de transport, mais aussi de l'existence d'une contrainte qui force la circulation à ne s'effectuer que dans une certaine partie de la chaussée (fig. 30). En effet, comme à la hauteur des dalles surélevées des rues de Pompéi (Adam, 1989, p. 305). l'usure marquée de la zone de circulation met en évidence des lieux de passage obligés. A Saint-Romain-en-Gal, ces manifestations se décèlent aussi sur les voies dallées, au niveau de leurs changements de direction notamment, ce qui est le cas de la Voie Il à la hauteur du sondage.

Les traces. rencontrées en certains de ces points bien spécifiques (coude de la Voie IIl notable au niveau du changement d'axe général est-ouest du site. jonction de la Voie X et de la Voie XI : fig. 2), nous permettent de restituer un écartement des roues des véhicules de l'ordre de $1.50 \mathrm{~m}$ au maximum et nous montrent que les charrettes demeurent à près de $0.70 \mathrm{~m}$ du point saillant de l'inflexion. Si nous transposons ces indications aux ornières des niveaux 26 et 40 , nous obtenons dans les 
deux cas ${ }^{39}$, en partant de la façade orientale de la rue, le découpage de la bande de roulement suivant : un bascôté est de $0,80 \mathrm{~m}$, un premier axe de circulation de $1.50 \mathrm{~m}$, un intervalle de $0.60 \mathrm{~m}$ avant un deuxième axe de circulation de $1.50 \mathrm{~m}$ et un bas-côté de $1.60 \mathrm{~m}$.

Compte-tenu de la largeur de la rue $(5,96 \mathrm{~m})$, il n'est pas surprenant de constater que deux véhicules se croisent sans difficulté. La surprise vient plutôt de la largeur de la bande latérale ouest. Celle-ci, située du côté du point saillant du changement de direction. devrait être beaucoup plus réduite $(0,70 \mathrm{~m})^{40}$.

La permanence des points d'érosion, au fil du rehaussement, montre qu'un obstacle s'est maintenu durant une longue période, déviant la circulation vers le centre de la chaussée. Nous devons rechercher les causes de ce déportement dans le Bâtiment Commercial voisin dont la construction en surélévation rend vraisemblable. du côté sud, la présence d'un accès empiétant sur la rue (cf. infira, p. 50, État $2 \mathrm{~B}$ de la zone V). Si nous retenons l'hypothèse d'un escalier de trois marches (fig. 59), celui-ci occupe, au sol, une largeur d'environ $0.75 \mathrm{~m}$ (cette valeur indicative correspond à trois marches de $0.25 \mathrm{~m}$ de large), ce qui nous laisse alors une bande latérale de $0.85 \mathrm{~m}$ de large, comparable à celle qui longe la façade est. Nous disposons ainsi d'une chaussée à deux voies pourvue d'un accotement suffisamment large. en dehors de l'emprise de l'escalier. pour permettre le stationnement des charrettes.

Il ne faut cependant pas perdre de vue que, au fur et à mesure de l'élévation du niveau de circulation, la taille de cet escalier, de même que son utilité se réduisirent. Dans ces conditions, nous devrions voir évoluer vers l'ouest la position des ornières, or ce n'est pas le cas. Il convient donc de prendre en considération l'aspect fonctionnel de cet espace qui, tout en assirant aux boutiques une facilité de manutention lors de livraisons ou de chargements de marchandises, ne gêne ni le passage des véhicules, ni celui des piétons, ces derniers ayant à leur disposition le portique du Bâtiment Commercial.

Durant la période d'utilisation de la chaussée 26. nous assistons à un changement de structure du Bâtiment Commercial (cf. État 2C de la zone V). La construction d'un nouveau mur de façade (fig. 6()) isole dorénavant le bâtiment de la rue. Une canalisation estouest, destinée à l'alimentation de la maison des Dieux Océans, est alors installée (fig. 53). Selon toute vraisemblance, son raccordement avec $\mathrm{T} 2$ s'effectue à quelques mètres au nord du sondage Voie II 2.

39 Les empreintes des deux niveaux se superposent avec une étonnante coüncidence. Il convient d'ailleurs de noter que l'ornière la plus marquée de la voie 26 (fig. 30) se situe juste au-dessus de l'empreinte profonde repérée dans la couche 40) (fig. 31 ).

40) Le souci de réduire au maximum les manoxuvres à effectuer incite naturellement les conducteurs à prendre les virages à la corde.

\section{Les regards}

Trois regards sont situés en face de la parcelle de la maison aux Cing Mosaïques (tabl. II). Nous avons vu précédemment (état 2B) que l'un d'entre eux, R6, avait toutes les chances d'exister depuis la création de l'égout. En ce qui concerne les deux autres, R5 et R7, la question est de savoir à quel moment ils ont pu être créés. Bien que letir restauration drastique rende cette détermination hasardeuse, nous pouvons remarquer que ces trois regards, par leur répartition à peu près régulière, constituent en quelque sorte une réponse à la distribution des débouchés, également au nombre de trois, prévus dans le collecteur pour les égouts du Bâtiment Commercial des états 2A et 2B (tabl. I). Nous pouvons donc envisager l'existence d'une relation entre débouchés et regards qui permettrait de placer leur apparition soit au début, soit dans le courant de l'état 2B dé la parcelle. c'est-à-dire durant l'état $2 \mathrm{C}$ de la rue (fig. 50).

Par ailleurs, le rehaussement régulier du niveau de la rue pose le problème de l'adaptation des cheminées des regards aux nouvelles chaussées.

A ce propos, le regard R.3 fournit des indications précieuses sur ce qui a pu se passer. Si nous le transposons dans le sondage Voie II 2. nous constatons que sa dalle de couverture affleure la surface de la chaussée 40. Pour aboutir à cette altitude, il suffit, dans le cas présent, de remplacer la dalle initiale, à qui nous donnions une épaisseur de 2() $\mathrm{cm}$, par une nouvelle. plus haute $(39 \mathrm{~cm}$ dans le cas de R3) (fig. 23). Néanmoins, cette méthode a ses limites et il semble difficile de continuer à l'adopter lorsque l'on dépasse le seuil des $40 \mathrm{~cm}$, les blocs devenant dès lors de moins en moins maniables.

Une solution à moindre coût peut être envisagée : la rue est rehaussée partout. sauf aux emplacements des regards qui, de ce fait. se retrouvent au centre de cuvettes. Ce système, souvent utilisé dans les voies dallées du site, peut être également applicable aux chaussées empierrées. Il présente en outre l'intérêt de faciliter le recueillement des eaux de ruissellement qui s'évacuent ainsi par le trou percé au centre de la dalle.

Avec la présence de pentes douces, des dénivellations d'une quarantaine de centimètres sont envisageables. Dans ces conditions, le remblaiement a pu atteindre le niveau de la voie 26 , dont la surface se situe à $2.80 \mathrm{~m}$ du fond de l'égout. sans que l'on ait éprouvé le besoin impérieux d'exhausser les cheminées. Pourtant, ici aussi, nous atteignons une limite de commodité. Si nous reprenons l'exemple de $R .3$. une fois la dalle enlevée pour effectuer l'entretien du collecteur, nous aurions $80 \mathrm{~cm}$ de remblais prêts à se répandre dans le conduit au moindre ravinement.

Même si un schéma d'évolution, comme celui que nous venons d'évoquer (changement de couverture, regard en fond de cuvette) a sans doute été appliqué le plus longtemps possible. la surélévation des regards a dû très certainement débuter durant l'état 2C. La 
dégradation des regards et leurs restaurations font qu aucune reprise des maçonneries pouvant être attribuée à cette période n'est plus aujourd'hui perceptible.

\section{ETAT 2D \\ (PREMIÈRE MOITIÉ DU II $\mathbf{e}$. après J.-C.)}

Cette nouvelle phase de l'histoire de la rue est caractérisée par des travaux qui interviennent durant l'état 2C de la zone V (infra. p. 57, fig. 60).

Une réparation du tuyau en bois occidental $\mathrm{T} 2$ est entreprise alors que la chaussée se trouve parvenue au niveau de la couche 26 , à la cote $151,80 \mathrm{~m}$. Une grande tranchée atteignant plus de $1,50 \mathrm{~m}$ de large dans sa partie supérieure est alors creusée le long de la façade est. dans le but de remettre au jour la ou les sections de la canalisation usagée située $1 \mathrm{~m}$ plus bas (fig. 7 et 8 ). Après avoir effleuré le tuyau oriental T1, l'excavation se rétrécie jusqu'à atteindre une largeur d'environ $25 \mathrm{~cm}$ à l'emplacement du niveau d'installation de $\mathrm{T} 2$.

Pendant toute l'opération. T1 demeure en place. préservé par son remblai d'installation que l'on a pris soin de ne pas entamer. Au-dessus de lui, la fine couche limoneuse 52 est à assimiler à un sol de travail qui s'est constitué lors de ces travaux. La présence de fragments de frettes en place à la base de l'excavation, de même que l'existence, dans le comblement 20, d'un effondrement situé à l'aplomb de l'emplacement du tuyau. indiquent que l'on a bien procédé à un remplacement de $\mathrm{T} 2$ et non à une simple récupération ${ }^{41}$.

Nous connaissions déjà, à Saint-Romain-en-Gal, un exemple de réparations effectuées sur un tuyau en plomb de l'état 2 de la maison des Dieux Océans : il s'agissait de travaux ponctuels touchant le branchement d'un particulier ${ }^{42}$. Mais, c'est la première fois qu'il nous est possible de mettre en évidence la réparation d'une canalisation en bois appartenant au réseau public d'adduction d'eau. Des exemples de ce type ont déjà été recueillis à Pompéi où, au moment de l'éruption de 79. des tranchées étaient en cours d'exécution afin de permettre la réparation des conduites endommagées lors du tremblement de terre de 62 (Maiuri, 1942, p. 93).

4l Comme nous l'avons déjà observé à Saint-Romain-enGal pour l'ćtat 2B (supra, p. 27), les tuyaux en plomb ont fait l'objet d'une récupération intensive, tant à l'ćpoque moderne qu'à l'époque antique. Il n'en va pas de même pour les conduites en bois. Dans toutes les rues principales actucllement explorées (Voies I. II. III et XI), nous retrouvons quasi systématiquement les frèttes en place dans les saignées qui résultent de la désagrégation du bois, et ce quelque soit l'état d'installation.

42 Cochet. Hansen. 1986, p. 76 : «Si l'on envisage le développement des conduites d'eau. il est intéressant de remarquer la présence, sous le scuil de l'état 2. d'un tuyau en plomb (...) présentant des traces de fractures, les unes réparées. les autres pas. Ces fractures sont consécutives à l'effondrement du seuil, à l'instabilité du sol et au tassement du terrain. Ce tuyau porte des traces de réparations et présente. sur un seul mètre, 3 assemblages».

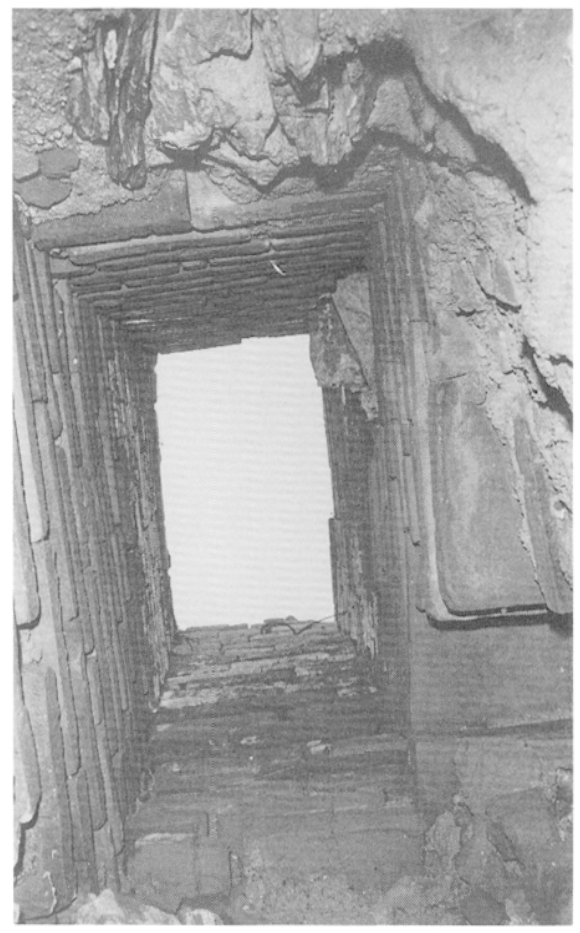

Fig. 34 - Voie II : regard R4 avant restauration.

La remise en état de la conduite T2 est étroitement liée à une réfection plus générale de la rue qui se traduit par l'apparition d'une nouvelle chaussée vers la cote $152,10 \mathrm{~m}$, à la surface des couches 20 et 22 qui ne constituent en réalité qu'un seul et même remblai.

Notons que, sur la plus grande partie du sondage, le comblement de la tranchée recouvre la voie 26 sur une vingtaine de centimètres d'épaisseur (fig. 8, couches 20 et 22 ) et qu 'il ne correspond pas, par sa composition, aux différents dépôts qui constituent le sous-sol de la rue. Ainsi, la couche 20 est issue d'un dépotoir ménager abondamment pourvu en amphores, huîtres, ossements et charbon de bois.

L'utilisation d'un même remblai, étranger au soussol, pour refermer la tranchée et rehausser la voie tend à montrer que l'intervention sur T2 dépasse le simple stade de la réparation d'une fuite ou de l'établissement d'un raccordement. Nous pourrions avoir affaire ici à un changement complet du tuyau, peut-être suscité par son état de dégradation, qui aurait été effectué lors d'un nouveau rehaussement.

Précisons que la création du regard $\mathrm{R} 4$, situé au sud du sondage Voie II 2, remonte à cette époque, si l'on en juge par la hauteur initiale de sa cheminée en brique (tabl. II). Son apparition s'insère ainsi parmi les réaménagements qui affectent la rue (fig. 34). Nous pouvons également envisager que la condamnation de R3, si elle n'a pas eu lieu auparavant, se produit au même moment. Ce regard serait alors remplacé par $\mathrm{R} 4$ qui n'en est distant que d'environ $6 \mathrm{~m}$. 


\section{ETAT 2E}

(SECONDE MOITIÉ DU $\Pi^{\mathrm{e}} \mathbf{s}$. après J.-C.)

A partir du niveau de chaussée matérialisé par les couches 20-22. d'importantes transformations ont été apportées de part et d'autre de la rue (cf. infra, p. 60. fig. 64).

\section{Façade ouest}

Les deux murs de façade originels, M7 et M8, ont été détruits. Ils sont alors remplacés par un mur unique et homogène, $\mathrm{Ml}$, qui conserve leurs orientations (fig. 35). La réunification des deux parcelles, révélée par ce mur, gomme légèrement le changement d'axe antérieur qui perd ainsi de son importance. Ce phénomène se trouve d'ailleurs confirmé par l'implantation d'une nouvelle structuration interne signalée par le mur M4 (fig. 4). En effet, ce dernier correspondant plutôt à un cloisonnement est situé à $1 \mathrm{~m}$ au nord de l'ancienne limite ${ }^{43}$. Nous assistons ainsi à une nouvelle définition de la division parcellaire de l'îlot $\mathrm{C}$ qu'il faut, peut-être, mettre en relation avec la création, plus au nord, de l'ensemble artisanal et commercial (fig. 2, zone II).

Au-dessus d'une fondation en tranchée étroite qui s'appuie sur M7 et M8, arasés à l'altitude moyenne de $151,30 \mathrm{~m}$, l'élévation de Ml présente la particularité d'être pourvue de joints verticaux marqués d'un double ou triple coup de truelle. La réalisation de cette construction n'entraine pas de changement dans le niveau de circulation qui demeure celui de la voie 20/22.

Dans le même temps, le massif M3, constitué de blocs schisteux liés avec un mortier jaune beige et possédant une forme sensiblement carrée d'environ $0,90 \mathrm{~m}$ de côté, est implanté parallèlement à $\mathrm{M} 7$. en face de son extrémité sud (fig. 4). Vraisemblablement réalisé, lui aussi, à partir de la chaussée $20 / 22$, il peut correspondre au support d'un poteau ou d'un pilier mais l'arasement extrême de cette maçonnerie $(152,18 \mathrm{~m})$ ne facilite ni son identification, ni la détermination de sa durée de vie qui, néanmoins, pourrait ne pas dépasser la longévité de la première voie dallée.

L'implantation de ce massif se trouve-t-elle liée au changement d'axe de la rue ? Sommes-nous en présence d'un aménagement temporaire, en relation par exemple avec l'échafaudage qu'a nécessité l'édification de M1, ou bien nous trouvons-nous devant le support d'un chasseroue ou d'un bloc destiné à délimiter la bande de roulement ? En ce qui concerne cette dernière proposition, il faut remarquer que ce soubassement. fondé seulement sur une vingtaine de centimètres, est placé à $0.50 \mathrm{~m}$ de la façade est. Cette distance est peu

43 Les deux murs, composés de moellons issus de roches métamorphiques liés au mortier jaune, ne sont pas chaînés. M4 s'appuic contre M1 à angle droit et il est plus étroit que lui $(0,50 \mathrm{~m}$ au licu de $0.60 \mathrm{~m})$.

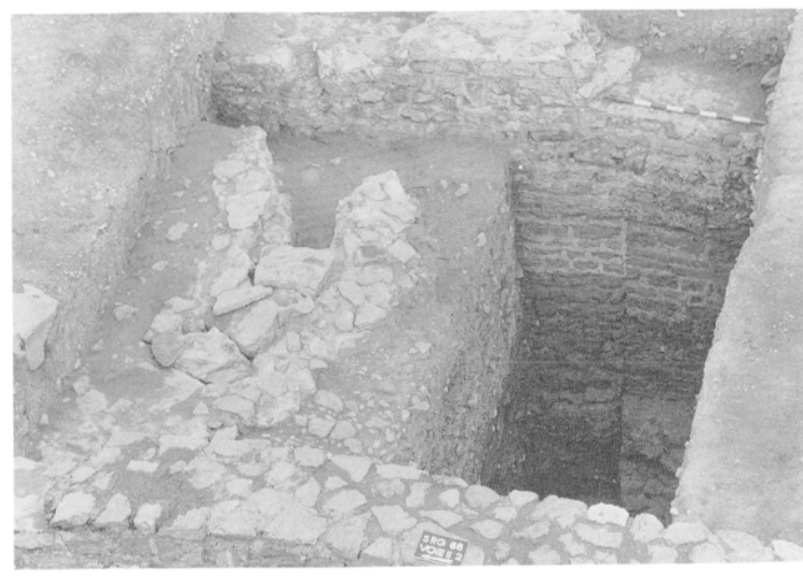

Fig. 35 - Voie II 2 : vue de face du mur de façade M1. ćgout M2 (état 2E).

éloignée de la largeur du bas-côté que nous avons pu restituer pour les chaussées de l'état $2 \mathrm{C}(0,80 \mathrm{~m})^{44}$.

En tout état de cause, il ne peut s'agir de l'élément d'un portique de façade. Hormis le fait que la fondation de celui-ci ne serait pas continue d'un support à l'autre ${ }^{45}$. l'espace de circulation. ainsi déterminé entre le mur de façade et les piliers, s'avérerait trop étroit pour permettre une circulation aisée. Cependant. ce massif peut fort bien appartenir à un porche signalant l'entrée du nouveau bâtiment. Notre méconnaissance de la structure interne de cette construction rend. pour l'instant, cette hypothèse tout à fait envisageable.

\section{Le dallage de la rue}

Après la construction de MI. un événement important a engendré une perturbation notable dans la sédimentation jusque-là régulière de la voie II. Celui-ci n'est perceptible que par la forme irrégulière de la base de la couche 17. En effet, cet épais remblai moule des dépressions qui nous font penser à des empreintes de blocs issus d'une première voie dallée dont la couche 19 constituerait le remblai d'installation (fig. 8) ${ }^{46}$. Compte-tenu de la profondeur des dépressions. le niveau de cette chaussée avoisinerait une altitude de $152.40 \mathrm{~m}$ qui correspond à celle du seuil d'entrée de la maison au Bassin Excentré (état 3 de la zone V). Les dalles de granite utilisées sur le site ont des épaisseurs très variables allant d'une trentaine à une soixantaine de centimètres.

44 Cet écartement correspondrait de manière encore plus satisfaisante si le bloc coiffant celte fondation s'avérait moins large qu clle.

45 Bien que techniquement possible, un aménagement de cet ordre ne semble pas se rencontrer sur ke site, pour les façades.

46 Nous observons le même phénomène dans les sondages de la Voie XI où des dalles se sont succédé dans deux chaussées avant d'être récupérées, laissant un enchevêtrement de fosses comblées de terre noire pour le premier niveau et de terre ocre jaune pour le second. 
Par la suite, un nouveau rehaussement étant mis en ceuvre, le remblai 17 se substitue aux dalles initiales qui sont d'ailleurs très probablement réutilisées ${ }^{47}$ pour paver la nouvelle chaussée installée vers la cote $152.70 \mathrm{~m}$ et qui constitue le dernier niveau de circulation de la Voie II. Le dallage, composé de blocs de granite à grains fins et de granite porphyrö̈de ${ }^{48}$, a été en grande partie préservé jusqu'à nos jours. Seule la portion de voie longeant la maison aux Cinq Mosaïques et le bâtiment nord des Petits Entrepôts a fait l'objet d'une intense récupération des blocs, à une époque indéterminée. A l'emplacement du sondage. l'existence de cette chaussée n'est plus perceptible que par la base des empreintes des dalles, comblées par la couche 6 (fig. 8). La disparition des blocs sur ce secteur bien précis s'explique peut-être par le fait qu'il s'agit du point haut de la rue.

Le bon état de conservation de ce niveau de circulation sur l'ensemble de la Voie II nous permet d'en préciser le profil général ${ }^{49}$. En partant du nord, il présente devant les Grands Entrepôts une légère pente ascendante $(1 \mathrm{~cm} / \mathrm{m})$ qui s'atténue à la hauteur de la Voie IV. Il devient ensuite pratiquement horizontal jusqu'à la limite sud du bâtiment nord des Petits Entrepôts (pente ascendante de $0.2 \mathrm{~cm} / \mathrm{m}$ ). A partir de cet endroit, la rue perd rapidement de l'altitude, $0.82 \mathrm{~m}$ sur une longueur de $33 \mathrm{~m}(2,5 \mathrm{~cm} / \mathrm{m})$. Cette pente descendante s'adoucit devant le passage central des Petits Entrepôts $(1.6 \mathrm{~cm} / \mathrm{m})$ pour se terminer au point bas de la rue qui se situe à la hauteur du passage méridional des Petits Entrepôts. Finalement, le niveau remonte légèrement jusqu'au carrefour des Voies I et II $(0.9 \mathrm{~cm} / \mathrm{m})$.

Installé dans le remblai 17. le conduit M2 permet à l'égout domestique M5, accolé au mur M4, situé à l'intérieur de la parcelle orientale, de rejoindre le collecteur public. La relation entre ces deux conduits ${ }^{50}$

47 Compte-tenu du travail d'extraction el de transport que représente l'aménagement d'une telle chaussée, la présence sur place de blocs prêts à l'emploi constitue une aubaine qui n'a sûrement pas été dédaignée.

$18 \mathrm{Si}$ pour les premiers, aucun affleurement local n'a été repéré. les seconds proviennent sans doute d'un affleurement situé sur la rive gauche, à Pont-Evêque (information communiquée par H. Savay-Guerraz).

49 En dépit des tassements inhérents au temps, au poids des blocs, aux remblais mal compactés. et malgré les restaurations de 1988. ce profil est resté peu différent de ce qu'il ćtait au moment de l'abandon du site.

$50 \mathrm{Ils}$ ont tous deux la même largeur intéricure de $0.36 \mathrm{~m}$. Le fond et les piédroits de M5, très arasés, sont composés de briques et de pierres liées au mortier jaune. M2, pour sa part. est essentiellement constitué de moellons schisteux. Seul son fond est recouvert de tuiles. Il a en partic conservé sa couverture maçonnée de plaques de schistes qui laisse un passage libre variant de $0.32 \mathrm{~m}$ du côté est à $0.26 \mathrm{~m}$ au niveau du regard. n'est pas évidente puisqu'ils présentent, de part et d'autre de Ml, une différence d'altitude d'environ $0.70 \mathrm{~m}$ qui équivaut à une pente de $41 \mathrm{~cm} / \mathrm{m}$. alors que l'inclinaison moyenne de M2 n'est que de $6 \mathrm{~cm} / \mathrm{m}$. Nous avons affaire à une véritable chute. probablement liée à la nécessité de faire passer la canalisation sous le dallage de la rue. Bien que le raccord soit détruit. cette rupture de niveau et le fait que les embouchures des deux conduits ne se trouvent pas exactement en face l'une de l'autre laissent envisager la présence d'un petit réceptacle qui aurait assuré leur jonction et qui aurait également pu servir à recueillir des eaux de toiture ${ }^{51}$.

Pour sa part, l'égout M2 présente un parcours singulier. Après avoir écorné le massif $M 3$, qui reste peut-être en service. et suivi sur $1 \mathrm{~m}$ une direction estouest, il s'incurve vers le nord pour aller se jeter dans la cheminée du regard R5, à travers sa paroi sud, à la cote $151,53 \mathrm{~m}$ (fig. 4). Si le choix du déversement dans le regard se comprend aisément. puisqu'il entraîne moins de travaux de terrassement qu'un raccord direct à l'égout, le tracé curviligne de $M 2$ demeure énigmatique.

Compte-tenu des divers exhaussements de chaussée intervenus depuis la construction de MI. l'installation de ce réseau hydraulique est à rattacher à une seconde phase d'occupation du bâtiment voisin.

L'établissement d'un deuxième niveau dallé correspond à une transformation majeure de la structure de la rue. La chaussée est dorénavant réduite à une largeur de $4 \mathrm{~m}$ en raison de l'installation sur le côté ouest, et sur toute la longueur de la voie, d'un trottoir constitué de grandes plaques calcaires reposant soit sur un massif plein, soit sur un drain.

\section{Le trottoir}

Le trottoir qui est construit occupe le tiers de la largeur de la rue et présente deux faciès différents.

Le long de la façade des Grands Entrepôts et jusqu'au côté nord de l'entrée de la maison aux Cinq Mosaiques. nous avons affaire à une maçonnerie continue, pleine, d'environ $1.10 \mathrm{~m}$ d'épaisseur ${ }^{52}$ et de $1.70 \mathrm{~m}$ de largeur (fig. 43 et 69). Au sud de l'entrée des Grands Entrepôts. le sommet de ce massif horizontal se situe à la cote $152,60 \mathrm{~m}$, tandis qu'il demeure en moyenne à $152,51 \mathrm{~m}$, au nord. Le dallage calcaire de cette entrée charretière étant situé à $152.23 \mathrm{~m}$. le trottoir avec ses dalles de couverture présente ainsi une surélévation de $0,54 \mathrm{~m}$ au sud et de $0,45 \mathrm{~m}$ au nord. Nous incluons, dans ces deux valeurs, une épaisseur moyenne de dalle de $0,17 \mathrm{~m}$. Cette différence de niveau est rattrapée par

51 L'inflexion de la chaussée induit un raccord de toiture en creux qui concentre les caux de pluie. Il est donc envisageable qu'une récupération de ces caux soil assurée dans la rue (cf. le ravinement de l'état $2 \mathrm{~A}$. fig. 18)

52 Devant l'entrée des Grands Entrepôts. en raison de leur accès de plain-pied avec la chaussée. cette épaisseur tombe à près de $0.70 \mathrm{~m}$. 
deux escaliers, installés de chaque côté de l'embrasure, qui sont composés chacun de trois marches dont les largeurs sont comprises entre $0,60 \mathrm{~m}$ et $0,70 \mathrm{~m}$.

Le trottoir ne s'interrompt pas en face du passage des Grands Entrepôts (Voie IV). Le massif se trouve alors au même niveau que la chaussée, ce qui signifie que la dalle qui le recouvre constitue une marche. Cette rupture souligne bien le caractère privé ou semi-public de ce passage qui peut correspondre soit à une desserte interne de l'îlot, en cul-de-sac, soit à une liaison secondaire entre deux rues. A Pompéi, nous pouvons observer l'un (VII 4 8: De Vos, 1982, p. 189) et l'autre cas (ruelle à degrés séparant les îlots I 6 et I 7 : De Vos, 1982. p. 85). L'exemple fourni par ce dernier est particulièrement instructif. Si son accès sud-est est marqué par une large porte sans seuil, située en retrait par rapport au carrefour, il n'en est pas de même pour sa jonction avec la rue de l'Abondance. Après avoir gravi cette ruelle pentue, nous débouchons, par l'intermédiaire d'une parte étroite $(1.47 \mathrm{~m})$ pourvue d'un seuil proéminent, sur le trottoir et non sur la chaussée. Cette disposition traduit clairement la destination piétonnière du passage.

A partir de l'entrée de la maison aux Cinq Mosaïques et jusqu'à la hauteur du portique du Bâtiment Sud des Petits Entrepôts, nous sommes en présence d'un trottoir sur drain (fig. 36). Les dalles de couverture reposent dorénavant sur deux murets distants de $0.80 \mathrm{~m}$ qui possèdent des largeurs différentes, $0.50 \mathrm{~m}$ pour le piédroit est et $0,60 \mathrm{~m}$ pour le piédroit ouest. Ces murs, dotés d'une hauteur moyenne de 1,64 m, présentent, à $0,60 \mathrm{~m}$ de leur base, des trous de boulins de $10 \mathrm{~cm}$ de côté qui se retrouvent, assez régulièrement espacés (intervalles de $1.66 \mathrm{~m}$ à $1.94 \mathrm{~m}$ ), sur toute la longueur du drain. Par ailleurs, le long des Petits Entrepôts, en façade du bâtiment comprenant huit pièces, le piédroit oriental est pourvu de cinq ouvertures verticales qui débutent au niveau de la chaussée dallée pour se terminer sous le dallage de couverture (fig. 37). Ces évents. dont la largeur fluctue de 12 à $2 \mathrm{l} \mathrm{cm}$, sont séparés par des distances variant de $2,70 \mathrm{~m}$ à $3,25 \mathrm{~m}$. Leur présence dans ce secteur coïncide avec la portion de voie la plus basse. Ils constituent des bouches d'égout évacuant dans le drain les eaux de ruissellement de la rue.

Le fond du drain, actuellement détruit, était constitué de «larges plaques de terre cuite supportant des canalisations en plomb» (Le Glay, 1971, p. 421 : voir aussi : Le Glay, 1970, p. 175). Il est difficile de savoir quelle pente pouvait avoir le conduit mais, si nous nous en tenons à son état présent, nous observons la présence de deux points bas. L'in se trouve à la hauteur de l'ambitus qui sépare la maison aux Cinq Mosaïques des Petits Entrepôts : l'autre, moins prononcé, se situe vers le passage qui sépare, dans la parcelle des Petits Entrepôts, les deux bâtiments méridionaux. Le premier se superpose au conduit qui raccorde l'ambitus au collecteur tandis que le second se trouve à proximité de

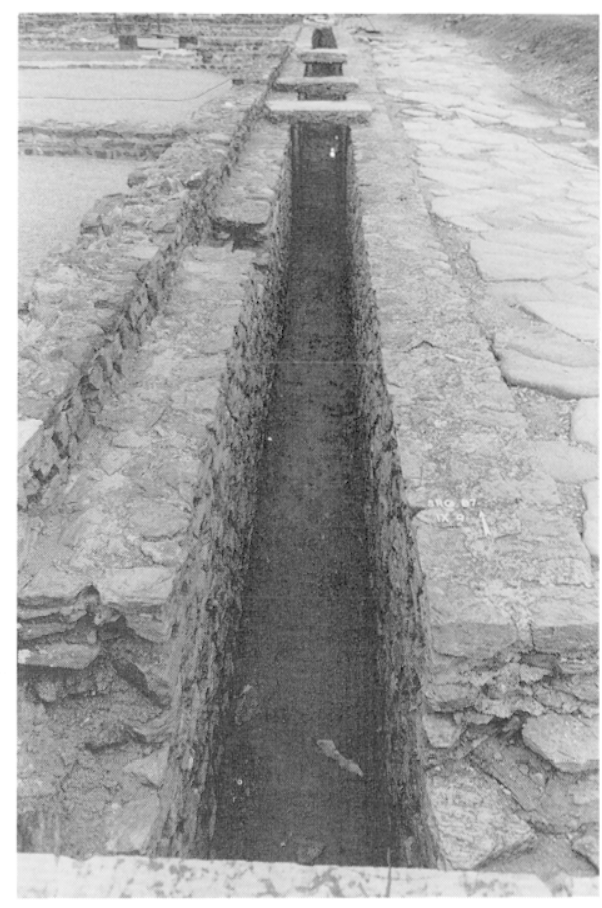

Fig. 36 - Voie II : trottoir sur drain (état 2E).

la canalisation de vidange des bassins de la teinturerie qui occupe le corps de bâtiment sud des Petits Entrepôts.

Ces deux évacuations constituent les seuls débouchés susceptibles d'évacuer les eaux récupérées dans le drain. Cependant, dans la mesure où elles ont conservé, au moins en partie, leurs couvertures maçonnées, et, compte-tenu du fait qu'elles passent audessous du fond du conduit sans être clairement intégrés à celui-ci, nous pouvons nous demander si elles ont bien été reliées au drain. Malheureusement, leur mauvais état de conservation ne permet pas d'obtenir de réponse définitive.

Il convient toutefois de prendre en considération le fait que le drain n'a pas été prévu, à l'origine, pour recevoir des eaux usées. En effet, la conduite d'évacuation des latrines de la maison aux Cinq Mosaïques est intégrée dans le piédroit ouest (fig. 43 et 76). Elle se poursuit ensuite sous le fond du drain pour se déverser dans le collecteur principal. La mise en place de ce dispositif, qui se traduit par un renflement conséquent du piédroit ouest, montre nettement que le drain n'est pas un égout. Dans ces conditions, son raccordement au collecteur pourrait ne pas constituer une obligation. Seule la porosité du fond du drain serait alors susceptible d'assurer l'élimination des eaux de pluie. La faible épaisseur du radier qui supportait les plaques de terre cuite rend plausible cette hypothèse surprenante. A une époque ultérieure, indéterminée. les Petits Entrepôts ont été dotés d'égouts, dont celui issu des latrines de la maison des Dieux Océans. Ceux-ci se déversent alors directement dans le drain. Afin d'éviter 
Fïg. $37-$

Voie II : évents du trottoir sur drain (ćtat 2E).

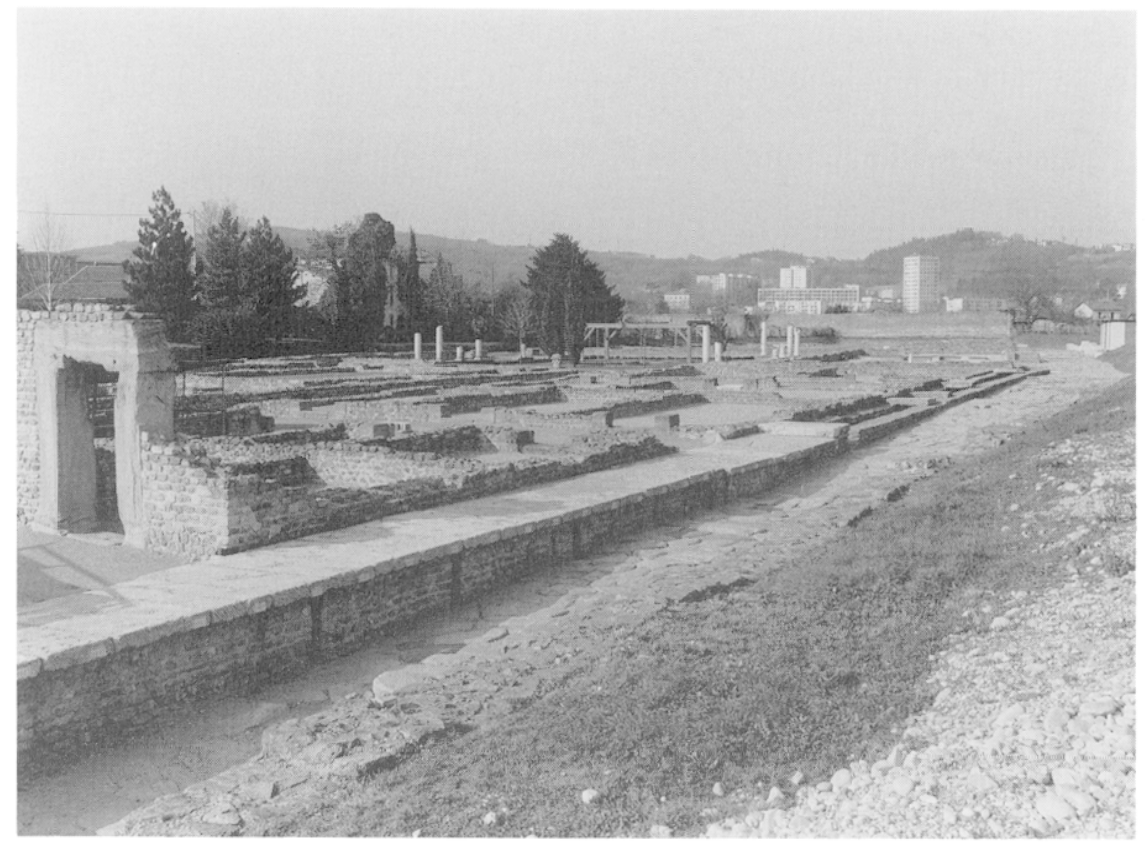

des odeurs nauséabondes, nous pouvons penser qu'une liaison, au moins, a dû alors être établie avec le collecteur, probablement par l'intermédiaire de l'évacuation sud qui. étant située au point le plus bas, s'avère la plus adéquate.

Les dalles en calcaire épaisses de 14 à $23 \mathrm{~cm}$ qui composent la couverture du drain ont une largeur comprise entre $0,71 \mathrm{~m}$ et $1,28 \mathrm{~m}$ pour une longueur variant de $1,87 \mathrm{~m}$ à $2,13 \mathrm{~m}$. Il n'est pas certain que les dalles qui recouvrent le massif de maçonnerie aient été aussi longues. Il existe en effet $20 \mathrm{~cm}$ de différence entre les largeurs du drain et du massif. Cependant. aucune d'elles n'ayant été retrouvée ${ }^{53}$, nous pouvons envisager que des plaques de même gabarit aient pu être utilisées. Elles déborderaient alors d'une vingtaine de centimètres de leur support, contribuant ainsi à élargir le trottoir.

Ce dallage de couverture présente des paliers horizontaux, plus ou moins longs, qui ne coïncident pas exactement avec les modifications de niveau de la chaussée que nous avons précédemment mis en évidence. Ainsi la partie la plus haute, vers $152.95 \mathrm{~m}$ (avec dalles), est limitée au bâtiment et au passage nord des Petits Entrepôts. En direction du nord. une marche située à la hauteur de l'ambitus permet d'accéder à une vaste portion plane qui longe la maison aux Cinq Mosaiques et se poursuit jusquau nord des Grands

5.3 Celles qui composaient la couverture du drain se sont effondrées dans le canal et ont ainsi été partiellement préservées.

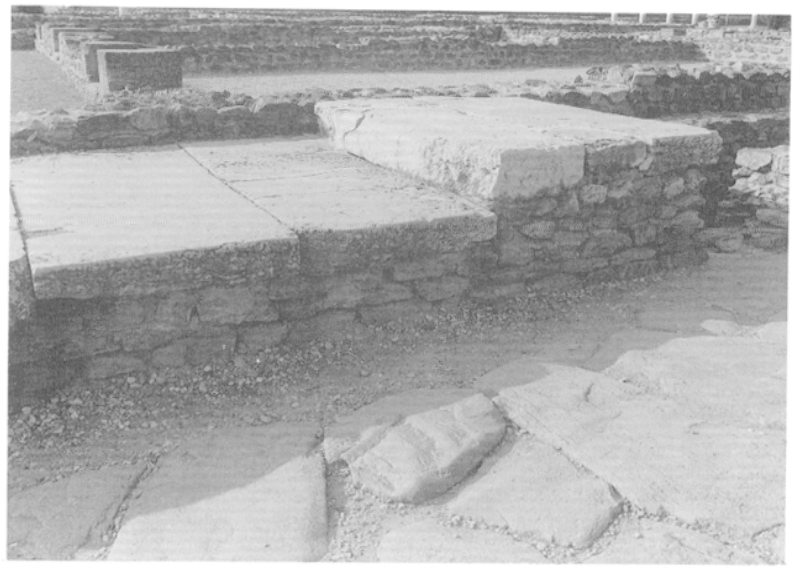

Fig. 38 - Voic II : marche du trottoir sur drain mise en évidence à la hauteur des Petits Entrepôts.

Entrepôts ${ }^{54}$. Vers le sud, trois marches peuvent être restituées le long du bâtiment central des Petits Entrepôts, composé de cinq pièces (fïg. 38). Elles sont placées à la hauteur des façades nord et sud, ainsi qu'au niveau du mur de refend central. Le trottoir demeure ensuite horizontal jusqu'au portique de la Voie I, dont il rattrape le niveau. Il présente alors une dénivellation de $1 \mathrm{~m}$ par rapport à la chaussée.

54 A l'exception de l'entrée de ces derniers (ef. supra. p. 35). la hauteur des marches correspond à une épaisseur de dalle comme nous l'indique l'agencement qui a pu être reconstitué au niveau de l'allée centrale des Petits Entrepôts. 


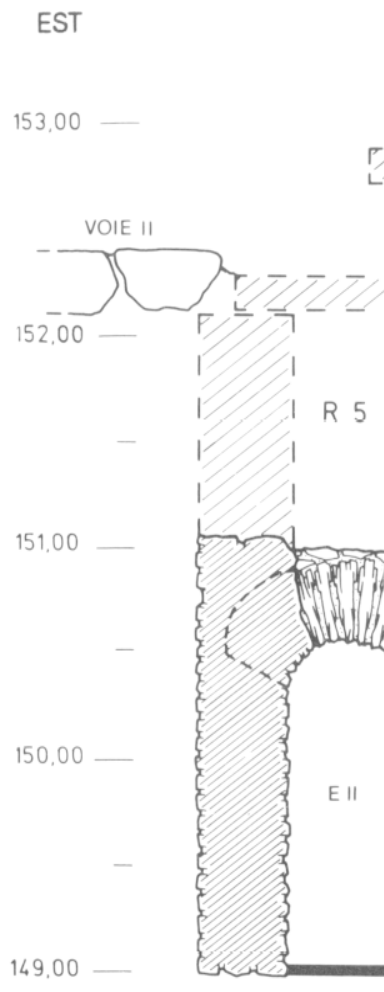

Pour quelle raison a-t-on éprouvé le besoin de réaliser ce trottoir sur drain qui demeure, pour l'instant. une structure unique sur le site? Si son implantation lui permet de border l'ensemble des Petits Entrepôts, il ne constitue pas pour autant un système sanitaire spécifiquement attaché à la présence de bâtiments commerciaux puisque les Grands Entrepôts en sont dépourvus.

Aussi, il convient de prendre en considération le fait qu'il s'agit avant tout d'un trottoir. Son apparition paraît s'insérer dans un programme qui consiste à mettre en place une circulation piétonne à part entière dans les rues principales du quartier. Cet aménagement urbain touche notamment la Voie III qui, comme la Voie II,

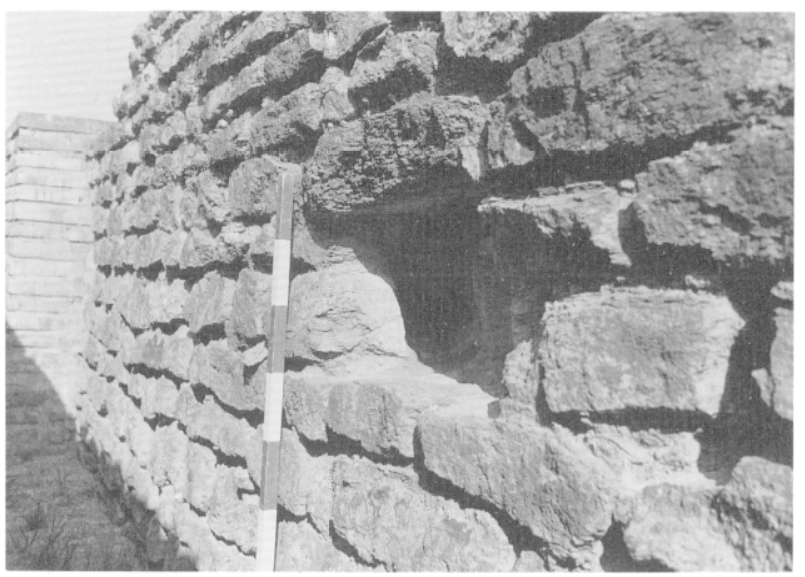

Fig. 39 - Voic II :

conduit destiné au passage d'un tuyau en plomb à travers le piédroit oriental du trottoir sur drain (état 2E).

\section{OUEST}
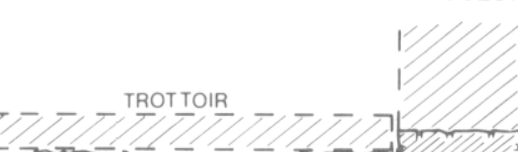

reçoit tardivement un trottoir. En ce qui concerne celui qui longe les thermes des Lutteurs, son existence est également liée au deuxième et dernier état de rue dallée qui n'intervient pas avant le courant du $\mathrm{II}^{\mathrm{E}} \mathrm{s}$. après J.-C.

Dans le cas de la Voie II, il est intéressant de considérer le problème d'un point de vue technique. Compte-tenu de la hauteur en élévation nécessaire pour rattraper le niveau du portique de la Voie I, le choix du drain, de préférence à une fondation massive, représente une économie appréciable de matériau, mais ce n'est pas le seul intérêt. L'existence d'évents aux points bas de la chaussée montre clairement que le drain était destiné à récupérer les eaux de ruissellement. Lors de l'utilisation de la première voie dallée, il semble que la pente prononcée de la rue devant les Petits Entrepôts et la faible altitude de la Voie ${ }^{55}$, associées au pavage de la chaussée, aient pu occasionner la création d'une vaste flaque à la hauteur du carrefour, rendant la circulation délicate dans ce secteur.

Ce problème aurait reçu une solution par la création d'un trottoir surélevé, permettant un passage au sec, combiné à un drain recueillant le surplus d'eau de la chaussée.

55 La chaussée dallée de la Voie I se trouve nettement en contrebas de celles des Voies X et II. Malgré la remise à niveau du dallage, cette disposition s'avère aujourd'hui encore propice à la création de flaques, lors d'orages notamment, qui mettent parfois plusicurs jours à se résorber. Dans l'Antiquité. les bâtiments ayant tous des toitures, la quantité d'eau recueillie par la rue devait être encore plus importante qu'à notre époque.

EST

ou

Mur restitué

Briques 
Il faut demeurer prudent vis-à-vis du rôle protecteur que le drain peut offrir en cas de crues ou dans la lutte contre l'humidité ambiante suggérée, sur le site, par la présence d'ambitus et de nombreux vides sanitaires composés d'amphores (Le Glay. 1968, p. 580) 1970. p. 175 ; 1971, p. 421). S'il est vrai que le quartier est bâti sur une plaine inondable, ce canal ne présente aucun intérêt particulier en cas de crue. Dans la mesure où il se trouve limité à un petit secteur. il ne peut faciliter l'évacuation d'un surplus d'eau en direction du fleuve. Il aura au contraire tendance à retenir cette eau, en tenant lieu de réservoir.

Il convient surtout de ne pas oublier la dimension chronologique des constructions. Ainsi, la réalisation du drain intervient à peu près un siècle après le début de la constitution des Petits Entrepôts qui, elle-même, se produit plusieurs décennies après l'apparition de l'ambitus séparant leur parcelle de celle de l'état 2 de la maison des Dieux Océans. Comme on le voit, la cohérencé finale de l'ensemble n'est qu'apparente.

Le souci essentiel des constructeurs étant de stocker des denrées, ceux-ci ont pris des mesures préventives contre le pourrissement, en installant des vides sanitaires sur amphores ou sur plancher, et contre le feu. en conservant ou en aménageant des ambitus qui semblent plutôt avoir leur utilité dans ce domaine. De telles mesures ont pu être prises dans des conditions normales d'environnement, c'est-à-dire au sein d'un milieu naturel n'étant pas excessivement humide. Nous avons en effet des difficultés à imaginer l'implantation de bâtiments de stockage dans un marais !

\section{Le troisième réseau d'adduction}

En ce qui concerne les tuyaux en plomb qui étaient placés dans le drain, mentionnés lors de la découverte du site, il nous faut déplorer leur disparition. Nous avons toutefois retrouvé le point d'entrée de l'un d'entre eux (fig. 39). Situé à $2,50 \mathrm{~m}$ au sud du regard $\mathrm{R} 6$, un conduit rectangulaire de $11 \mathrm{~cm}$ de large et de $23 \mathrm{~cm}$ de haut, permettant le passage d'un tuyau de $10 \mathrm{~cm}$ de diamètre, traverse en oblique le piédroit est du drain ${ }^{56}$. Cet orifice, placé à une profondeur suffisante $(151.61 \mathrm{~m})$ pour que la canalisation puisse passer sous les dalles de la voie, débouche un mètre au-dessus du fond actuel. Un autre accès de largeur identique, au fond tapissé de fragments de tuiles, a été repéré au sud du drain, au niveau de la base des piédroits à $150,85 \mathrm{~m}^{57}$. Il permet à un tuyau dont le diamètre atteint également $10 \mathrm{~cm}$, de ressortir dans la Voie I, le long de la façade des bâtiments.

56 Deux conduits de ce type ont été mis en évidence. en 1992. dans la maçonnerie du trottoir de la Voie III.

$57 \mathrm{Ce}$ passage n'a pas été mis en évidence dans la maçonnerie du drain, complètement récupérée à cet emplacement, mais dans un mur antérieur contigu. Cette disposition ne serait pas suffisante pour affirmer qu'il s'agit bien d'une saignée réalisée à l'époque du drain. si nous n'observions la présence. à la même profondeur, d'une tranchéc de récupération qui longe la façade nord de la Voie I. Cette tranchée correspond au passage du même tuyau et elle nous indique que celui-ci n'a été mis en place qu'à une période récente. en tout cas. postéricure à celle qui a vu l'installation des tuyaux en bois du deuxième réscau d'adduction (cf. état 2C).

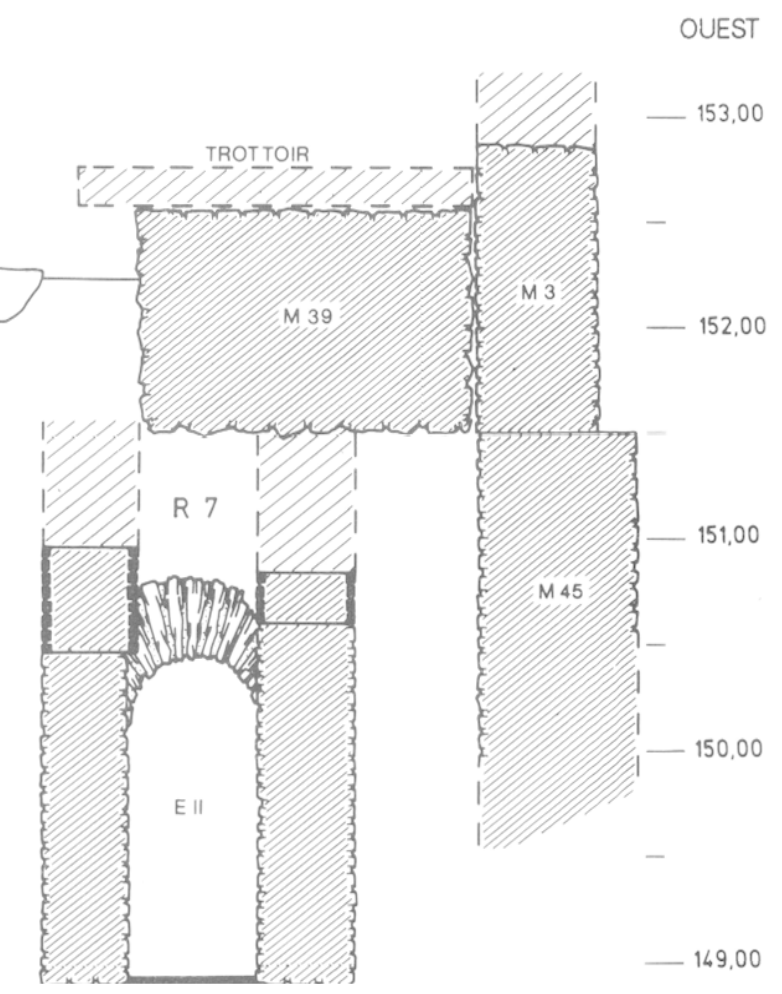

Fig. 40 - Voie II : coupes des trois regards situés en façade de la maison aux Cinq Mosaïques. 
$\mathrm{Si}$ nous supposons que ces deux orifices correspondent au passage d'une seule canalisation, il faut se poser des questions sur l'origine et sur la destination de la seconde ${ }^{58}$. La partie sud du drain ayant fait l'objet d'une forte récupération, un autre passage a alors fort bien pu disparaître. Cependant nous n'en trouvons pas de trace au nord. A partir de ces constatations, nous pouvons néanmoins supposer l'existence d'un premier tuyau appartenant à un réseau dont le cheminement emprunterait le drain lors de sa construction ${ }^{59}$, tandis que le second aurait pu être mis en place plus tard, notamment au moment de la création d'égouts dans les Petits Entrepôts. Dans ce cas, cette autre canalisation pourrait constituer l'alimentation spécifique de ces bâtiments.

\section{Les regards}

Sur son parcours, le trottoir sur drain se heurte à deux regards, R5 et R6. En ce qui concerne le premier, la paroi ouest de sa cheminée se trouve intégrée telle quelle dans le piédroit est du canal, comme nous le suggère le dessin réalisé avant restauration (fig. 40). On remarquera, sur le sommet du regard, la largeur réduite du mur du drain. Cette disposition est destinée à permettre la pose de la dalle de fermeture.

Quant au second, il coïncide avec l'extrémité nord du drain. L'étroite relation qui existe entre ces deux structures laisse supposer que la cheminée. construite en tuiles, du regard $\mathrm{R} 6$, date de cette époque (tabl. II). La présence de ce conduit vertical provoque un rétrécissement du canal du drain, dont la largeur passe de $0,90 \mathrm{~m}$ à $0,60 \mathrm{~m}$. Ce resserrement paraît d'autant plus incongru que cette structure se termine à la hauteur du côté nord du regard. Il aurait en effet été plus simple d'interrompre le drain contre la face sud de la cheminée. Seule l'existence d'un débouché à travers la paroi ouest de celle-ci serait à même de justifier cet aménagement ${ }^{60}$.
Dans ces conditions, la création de ce débouché pourrait être la cause de la reconstruction du regard.

Malgré les effondrements et les récupérations dont les regards ont fait l'objet, il semble que la construction du massif plein du trottoir ait entrâné la condamnation de certains d'entre eux. Ainsi, les regards R7 et R9, qui n'accueillaient par ailleurs aucune évacuation, ont dû être occultés par cette maçonnerie qui repose sur leurs cheminées. Pour R7, les empreintes des briques étaient encore visibles sous le massif. En revanche, la présence de plusieurs conduits débouchant dans $R 8$, troisième regard concerné par cette opération, a pu justifier son maintien. Dans ces conditions, la couverture de sa cheminée devait directement être assurée par les dalles du trottoir. Toutefois, il reste à contrôler que ces évacuations se trouvaient encore en service à l'époque de la construction du trottoir.

\section{L'abandon}

La phase d'abandon de la rue du Commerce est mal connue car les niveaux archéologiques postérieurs à la voie dallée ont été ôtés lors du décapage général de surface effectué sur le site en 1967.

L'arasement de M1 (fig. 8, comblement de la tranchée de récupération du mur de façade : couche 8) ainsi qu'une récupération partielle des dalles de granite issues de la dernière rue, effectuée à une date indéterminée, constituent les seuls faits marquants notables à la hauteur du sondage.

Dans ces conditions, il est difficile de savoir si la voie a survécu à l'abandon des bâtiments qui la bordaicnt. Cependant, l'abondance des blocs calcaires retrouvés sur la chaussée, le long de la moitié sud des Petits Entrepôts, suggère que la voie dallée, en tant que niveau de circulation, a été assez vite désaffectée après la destruction et la récupération des maçonneries, tout du moins dans cette portion de la rue.

Laurence BRISSAUD
58 M. L.e Glay ne précisant pas leur nombre, nous n'avons à notre disposition que la tradition orale qui fait mention de la présence de deux luyaux. l'un de plus gros diamètre que l'autre, qui ont disparu peu après leur mise au jour.

59 L'accès nord est manifestement contemporain de la réalisation du drain. Le nouveau réseau d'adduction est-il créé

\footnotetext{
à ce moment ou bien ne s'agit-il que d'un déplacement de son implantation, son apparition seffectuant lors de l'aménagement de la première voie dallée?

60 L'état de conservation du regard, avant restauration. laisse toute liberté à cette hypothèse dans la mesure où la plus grande partic du piédroit ouest de la cheminécéclait aratiée au niveau du fond du drain.
} 